\title{
The making of ageing-in-place
}

Citation for published version (APA):

van Hees, S. V. (2017). The making of ageing-in-place: Perspectives on a Dutch social policy towards lifecycle-robust neighbourhoods. [Doctoral Thesis, Maastricht University]. Maastricht University. https://doi.org/10.26481/dis.20171219svh

Document status and date:

Published: 01/01/2017

DOI:

10.26481/dis.20171219svh

Document Version:

Publisher's PDF, also known as Version of record

\section{Please check the document version of this publication:}

- A submitted manuscript is the version of the article upon submission and before peer-review. There can be important differences between the submitted version and the official published version of record.

People interested in the research are advised to contact the author for the final version of the publication, or visit the DOI to the publisher's website.

- The final author version and the galley proof are versions of the publication after peer review.

- The final published version features the final layout of the paper including the volume, issue and page numbers.

Link to publication

\footnotetext{
General rights rights.

- You may freely distribute the URL identifying the publication in the public portal. please follow below link for the End User Agreement:

www.umlib.nl/taverne-license

Take down policy

If you believe that this document breaches copyright please contact us at:

repository@maastrichtuniversity.nl

providing details and we will investigate your claim.
}

Copyright and moral rights for the publications made accessible in the public portal are retained by the authors and/or other copyright owners and it is a condition of accessing publications that users recognise and abide by the legal requirements associated with these

- Users may download and print one copy of any publication from the public portal for the purpose of private study or research.

- You may not further distribute the material or use it for any profit-making activity or commercial gain

If the publication is distributed under the terms of Article $25 \mathrm{fa}$ of the Dutch Copyright Act, indicated by the "Taverne" license above, 


\section{The making of ageing-in-place \\ Perspectives on a Dutch social policy \\ towards lifecycle-robust neighbourhoods}

Susan van Hees 
The research presented in this dissertation was conducted at the Care and Public Health Research Institute (CAPHRI), Department of Health Services Research, Maastricht University. CAPHRI participates in the Netherlands School of Primary Care Research (CaRe), which has been acknowledged by the Royal Netherlands Academy of Science (KNAW).

Funding for the research of this dissertation was provided by The Netherlands Organisation for Health Research and Development (ZonMw), grant 314070201.

Printing of this thesis was financially supported by the Netherlands Graduate Research School of Science, Technology and Modern Culture (WTMC).

(c) Susan van Hees, Breda 2017

ISBN: 978-94-6233-766-4

Lay-out and Cover design: Evelien Jagtman (www.evelienjagtman.com) Printing: Gildeprint Enschede

All rights reserved. No part of this thesis may be reproduced or transmitted in any form or by any means, electronic or mechanical, including photocopying, recording or any information storage or retrieval system, without prior written permission of the holder of the copyright. 


\title{
The making of ageing-in-place Perspectives on a Dutch social policy towards lifecycle-robust neighbourhoods
}

\section{PROEFSCHRIFT}

\author{
ter verkrijging van de graad van doctor aan \\ de Universiteit Maastricht \\ op gezag van de Rector Magnificus, \\ Prof. dr. Rianne M. Letschert,
} volgens het besluit van het College van Decanen,

in het openbaar te verdedigen

op 19 december om 12.00 uur

door

Susan Vivette van Hees 


\section{Promotores}

Prof. dr. D. Ruwaard

Prof. dr. K. Horstman

Prof. dr. M. Jansen

\section{Beoordelingscommissie}

Prof. dr. G. Kempen (voorzitter)

Dr. M. Knibbe

Dr. L. Neven (Avans University of Applied Sciences Breda)

Prof. dr. G. Roets (Ghent University)

Prof. dr. T. Swierstra 


\section{Table of contents}

$\begin{array}{lll}\text { Chapter } 1 & \text { Introduction } & 7\end{array}$

Chapter 2 Conflicting notions of citizenship in old age. 23

An analysis of an activation practice

Chapter 3 How does an ageing policy translate into professional practices?

An analysis of kitchen table conversations in the Netherlands

Chapter 4 Meanings of 'lifecycle-robust neighbourhoods'.

Constructing versus attaching to places

Chapter 5 Photovoicing the neighbourhood.

Understanding the situated meaning of intangible places for ageingin-place

Chapter 6 Discussion

Summary

Samenvatting

Valorisation

Dankwoord

About the author

179

List of publications

183 



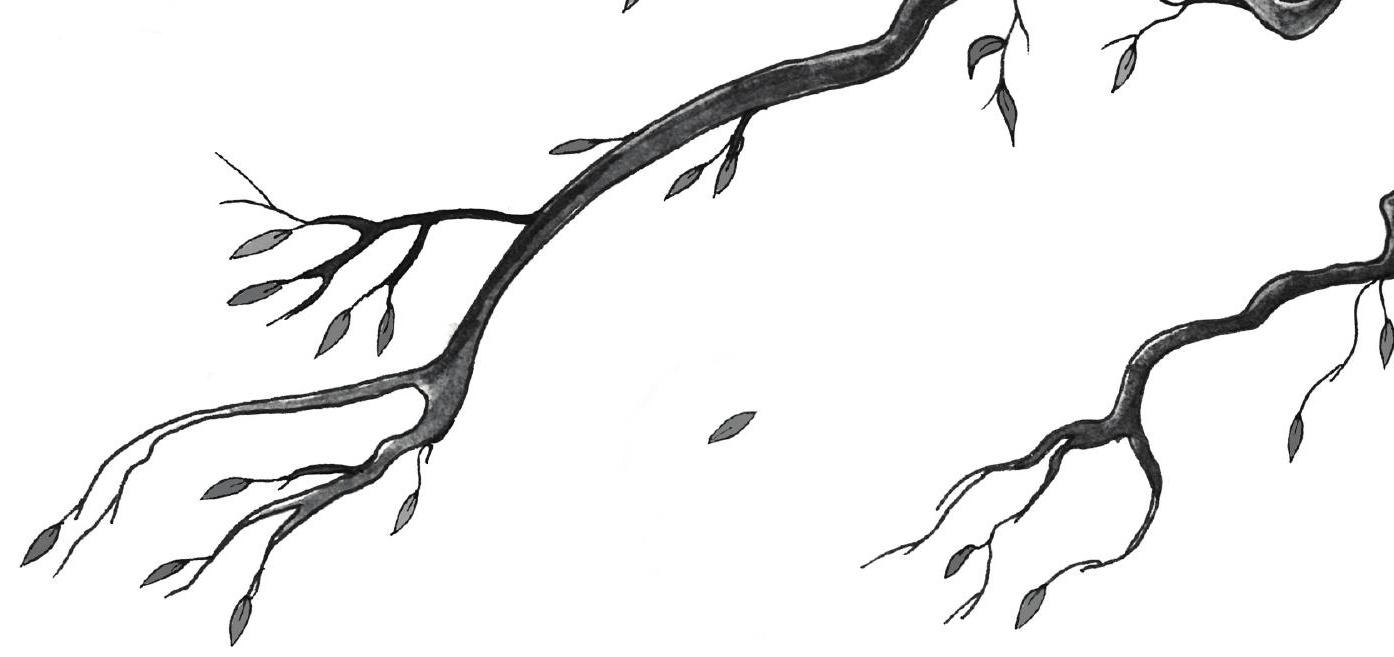

Chapter 1

Introduction 



\subsection{Reforming care in ageing societies}

An ageing population and associated public health-care expenditure has caused an increasing number of Western welfare states to shift more and more of their healthcare responsibilities to individual citizens (Bond et al. 2007; Dunn 2005). Activation policies are used within these care reforms as a strategy to maintain an affordable and sustainable health-care and welfare system. Simultaneously, these states are decentralising welfare and care functions from national to local governments (Hacker 2009; Kroneman, Cardol and Friele 2012; Nowak et al. 2015; Singh 2008). Participation is an important element within these developments. Governments promote deinstitutionalisation, and to achieve this they do not only emphasise individuals' own responsibilities for their health and well-being, but also aim to activate people to help each other (Rudman 2015; Lamb 2014; Newman and Tonkens 2011). Increasing people's options to remain living in their own place independently for longer are part of such individualisation strategies.

To meet the needs of an ageing population, the World Health Organization (WHO) developed policy frameworks to encourage ageing-in-place. These frameworks were created to stimulate and enable active ageing and the development of age-friendly places (WHO 2015). With these frameworks, the WHO intends to provide governments with guidelines to help them develop new policies. In line with these ideals, the Dutch government aims to enable ageing-in-place, and emphasises the importance of encouraging independence and individual responsibility in an activation policy (Newman and Tonkens 2011). In 2007, the Social Support Act (Wet maatschappelijke ondersteuning) was implemented. One of its aims was - and still is - to encourage older adults to live independently for longer. This Act has been continuously adjusted since its introduction and other reforms have been introduced to further facilitate a shift towards a more participatory society. The Dutch policy is further informed by current discussions on 'positive health', a notion introduced by Huber et al. (2011). They argue that modern societies need a more positive conceptualisation of health than the WHO definition of health as a 'state of complete physical, mental and social well-being', namely as 'the ability to adapt and to self-manage, in the face of social, physical and emotional challenges'. In this view, health is primarily related to individual abilities and not just to physical and mental health status. To understand the abilities relevant to positive health, the environment in which people live plays a pivotal role, especially for older adults, as they often spend a growing amount of time in their own home and neighbourhood (Andrews et al. 2013; Beard et al. 2009; Ottoni et al. 2016).

To improve our understanding of how this activation policy functions, we studied one innovative public care initiative in particular. In this initiative, the main aim was 'to encourage and enable ageing-in-place', by understanding and developing neighbourhoods as ageing technologies, as mediators of ageing-in-place. Instead of a traditional evaluation study, in which outcomes and effects are monitored to evaluate 
the quality and success of a policy, we aimed to understand the meanings given to the 'making of ageing-in-place' and how meanings change, by observing this policy in practice. To achieve this, we used a social-constructivist approach.

In this chapter, ageing-in-place is first introduced as part of the broader category of activation policies. Next, we describe the innovative public care initiative 'Voor Elkaar in Parkstad' (literally For Each Other in Parkstad, but also meaning 'getting things done' or 'all well'), which we used as a case to study the development of an ageing-in-place policy. And finally, we discuss the theoretical approach, our main research questions and the methodological approach we used to study this initiative. An outline of the various chapters that are part of this thesis is included at the end of this chapter.

\subsection{Ageing-in-place: Places as ageing technologies}

Place is increasingly considered to be an important facilitator (or mediator) of ageing-in-place. It is argued that ageing-in-place should be given preference over ageing in institutional settings, as it is presumed to enhance people's choices in live. According to Gilleard and Higgs (1998), Higgs (1995) and Persson and Berg (2008), being able to move in the own home and neighbourhood is important, not only to remain independent, but also to maintain one's status as a citizen, as a participative member of society. The ability to participate in social activities is considered elementary in remaining independent. The place where one lives is thus assumed to play an important role in maintaining one's status as a citizen (Sixsmith et al. 2014) and in preventing institutionalisation in accordance with most people's preferences (Wiles et al. 2011). Social constructivists such as Gieryn (2000) emphasise that it is not so much a particular place in itself that is important, but mainly the way in which place mediates social life, because it is the emotional or social relations in and historical associations of a place that people are really attached to. Lamont and Molnár (2002) demonstrated that places become meaningful through the way they reflect and constitute social relations.

In the Dutch activation policy, which is part of care reforms aimed at creating a more participatory society, care and welfare professionals play a pivotal role in optimising places as age-friendly. In their policymaking processes, governments draw on the WHO frameworks for active ageing and age-friendly places. The WHO describes age-friendly places as places that increase 'opportunities for health, participation and security'. Ageing-in-place is further framed in relation to a policy of active ageing and the development of age-friendly communities, thereby considering active ageing as a 'process of optimizing opportunities for health, participation and security in order to enhance quality of life as people age' (2007, p. 5). 
National as well as local governments expect professionals to activate and empower people as much as possible. Therefore, professionals need to develop a new kind of professionalism. Instead of providing care, professionals have to increasingly support people in taking care of themselves. To mediate this 'new professionalism', a new social tool was introduced: the 'kitchen table conversation' (i.e. designs for ideal conversations with individuals asking for, or in need of, help). Policymakers consider these tools to be helpful for professionals in giving meaning to their new roles. Within the professional field, too, the place where people live is considered important. Professionals and individuals are urged to find care solutions within the individual's immediate surroundings, meaning the individual's own personal and informal social network. A neighbour might be able to help a disabled person when doing the groceries, for example. These activation policies are part of regimes influenced by neoliberal ideals, based on which governments put more emphasis on decentralised and individual responsibilities. Several scholars describe systems of responsibilisation, with reduced levels of state intervention, where the state only provides what are considered absolute necessities (Newman and Tonkens 2011; Liebenberg et al. 2015). The role of place is thus elementary in policies that aim for a sustainable health-care system, as places are considered to have activating and enabling abilities.

\subsection{Making ageing-in-place: Parkstad as a place to age in life- cycle-robust neighbourhoods}

In this thesis, we describe the evaluation study we conducted on an innovative public care initiative situated in Parkstad, an area in the south-eastern part of the Netherlands. The eight Parkstad municipalities, several housing, welfare and healthcare organisations (including one health-care insurer) and representatives of older adults (formally organised older adults who represent older adults in the area by participating in and monitoring policy activities, such as policy meetings) initiated a collaborative transition process they called 'Voor Elkaar in Parkstad'. The aim of this initiative was to confront regional challenges such as increasing health-care expenditure, caused by a rapidly ageing as well as a shrinking population. In an effort to maintain an affordable and sustainable health-care system, these actors agreed to collaboratively develop so-called lifecycle-robust neighbourhoods. This entails an ideal of a neighbourhood where older adults can remain living independently when ageing. In general, it refers to the ideal of a neighbourhood that is in line with the ideals of age-friendly communities described above (WHO 2007), as a place that encourages and enables ageing-in-place.

This collaboration was initiated in Parkstad for good reason. In this area in particular, demographics and related prospects for health and ageing developments have induced a sense of urgency in policymakers to change the existing policies. 
Parkstad's 250,00o inhabitants are spread over eight municipalities, which vary from rural communities with fewer than 8,00o inhabitants to urban areas with almost 88,000 inhabitants. A policy document written in 2011 reflected a specific urgency for this area because of 'an increasing demand for care (caused by ageing, 'a decrease in the number of professionals', 'a smaller budget' and 'a changing demand for care' (Transition Plan Voor Elkaar in Parkstad 2011). This urgency is substantiated in several economic and health reports about this region (OECD 2013; RVTV 2010, 2014).

Many (and especially younger) inhabitants have left Parkstad in recent decades, and its population is ageing. The OECD (the Organisation for Economic Co-operation and Development) has also referred to the rapidly ageing and shrinking population in South Limburg. While other areas in the Netherlands faced an increase of 3.7 percentage points of people older than 65 (OECD, p. 105), South Limburg aged with a 7.7 percentage-points increase between 1988 and 2012 (OECD, p. 105). At the same time, the share of young people in this area was lower than in other parts of the country. What also makes Parkstad an interesting area to study is the fact that, in contrast to other shrinking areas in the Netherlands, it is a mostly urban area (Elzerman and Bontje 2015). Due to the developments described, Limburg faces a structurally higher unemployment rate, combined with a low socioeconomic status (SES) and poor health (RVTV 2010). The Regional Public Health Service states in its reports in 2010 and 2014 that the average lifestyle of people in South Limburg remained less healthy than in other parts of the country (RVTV 2010, 2014). The Service argues that although improvements are visible in recent years, it will be difficult to make up for these differences because of the shrinking and ageing population (as older people cope with health problems more often) (RVTV 2014, p. 91).

The area is further known for its relatively abundant greenery (it is named Parkstad, meaning 'Park City', for that reason), its attractiveness to tourists, its mining history, and its position directly at the Dutch-German border. In recent years, several projects and trajectories were initiated to develop this area, in which the area is often considered a laboratory for the Netherlands, dealing with challenges the rest of the country will probably have to cope with in the foreseeable future (among others, projects started as part of an event called IBA, a German acronym for 'Internationale Bauausstellung, or international building exhibition'. IBA aims to promote innovative projects in Parkstad between 2012 and 2020). All these projects and initiatives, 'Voor Elkaar in Parkstad' included, attempt to reconstruct Parkstad as a sustainable area. From a mostly agricultural region, the area industrialised rapidly around 1900 with the opening of several large mines. The region was generally economically prosperous, until the period after the Second World War when the coal mines were closed by the government in the mid-196os (Hoekveld and Bontje 2015; Ročak, Hospers and Reverda 2016).

It is important to understand the particularities of this area to be able to learn from the developments there. A lack of empowerment and a lack of trust are described as having created an 'obedient mentality' (Elzerman and Bontje 2013; Ročak, Hospers 
and Reverda 2016). Participants in our study mention seeing this obedient mentality in many Parkstad inhabitants as well. It is argued that this mentality dates back to the organisation of community life by the mining companies and the Roman Catholic Church. Together, these institutions provided for both the economic and social needs of the mining employees and their families, because they both 'wanted strong communities with obedient workers and social peace' (Ročak, Hospers and Reverda 2016). Ročak, Hospers and Reverda (2016) describe a strong community and place attachment in their study of urban shrinkage in Heerlen (the largest Parkstad municipality), but also how 'the current situation in the city relates directly to its mining history: miners were expected to obey the rules and these attitudes of disempowerment and low entrepreneurship are still present' (p. 13). Not only are citizens of Parkstad not used to participating in politics, according to these studies as well as according to the initiators of 'Voor Elkaar in Parkstad'; Ročak, Hospers and Reverda state there is also a lack of trust between citizens and politicians and low trust in public institutions among citizens.

\subsection{Exploring 'the making of ageing-in-place': Research aim and question}

This thesis describes the study of an innovative public care initiative that can be regarded as a local activation policy. The aim of this policy is to encourage and enable older adults to remain living independently for longer. We explore the meanings of this 'policy in the making' by unravelling the 'black box' of the practices through which the policy is actually made, studying the policy in process. This study aims to understand this process. In practice, we encountered different things that participants found important in relation to this ageing-in-place policy. We also explored the meaning of citizenship in old age, a new form of professionalism (including the mediating role of social technologies) and lifecycle-robust neighbourhoods (as places). In unravelling these concepts, constructions made by different actors involved in or affected by this policy were important: constructions by policymakers, civil servants, housing, care and welfare directors, managers and professionals, representatives of older adults and older adults living independently in these neighbourhoods themselves. This thesis aims to reveal the meaning of ageing-in-place policies by exploring how these policies play out in practice, in interaction with governmental, housing, care and welfare organisations, as well as with older adults and their representatives. The main research question is: How do ageing-in-place policies work out in practice? To explore that question, we have investigated: the meaning of citizenship in old age (Chapter 2), the use of a new social technology - the kitchen table-conversation -, that was introduced to facilitate professionals in their practices to encourage ageingin-place (Chapter 3 ) and the meaning of place (Chapters 4 and 5). 


\subsection{Understanding a policy in practice: Analytical framework}

The chapters of this thesis are written as individual journal articles, which implies that each chapter includes a separate methods section in which the specific materials and methods used for that particular chapter are explained. However, for the purpose of overview and an understanding of these different chapters as parts of the whole study, information is included in this introduction about all the data collection methods and analysis applied as well. First, the social-constructivist approach we used in this study to explore the meanings of an innovative public care initiative will be elaborated on. We used this approach to unravel the underlying activation policy of the initiative in practice.

Instead of a traditional evaluation study, which emphasises monitoring outcomes or measuring effects by looking at technical, organisational and economical aspects of policy, we used a social-constructivist approach to study the process of this particular care initiative, situated in the south-eastern part of the Netherlands (cf. Abma and In 't Veld 2001; Van der Veen 1990;). We explored different meanings of this policy in practice by conducting a sociological analysis. Social constructivism draws on the idea that social reality is constructed and depends on the meanings people give to it, paying attention to the processes of meaning in particular, including the exploration of what meanings actors assign to situations or concepts (Van der Veen 1990). As for instance Lipsky (1980) demonstrated in his work on lower-level civil servants, policy is eventually made in practice, which means that if you want to investigate the meanings of a specific policy, it is necessary to not only explore that policy on a policymaking level, but to also investigate the way it is implemented. As Van der Veen (1990, p. 233) phrases it, 'we need to endeavour to open the 'black box' of daily practice'. Therefore, it is not only necessary to unravel processes, Van der Veen (1990) explains, but also to understand their contexts and backgrounds, as this helps us find out why people give specific meanings to specific situations and concepts. In his study, he investigated a social policy by exploring its meanings at the level of policy as well as in practice. He investigated policymaking and the boundaries of policy, by exploring how policy, professionals' decision-making processes in practice (based on policy), and the acts of citizens as clients are affected by meanings given to policy. Based on these ideas and insights, we investigated not only the way 'Voor Elkaar in Parkstad' came about at a formal policy and decision-making level, but also how it functions in practice, for instance in interactions between professionals and older adults, as a policy is actually made at different levels and eventually acquires its meaning in practice. Policy is shaped in practice, but the way policy is understood also constructs the way people act in practice (Van der Veen 1990). Van der Veen's study on social policy explores the changing welfare state and its boundaries. Social policy in this changing welfare state is reconstructed, because policymakers felt that entitlements related to citizenship created an unaffordable welfare system, including incentives for unemployed people to remain unemployed (see Chapter 2 
for a further description of developments within citizenship studies). Our study too is situated within a changing welfare state, and explores the meanings of the new changes affecting it.

In exploring these practices, we were inspired by insights from Science and Technology Studies (STS) (Hackett et al. 2008; Jasanoff et al. 1995). STS can be described as an interdisciplinary field in which relations and interactions between science, technology and society are investigated by, among others, sociologists, anthropologists, philosophers and historians. The interest in social policy as a topic of research within STS is growing. Thorpe states in Hackett et al. (2008) that 'The interdisciplinary field of science and technology studies (STS) is increasingly explicitly concerned with political questions' (p. 63). Practices have their own dynamics and logic (Mol 2008) and STS can help deconstruct actual meanings of, and in, these practices to understand policy in practice. For instance, it helped to understand and reflect upon who counts as a citizen, within specific contexts and on what basis, besides regarding citizenship as a frame that offers a classical categorisation in terms of inclusion and exclusion (cf. Jasanoff 2004; and also, Chapter 2 of this thesis). Understanding not just actual technological devices and instruments as technologies, but social processes, structures, networks and techniques as well, helps to reflect on the meanings given to them in different practices, as they also shape these practices.

In our study, we observed how the kitchen table conversation is introduced as a social technology to facilitate care and welfare professionals to mediate ageing-inplace in practice. This tool, the kitchen table conversation, draws on an idea of an informal, open warm, and in-depth conversation between professionals (care and welfare professionals mostly) and older adults that has to help mediate negotiations about customised care arrangements and opportunities to remain as self-sufficient as possible. Additional social technologies, such as procedures, designs and instruments, are also introduced to further enable activation (Chapter 3). Furthermore, specific procedures and meeting places are introduced to create a network of municipalities and organisations, and the neighbourhood itself can be considered a technology (or, more specifically, an ageing technology) as well, as it is envisioned as a place that can be made into an assemblage of characteristics and elements that are needed to be able to age-in-place (Chapters 4 and 5 ). Society in itself can be considered a technological culture (Bijker 2001), which is affected and shaped in relation to all these different kinds of technologies applied in practice. Technologies are shaped by their developers, and they do not only affect but are also affected by, their users (Hackett et al. 2008). Because the policy described in our study aims to engage and activate older people as users, using place as an important facilitator, the meaning older people give ageing-in-place in practice is emphasised in each chapter of this study, besides the meanings different actors apply in making this policy. STS is concerned with such politically inspired and policy-driven questions and helps to clarify, analyse and criticise policy in practice. Our study might not only help improve a current policy in practice, but might also offer insights to shape future policies. 


\subsection{Investigating a policy in practice: Methodology}

To provide insight into the meanings of this ageing-in-place policy in practice, we used different ethnographic methods in a qualitative research design: document study, interviews, observations, focus groups and photovoice. From July 2011 until February 2016, we followed developments within the 'Voor Elkaar in Parkstad' initiative. ${ }^{1}$ We started this study with a document analysis, reading documents drawn up by several committees involved in this initiative, such as policy notes, minutes of meetings and formal agreement documents (including a covenant). These documents provided background information about arguments and decisions made. Simultaneously, from the beginning, interviews and participatory observations took place. In total, 85 semi-structured interviews were conducted (including nine photovoice interviews) with policymakers and civil servants, housing, care and welfare directors and managers, housing care and welfare professionals and representatives of older adults, and with older adults living independently. Initially, interviewees were selected based on their role within this process, which meant semi-structured interviews with the initiating parties were conducted first. Based on their suggestions (snowball sampling) and induced by things that took place in the processes we observed, we selected the other interviewees. Triggers included the introduction of a social neighbourhood team, or the implementation of the kitchen table conversation. Interviewees were given an important role in deciding on what they wanted to talk about, but in general they discussed at least the following topics: the meanings of 'Voor Elkaar in Parkstad', ageing, participation, citizenship, collaboration within this activation initiative and lifecycle-robust neighbourhoods. Older adults were selected for interviews in various ways: some decided to participate after being approached during informal meetings (such as a lunch meeting), but most older adults who were willing to participate were approached via care and welfare professionals or via a representative of older adults who lived in the same neighbourhood. Recurrent topics in the interviews with older adults were: growing older and living independently in their own neighbourhood, citizenship, participation, lifecycle-robust neighbourhoods (explained as places that are suitable to ageing-in-place) and knowledge about the initiative (although introduced as a transition towards ageing-in-place, which would be an ongoing process according to the initiators, at local levels it was mostly translated and communicated as a project, which implies a clear end) or thoughts about local politics related to older adults. Most of the older adults who participated were unfamiliar with the initiative, and the larger national policy shift towards a participatory society often served as a clarifying context for them.

In addition to these interviews, participants were observed during 57 formal and informal meetings, and during 15 activation sessions (professionals conducting kitchen table conversations). Furthermore, we organised 6 focus groups to obtain

1 The chapters of this thesis are based on articles written in collaboration with my promotors. I started as a scholar in June 2012. Some of the data used in this study were gathered in the second half of 2011 by another scholar. 
feedback on our preliminary findings and explore a number of topics in further detail, such as the experiences of professionals with their new roles. One focus group involved policymakers, one involved what were called project members, one involved social neighbourhood team (professionals and a few managers), one involved housing, care and welfare professionals and two involved older adults. All focus groups were audio-recorded and transcribed verbatim.

Based on findings in this research project, we organised a photovoice project in the second half of 2015 in two municipalities in Parkstad. Photovoice is a method from visual sociology that aims to make data visual (Catalani and Minkler 2010; Lockett et al. 2011; Wang and Burris 1997; Wang and Redwood-Jones 2001). In different neighbourhoods, housing, care, and welfare professionals and older adults were asked to photograph those places in their neighbourhoods that they considered important or relevant when they think about ageing-in-place. In short interviews and in two separate dialogue meetings, participants reflected upon these photographs and the stories these images represent, stories about places that participants consider important because they think they enable or restrict people in ageing-in-place (inspired by Kohon and Carder 2014; Novek et al. 2012). An important advantage of this method is that it enables people to actually show what makes a place important to them, instead of having to describe it.

As the research was an ongoing process, we organised member checks, by regularly feeding back our preliminary findings to participants in this study. This was often done by giving a presentation of preliminary findings, followed by a discussion during a formal meeting of steering committees, for instance, or project groups. We also organised focus groups, of which reports were written immediately afterwards that were sent to all participants for approval. As we studied the implementation of a policy in practice, the emphasis of our research was also provided by this practice. By using documents, interviews, observations, focus groups and the photovoice project to collect data, we explored different elements that were important to participants when talking about ageing-in-place in general and this initiative in particular. Based on our research, in this thesis our analysis of the meanings of citizenship in old age, of professionals in activation practices and the social technologies they use, and of age-friendly places and ageing-in-place is described in four different chapters.

\subsection{Outline of thesis}

In this study, we investigated meanings of ageing, citizenship, participation and the development of age-friendly places by closely examining an innovative public care initiative in the Netherlands. Within this initiative municipalities, organisations in the fields of housing, care and welfare (including a health-care insurance organisation) and representatives of older adults joined forces to develop so-called lifecycle-robust neighbourhoods. These are neighbourhoods where older adults can 
live independently for longer, which should help maintain a sustainable care system in the long term. This development is taking place in the context of a national care reform, an activation policy that aims to reform the Dutch welfare state into a participatory society. The different chapters illuminate different elements of this activation policy, in which the neighbourhood is considered to be of huge importance, acting as an ageing technology.

In Chapter 2, we explore how citizenship in old age is constructed in the innovative public care initiative we studied. We explore how policymakers, civil servants, directors, managers, professionals, representatives of older adults and older adults themselves give different meanings to citizenship in relation to a policy that aims to enable older adults to remain living independently for longer. The new policy expects housing, care and welfare professionals, such as neighbourhood nurses, social workers and older adults' advisors, to play pivotal roles in activating older adults to remain independent as long as possible. Therefore, the kitchen table conversation is introduced as a new social tool, in which additional techniques such as questionnaires are often used. In Chapter 3, we analyse how a tool to mediate this 'new professionalism' plays out in practice, by looking at some kitchen table conversations and exploring how such conversations as mediating technologies play a role in constructing the professional's new role. To understand the meanings of 'lifecycle-robust neighbourhoods', different methodologies were used and constructions of different actors were analysed. In Chapter 4, interviews, observations and focus groups are used to unpack the meanings of lifecycle-robust neighbourhoods in policy and practice. Meanings provided by both 'developers' and 'users' are examined, including policymakers, housing, care and welfare directors and representatives of older adults as 'developers' and older adults themselves as 'users'. In Chapter 5, we further explore this notion by reporting on a photovoice project, in which both older adults and housing, care and welfare professionals endeavoured to visualise their ideas of lifecycle-robustness. We analyse the photographs they took in their neighbourhood and the conversations they held about these photographs in particular and lifecycle-robustness in their neighbourhood in general. Finally, in Chapter 6, the main research question will be answered by reflecting on the main findings of this thesis and discussing the most important lessons. 


\section{References}

Abma, T. and Veld, In 't, R., 2001. Handboek Beleidswetenschap. Uitgeverij Boom: Amsterdam

Andrews, G., Evans, J. and Wiles, J., 2013. Re-placing and re-spacing gerontology: Relationality and affect. Ageing \& Society, 33, o8, ,1339-1373. doi:http://dx.doi.org/10.1017/So144686X12000621

Beard, J., Blaney, S., Cerda, M., Frye, V., Loyasi, G., Ompad, D., Rundle, A. and Vlahov, D., 20o9. Neighborhood Characteristics and Disability in Older Adults. The Journal of Gerontology: Psychological Sciences and Social Sciences, 64, 02, 252-257. doi: 10.1093/geronb/gbno18

Bijker, W., 20o1. Understanding technological culture through a constructivist view of science, technology, and society. In: Cutcliffe, S. and Mitcham, C. (Eds.), 2001, Visions of STS: Counterpoints in science, technology and society studies. State University of New York Press: Albany, NY.

Bond, J., Peace, S., Dittmann-Kohli, F. and Westerhof, G. (Eds.), 2007. Ageing in society: European perspectives on gerontology (3rd ed.). Sage Publications Ltd: London.

Catalani, C. and Minkler, M., 2010. Photovoice: A review of the literature in health and public health. Health Education and Behavior 37, 03, 424-451. doi:10.1177/1090198109342084

Dunn, E., 2005. Standards and person-making in East-Central Europe. In Collier, S. and Ong, A. (Eds.), 2005, Global Assemblages: Technology, Politics and Ethics as Anthropological Problems. Blackwell: Malden, MA. doi:10.1002/9780470696569.chio

Elzerman, K. and Bontje, M., 2015. Urban shrinkage in Parkstad Limburg. European Planning Studies, 23, 01, 87-103. doi: http://dx.doi.org/10.108o/09654313.2013.820095

Gieryn, T., 200o. A space for place in sociology. Annual Review of Sociology, 26, o1, 463-96. doi:10.1145/annurev.soc.26.1463

Gilleard, C., and Higgs, P., 1998. Old people as users and consumers of healthcare: A third age rhetoric for a fourth age reality? Ageing \& Society, 18, 233-248.

Hacker, B., 2009. Hybridization instead of clustering: Transformation processes of welfare policies in Central and Eastern Europe. Social Policy and Administration, 43, 02, 152-69. doi:10.1111/j.1467-9515.2009.00653.x

Hackett, E., Amsterdamska, O., Lynch, M. and Wajcman, J. (Eds.), 20o8. The Handbook of Science and Technology Studies (Third edition). Massachussetts Institute of Technology: Cambridge, MA.

Hesdahl, B. and Sollet, O., 2011. Transitieplan Voor Elkaar in Parkstad + deeltransities [Transition Plan Voor Elkaar in Parkstad + Sub-transitions]. Available online at http://docplayer.nl/10671232-Transitieplan-voor-elkaar-in-parkstad-deeltransities.html, december 20, 2016.

Higgs, P., 1995. Citizenship and old age: The end of the road? Ageing \& Society, 15, 04, 535-550. doi:https://doi.org/10.1017/So144686Xoooo289o

Hoekveld, J. and Bontje, M., 2015. Intra-Regional Differentiation of Population Development in Southern-Limburg, the Netherlands. Tijdschrift voor economische en sociale geografie, 107, 03, 282-297. doi:10.1111/tesg.12149

Huber, M., Knottnerus, J., Green, L., Horst, H. van der, Jadad, A., Kromhout, D., Leonard, B., Lorig, K., Loureiro, M., Meer, J. van der, Schnabel, P., Smith, R., Weel, C. van and Smid, H., 2011. How should we define health?. BMJ, 343, 1-3. doi:https://doi.org/10.1136/bmj.d4163

Jasanoff, S., Markle, G., Petersen, J., and Pinch, T. (Eds.), 1995. Handbook of science and technology studies. Sage Publications Inc.: California.

Jasanoff, S., 2004. Science and citizenship: A new synergy. Science and Public Policy, 31, 02, 90-94. doi: https://doi. org/10.3152/147154304781780064

Kohon, J., Carder, P., 2014. Exploring identity and aging: Auto-photography and narratives of low income older adults. Journal of Aging Studies, 30, 47-55. doi:10.1016/j.jaging.2014.02.006

Kroneman, M., Cardol, M. and Friele, R., 2012. (De)centralization of social support in six Western European countries. Health Policy, 106, o1, 76-87.

doi:https://doi.org/10.1016/j.healthpol.2012.03.003

Lamb, S., 2014. Permanent personhood or meaningful decline? Toward a critical anthropology of successful aging. Journal of Aging Studies, 29, 41-52. doi:https://doi.org/10.1016/j.jaging.2013.12.006

Lamont, M. and Molnár, V., 2002. The study of boundaries in the social sciences. Annual Review of Sociology, 28, 167-195. doi: https://doi.org/10.1146/annurev.soc.28.110601.141107

Liebenberg, L., Ungar, M. and Ikeda, J., 2015 'Neo-Liberalism and Responsibilisation in the Discourse of Social Workers', British Journal of Social Work, 45, 1006-2021. doi:https://doi.org/10.1093/bjsw/bct172 
Lindenberg, J. and Westendorp, R.G., 2015. Overcoming Old in Age-Friendliness. Journal of social work practice, 29, o1, 85-98.

Lipsky, M., 1980 [2011], Street-Level Bureaucracy. Dilemmas of the individual in public services. Russell Sage Foundation: New York.

Lockett, D., Willis, A. and Edwards, N., 2005. Through seniors' eyes: an exploratory qualitative study to identify environmental barriers to and facilitators of walking. CJNR (Canadian Journal of Nursing Research), 37, 03, 48-65.

Mol, A., 2008. The logic of care: Health and the problem of patient choice. Routledge: New York.

Newman, J. and Tonkens, E., 2011. Participation, responsibility and choice: Summoning the active citizen in western European welfare states. Amsterdam University Press: Amsterdam.

Nowak, S., Molema, C., Baan, C., Oosting, S., Vaandrager, L., Hop, P. and Bruin, S. de, 2015. Decentralisation of longterm care in the Netherlands: the case of day care at green care farms for people with dementia. Ageing \& Society, $35,04,704-24$.

doi:https://doi.org/10.1017/So144686X13000937

Novek, S., Morris-Oswald, T. and Menec, V., 2012. Using photovoice with older adults: some methodological strengths and issues. Ageing \& Society, 32, 03, 451-470.

doi:http://dx.doi.org/10.1017/So144686X11000377

OECD, 2013. Demographic Change in the Netherlands: Strategies for resilient labour markets. markets. OECD Local Economic and Employment Development (LEED) Working Papers.

Ottoni, C., Sims-Gould, J., Winters, M., Heijnen, M. and McKay, H., 2016. "Benches become like porches”: Built and social environment influences on older adults' experiences of mobility and well-being. Social Science \& Medicine, 169, 33-41. doi:http://dx.doi.org/10.1016/j.socscimed.2016.08.044

Persson, T. and Berg, S., 2008. Older people's “voices”- on paper: Obstacles to influence in welfare states—A case study of Sweden. Journal of Aging \& Social Policy, 21, o1, 94-111. doi:http://dx.doi.org/10.1080/08959420802539118

Ročak, M., Hospers, G. J. and Reverda, N., 2016. Searching for Social Sustainability: The Case of the Shrinking City of Heerlen, The Netherlands. Sustainability, 8, 382, 1-22. doi:10.339o/su8040382

Rudman, D., 2015. Embodying positive aging and neoliberal rationality: Talking about the aging body within narratives of retirement. Journal of Aging Studies, 34, 10-20.

doi:https://doi.org/10.1016/j.jaging.2015.03.005

RVTV, 2010. Een gezonde kijk op Zuid-Limburg. Regionale Volksgezondheid Toekomst Verkenning 2010. GGD Zuid-Limburg: Geleen.

RVTV, 2014. Een nieuwe kijk op gezondheid in Zuid-Limburg. Regionaal rapport Volksgezondheid Toekomst Verkenning 2014. GGD Zuid-Limburg: Geleen.

Singh, N., 2008. Decentralization and public delivery of health care services in India. Health Affairs, 27, 04, 991-1001. doi: 10.1377/hlthaff.27.4.991

Sixsmith, J., Sixsmith, A., Malmgren Fänged, A., Naumanne, D., Kucseraf, C., Tomsone, S., Haak, M., Dahlin-Ivanoff, S., Woolrych, R., 2014. Healthy ageing and home: The perspectives of very old people in five European countries. Social Science \& Medicine, 106, 1-9. doi:https://doi.org/10.1016/j.socscimed.2014.01.006

Thorpe, C., 2008. Political theory in science and technology studies. In: Hackett, E.J., Amsterdamska, O., Lynch, M. and Wajcman, J. (Eds.), 2008. The handbook of science and technology studies, 63-82.

Veen, van der, R., 199o. De sociale grenzen van beleid. Een onderzoek naar de uitvoering en effecten van het stelsel van sociale zekerheid. Stenfert Kroese: Leiden / Antwerpen.

Wang, C. and Burris, M., 1997. Photovoice: Concept, methodology, and use for participatory needs assessment. Health Education \& Behavior, 24, 03, 369-387. doi:0.1177/109019819702400309

Wang, C. and Redwood-Jones, Y., 2001. Photovoice ethics: Perspectives from Flint photovoice. Health Education \& Behavior, 28, 05, 560-572. doi:10.1177/109019810102800504

Wiles, J., Leibing, A., Guberman, N., Reeve, J. and Allen, R., 2011. The meaning of "ageing in place" to older people. The gerontologist, 52, 03, 357-366. doi:10.1093/geront/gnro98

WHO, 2015. World report on Ageing and Health. World Health Organization: Geneva. Retrieved from: http://apps.who. int/iris/bitstream/10665/186463/1/9789240694811_eng.pdf?ua=1. 




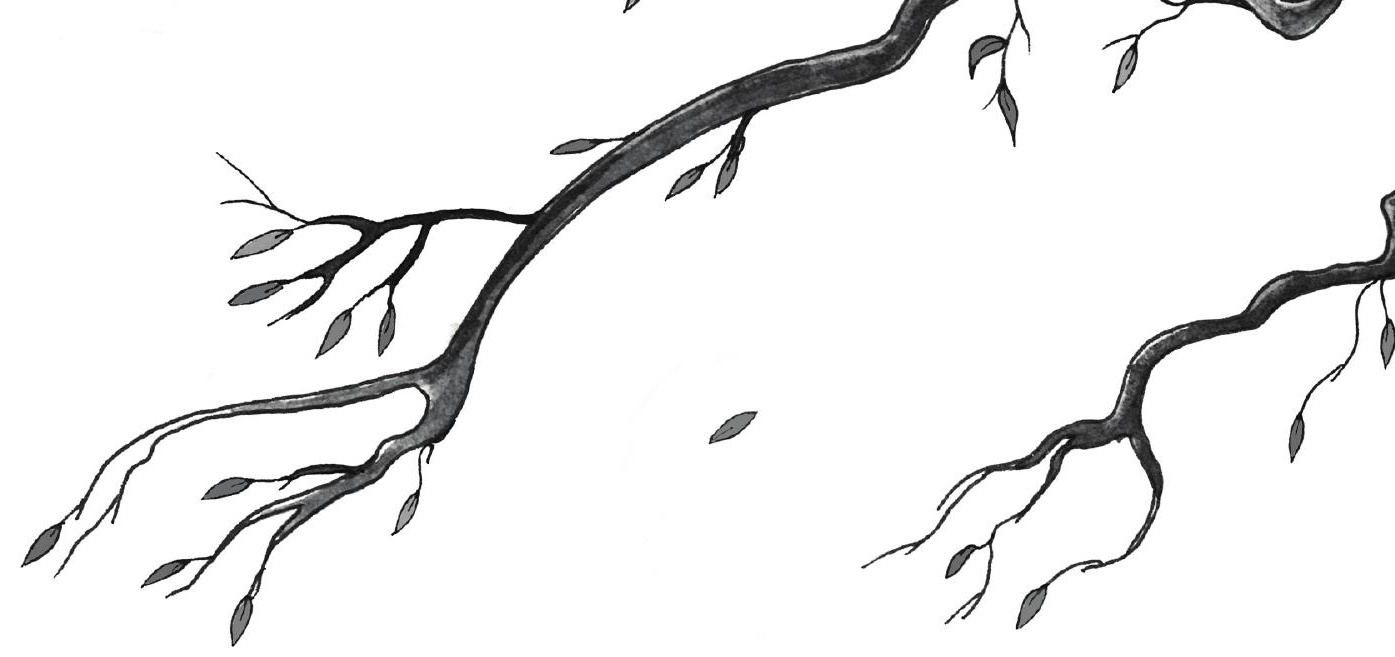

Chapter 2

\section{Conflicting notions of citizenship in old age}

An analysis of an activation practice

Published as:

Susan van Hees, Klasien Horstman, Maria Jansen and Dirk Ruwaard, 2015.

Conflicting notions of citizenship in old age: An analysis of an activation practice. Journal of Aging Studies, 35, 178-189.

http://dx.doi.org/10.1016/j.jaging.2015.09.001 


\section{Abstract}

Ageing societies and increasing healthcare expenditures are inducing Western welfare states to reform their care arrangements. In a qualitative research project, we explored how citizenship in old age is constructed in a public innovative care practice situated in the southern part of the Netherlands: the shaping of 'lifecycle-robust neighbourhoods'. Lifecycle-robustness entails a further not formally defined ideal of age-friendly places, enabling older adults to live independently for longer periods of time. Participation is being presented as an important element towards lifecycle-robustness. We used ethnographic methods to understand different constructions of citizenship in old age. We analysed documents and interviewed local policymakers and civil servants, managers and directors in the fields of housing, care and welfare, professionals working for these organisations, and older adults living (independently) in these neighbourhoods ( $n=73$ ). Additionally, we observed formal and informal meetings and organised focus groups.

Our findings demonstrate conflicting notions of old age. Policymakers and civil servants, managers and directors, professionals, and even representatives of older adults share a belief an activation policy is necessary, although they differ in how they interpret this need. Policymakers and civil servants are convinced that societal and financial incentives necessitate current reforms, managers and directors talk about quality and organisational needs, while professionals mainly strive to empower older adults (as citizens). Simultaneously, older adults try to live their lives as independent as possible. We argue that, whereas old age became a distinct category in the last century, we now recognise a new period in which this category is being more and more de-categorised. 


\subsection{Introduction}

Ageing societies and continuous increases in healthcare expenditures are inducing Western welfare states to reform care arrangements (Bond, Peace, Dittmann-Kohli, and Westerhof 2007). The Dutch national government is emphasising a need to shift from being a welfare society towards becoming a participatory society. Where participatory democracies encourage the democratic participation of citizens, a participatory society builds on neoliberal agendas that emphasise individuals' own responsibilities for their health and well-being, and an activation of people to help each other (Lamb 2014; Newman and Tonkens 2011; Rudman 2015). As part of these neoliberal agendas, an increasing amount of governmental and institutional responsibilities are being shifted to individuals (Dunn 2005). The Dutch government expects that the inhabitants become more independent and active in society by taking care of themselves and their immediate environments. Governmental strategies include a redefinition of participation, as part of a broader aim to maintain an affordable healthcare system, as was already illustrated by Newman and Tonkens (2011). No longer considered as a civic entitlement, participation has become a strategical promotion of citizens' moral obligations. Using 'positive public moral', citizens are expressively invited to play an active role in society (Tonkens 2008).

Participation is considered to be an important parameter of modern citizenship and everybody has been asked to participate as much and as actively as possible (part of the yearly Dutch Speech from the Throne, Troonrede 2013). Until recently, an active (social) citizenship was not expected of older (retired) adults, let alone the older old adults who were 75 years or over. Everybody was allowed, and sometimes even encouraged to pursue active citizenship and to volunteer in many societal roles, but an actual moral obligation was absent. Rather, people were supposed to enjoy their retirement days as much as possible. Expectations are now changing and even older adults are being stimulated to participate and to strive for self-sufficiency to realise a 'full' citizenship. By striving for self-sufficiency, governments mean that individuals should try to manage and regulate their own health and well-being (Lamb 2014). If help is needed, people are pressed to find and arrange this within their own immediate, informal networks. The term participation is used to explicate the things citizens are supposed to do for their immediate environments, such as keeping an eye on the safety of a frail neighbour, but also by actively contributing within the community, through participating in or organising social activities. Governments ask individuals to help other people and to do something in return. In other words, the rise of participatory societies is inducing new meanings of citizenship in old age, with an important role for active participation in society, while preferably ageing-in-place.

To better understand further existing notions of citizenship in old age, we performed a scoping review of notions of citizenship and participation in six academic journals about ageing: Age and Ageing, Ageing \& Society, Journal of Aging and Health, Journal of Aging \& Social Policy, Journal of Aging Studies and Research on 
Aging. Our search for citizenship resulted in 528 studies that appeared to address citizenship, after which we narrowed our search down to 383 studies by adding the term 'participation'. This number of publications indicated that the relationship between notions of ageing, citizenship and participation has been studied thoroughly. However, it appeared that many studies mainly focused on specific issues, such as legal citizen entitlements of specific older minorities. Notions of citizenship in these studies took citizenship as a given construction of entitlements without any further obligations (Barnes 2005; Gilleard and Higgs 2000; Walker 2008). Active, participative citizenship in old age as it is promoted nowadays, is occasionally mentioned and only as a voluntary achievement. The studies described older adults as being entitled to strive for an active, participative citizenship, with some public support if necessary (Craig 2004; Isin and Turner 2007; Wharf-Higgins 1999). As current activation policies aim for active, participative older adults, notions of citizenship and participation change. It is no longer only about managing and regulating one's own health, but also about taking care of others and participating in the community. Drawing on a large body of literature, we conceptualised citizenship in old age. This paper adds to the literature on ageing, citizenship and participation as it unfolds new understandings of older adults' participation in society, building on a qualitative research in a public innovative care practice.

\subsection{Contexts of citizenship in old age}

\section{Citizenship}

In the context of the rise of 'participatory societies' the meaning of citizenship as well as citizenship in old age is being reconstructed, as it is increasingly associated with active participation. 'Own responsibility', 'own strength', 'empowerment', and 'to let loose [as a government]' are mentioned as ideals of a participatory society (Rmo 2013; ROB 2012; RVZ 2012; RVZ 2013; SCP 2013; WRR 2012). Some scholars have criticised these ideals and consider the introduction of 'active citizenship' to be a solution for assumed shortcomings in social cohesion, people's consumerist and antisocial behaviour, social exclusion, and a gap between the citizens and policymakers (Tonkens 2008, p. 5). This debate pays little attention to the notion of 'citizenship in old age'. To understand how current developments affect older adults and constructions of their citizenship, we need to know more about the evolution of the concepts 'citizenship' and 'old age'.

The concept of citizenship and its evolution is often described based on three main dimensions: legal, political and social citizenship (Huisman and Oosterhuis 2014; Kymlicka and Norman 1994). Legal citizenship was introduced in 1789 and concerns sovereign citizens' rights. Between 1870 and 1945, a political dimension evolved with the introduction of a right to vote. Social citizenship, recognised and described by 
Marshall (1949), arose soon after the Second World War, and involves the idea that people who rightfully live in a city are automatically citizens and receive a social right to private and passive citizenship. In our study, we have merely explored this social dimension of citizenship. Whereas legal and even political rights are often conferred to most people upon birth, meanings given to social rights are more sensitive to changes, as its demarcations are less agreed upon and can be the subject of negotiations in policy reforms. Van de Wijdeven, De Graaf and Hendriks (2013) demonstrated how Marshall's social citizenship has enabled a development of active citizenship since the 1970s, encompassing three active citizenship generations: the acquisition of several participation entitlements introduced generations of 'voice' (first generation), coproduction and interactive policymaking (second generation) and a right within civil society to take initiative (third generation). Most recent developments are described using concepts such as 'do-democracy' and 'citizen power'.

Changing notions of citizenship have affected ideas about when a person is included as a citizen or considered to be 'a full member of society' (Kymlicka and Norman 1994). Wharf-Higgins (1999, p. 302) explained how 'full citizenship (...) distinguishes participants from non-participants', and how citizens need to be empowered to be able to participate in the society (see also Marschall 2004; Verba, Schlozman and Brady 1995, p. 38). Empowerment is considered to be necessary to support citizens in achieving a citizenship status at 'the moment they become unemployed, fall ill or become too old to take care of themselves' (Isin and Turner 2007, p. 16). Although participation is described as part of being a 'full citizen', it is also described as a choice. This choice can be valued differently. For example, Harbers (2005, p. 265) mentioned 'a political right to laziness', while Bang (2004) and Bang and Sørensen (1999) described people as 'free riders' when they choose not to participate, but derive benefits from the participation of other people. More recent ideas about reciprocity are related to the notion that 'free riders' demonstrate a blameworthy behaviour, they revealed how many people feel uncomfortable and dependent when they are unable to return a favour (Bredewold 2014; Linders 2009; Tonkens and De Wilde 2013). Recent studies used concepts of empowerment, inclusiveness, full citizenship, and reciprocity to describe ideals about an independent citizenship status, but they also explored the meaning of 'affective citizenship' (Kampen, Verhoeven, and Verplanke 2013) or 'ethical citizenship' (Muehlebach 2012). According to Muehlebach (2012, p. 146), the 'moral neoliberals' developed an idea that people can only 'remain' citizens under the condition that they remain active.

\section{Old age and ageing}

Notions about 'old age' and 'older adults' as described in the works of scholars like Bijsterveld (1995) and Bond et al. (2007) evolved as a consequence of the introduction of a welfare state and social rights. Bijsterveld wrote a dissertation on the history of the academic and political discourses on ageing, which included a history of how 
old age developed as a specific category, while Bond et al. provided an overview of a variety of perspectives on gerontology. Both studies considered the introduction of a notion of retirement in the 1940s to be an important turning point in the way ageing and old age were and have been constructed in Western societies. Preventing unemployment became an issue as a consequence of an ageing society; old age was now categorised as a specific or separate phase of life, a phase of retirement. Based on their age, people were enabled to enter a newly constructed phase in life, where there was no need to remain active and where they could withdraw from social life.

Retirement and the possibility that people could choose to live in retirement homes affected common thoughts about ageing and old age. The choice to live in a retirement home could now be understood as a choice to stay independent, especially independent from their children. In and around the 1960s, it was mainly the healthy older people who chose to live in these places, among other healthy, often wealthy older people. New nursing homes needed to be built for disabled or chronically ill, unhealthy older adults. At the same time, distinctions were introduced about the meaning of old age and new distinctions were made between being 'young-old' and 'old-old' (Bijsterveld 1995; Walker 2008), and between a 'third age' and a 'fourth age' (Laslett 1987). Autonomy, agency and self-actualisation were considered to be thirdage characteristics, while dependence and decrepitude were supposed to characterise the fourth age (Scourfield 2007). As Gilleard and Higgs (2010) argued, the positive status of the notion of third age relied on the active exclusion of the (older old) fourth agers.

In relation to the increased institutionalisation of older adults, it became clear that older adults were not a homogeneous group. General characteristics of old age were no longer adjusted to reality, and living arrangements did not consider the differences between older adults. The possibility of retirement was introduced to solve a social problem of unemployment and housing. Old age was increasingly understood as a new phase of life, a category of older adults, and these people were encouraged to leave their big family houses and move towards retirement homes. As a result of the new categorisation, some older adults found a new independence, but Bijsterveld also described how this categorisation caused feelings of loneliness, being redundant, losing a marginal preferential position and being discriminated against as a minority (although actually almost being a majority) (Bijsterveld 1995). By facilitating older adults to remain contributive and participative, but also by the 'social recognition of a hard-earned life', older adults experience how they are still of value to the society (Milton et al. 2015). Preferences about living at a retirement home in old age changed (Dahlin-Ivanoff, Haak, Fänge and Iwarsson 2007; Sixsmith et al. 2014); instead of moving towards retirement homes, a growing number of older adults now prefer to remain living independently in their own homes, although they are also encouraged to do so. The possibility to grow old at home has become valuable, since the home is considered to be a place that reflects a person's own identity and society, enabling options of independence, autonomy and participation (Sixsmith et al. 2014). 


\section{Where old age and citizenship meet}

The modern concept of citizenship, as introduced in 1789, developed from legal entitlements towards a criterion for being an active member of society. The increasing emphasis on participation and active citizenship by 'all citizens' influenced ideas about ageing and old age. Independence and the ability to participate have come to define a new concept of citizenship within old age. Governments are steering towards an increased independence of citizens, hoping to cut back on a need for public (paid) support. Actual consequences of 'not-participating' seem unclear, but new notions of citizenship might exclude nonconforming people, including people who are unable to organise support to remain independent, which is considered a crucial element of citizenship (Fraser and Gordon, 1994). According to Townsend (1981, p. 5) a governmental framing of older adults as costly and (socially) dependent was actually 'being manufactured socially', by 'concepts as retirement, pensionable status, institutional residence and rather passive community care.' Older adults were traditionally considered as passive 'recipients' of care (Petriwskyj, Gibson, and Webby 2014). Independence however, is also related to dignity, which is believed to encourage the maintaining of autonomy, relational and self-identity (Black and Dobbs 2014; Gilleard and Higgs, 2010; Lloyd, Calnan, Cameron, Seymour and Smith 2014). Some other enabling elements mentioned in recent studies were empowerment, affectivity, reciprocity and ageing-in-place.

These notions of citizenship in old age express an importance to remain in control of one's own decisions and actions, even when getting physically dependent. Within a current citizenship discourse, 'successful ageing' seems to play a more important role than ever, even though the subject of ageing and defining success is very complicated and heterogeneous (Bülow and Söderqvist 2014). Robert Havighurst introduced the term successful ageing already in 1961 but a uniform definition is still non-existent and a variety of labels is used, including active ageing, positive ageing, vital ageing and healthy ageing. The World Health Organization (WHO) encouraged active ageing ( $\mathrm{WHO}$ 2002), as an ageing population necessitates the development of strategies which allow older people to stay engaged and participative within their communities:

active aging [should be] a comprehensive strategy to maximize participation and well-being as people age. It should operate simultaneously at the individual (lifestyle), organizational (management), and societal (policy) levels and at all stages of the life course. (Walker 2008; p.86. WHO 2002).

Active ageing is considered a 'process of optimizing opportunities for health, participation and security in order to enhance quality of life as people age' (WHO 2007, p. 5). Although these definitions imply a facilitation of a participative, healthy ageing process based on individual preferences, these definitions do illustrate how 
possibilities of participation have become important within political, health and more theoretical discourses of ageing and old age. Nonetheless, some studies have criticised a marginalisation of old people who cannot live up to this active ageing standard (Minkler and Holstein 2008). Lassen and Moreira (2014) argued that if people are to accept active ageing as 'a way of life', a place for passivity seems crucial. They warned that following new ideals of a 'good late life', might deconstruct former structures and expectations of old age.

In his work, Higgs (1995) demonstrated how older people are sometimes implicitly denied citizenship when the body becomes a defining element for a person's opportunities to participate. Social rights of participation have become increasingly important to retaining a citizenship status, but also define this citizenship status. This status is restricted when a person has limited physical and mental abilities to actually participate. Being unable to leave a place restricts opportunities to genuinely participate. Scholars like Gilleard and Higgs (1998), Higgs (1995) and Persson and Berg (2008) illustrated how older people in welfare states who become ill or disabled are no longer able to use the options of 'exit' and 'voice', which limits their opportunities for genuine participation. As Persson and Berg (2008) argued: 'users of older services in welfare states may be deprived of their 'exit' options and face considerable constraints when it comes to raising their 'voices."

Older people who still live independently seem to have more choices than people who live in nursing homes, but they are also limited when they need anything. Several scholars have argued that the living place is assumed to play an important role in older adults' citizenship status. The term ageing-in-place is a widely-used concept to define this argument (Sixsmith et al. 2014). However, Dahlin-Ivanoff et al. (2007) remarked that the home of an older adult can also change into a workplace for social services and healthcare professionals and noted how this can cause a decrease in independence: 'Even if they [frail older adults] consider themselves to be in control of their daily activities, (...) [they] are in the hands of others in terms of not being allowed to decide for themselves.' Having to reorganise one's home and manage the frequent comings and goings of professionals can affect a person's sense of freedom. These frail older adults are no longer independent in the same way as before, and even if they consider themselves to be in control of their daily activities, they are in the hands of others in terms of not being allowed to make their own decisions. Freedom can be limited simply because older adults can no longer freely decide when and how to do things differently.

Given these notions of citizenship as strongly related to ideals of independency, autonomy, relational and self-identity, further understanding of notions of citizenship in old age within a contemporary society requires additional research. 


\subsection{Methodology}

Drawing on a qualitative research we explored how citizenship in old age is being constructed in a public innovative care practice, namely the shaping of life cycle robust neighbourhoods in a transition process called 'Voor Elkaar in Parkstad' (For Each Other in Parkstad). Following the WHO's concept of age-friendly communities from 2007, these life cycle robust neighbourhoods entail an ideal of age-friendly places where all inhabitants, including older adults, can live independently for longer periods of time. This resonates with ageing-in-place ambitions. Life cycle robust neighbourhoods are introduced as a suggested solution for the challenges induced by a rapidly ageing population and increasing healthcare expenditures in Parkstad (i.e., an area in the south of the Netherlands). However, it is not yet clear what these life cycle robust neighbourhoods should eventually look like. The importance of independent, participating older citizens has been emphasised recurrently in practice by several actors involved. But even definitions in project plans written at the start and during this study did not help in finding a good clarifying definition. In a few sentences these documents only describe an ideal neighbourhood that 'enables older adults to live independently and remain self-sufficient for longer periods of time.' This should be achieved by: 'not focussing on services, but on the way organisations collaborate.' Eight municipalities, a healthcare insurer, organisations in the fields of housing, welfare and healthcare, and a group of representatives of older adults, initiated this collaboration to face these challenges together. We analysed the process in general and investigated the practices in two specific neighbourhoods in-depth: Heerlerheide, located in the largest urban municipality (population greater than 88,000 ) and Onderbanken, a small rural municipality (population less than 8,ooo).

We tried to unpack the dynamics and practices of a project that we describe as a policy and care innovation, following insights from science and technology studies (STS) (Jasanoff, Markle, Petersen and Pinch 1995). STS helped to deconstruct the actual meaning of citizenship, by granting a way to understand and reflect upon who counts as a citizen, within specific contexts and based on what, besides offering a classical categorisation in inclusion and exclusion (Jasanoff 2004). The fieldwork in this study drew on ethnographic methods to analyse how citizenship is constructed in practice (Alvesson and Sköldberg 2009). Data collection took place from July 2011 until December 2014.

In this paper, we distinguished between many perspectives on (social) citizenship in old age: those of policymakers and civil servants; directors and managers of organisations; care and welfare professionals (i.e. social workers, neighbourhood nurses, specific advisors of older adults); and older adults and their representatives. As the project focussed on independent living older adults of 75 years and older, we mainly investigated the experiences of older adults who were 75 years or over. The institutional stakeholders (policymakers, managers et cetera) tried to engage older adults by inviting them to send representatives to participate in formal meetings. 
However, we discovered that other participants considered these representatives often as 'professional older adults' and it is unclear whether they actually represented the genuine voice of older adults, or only interpreted this voice. Participants assumed that these representatives grew biased over time, as they became accustomed to political language and procedures. Most of the representatives were also younger than the group of older adults they were asked to represent. We tried to capture a more genuine voice by interviewing and observing independent living older adults in and about their daily lives.

To understand the underlying ideals and goals, we started with an analysis of relevant documents, such as project plans and minutes from key meetings. In 55 semi-structured in-depth interviews, the first author interviewed 51 policymakers and civil servants, directors and managers, and professionals. Ten interviews were held with more than one representative at a time and eight people were interviewed more than once (two or three times). The main themes we discussed with these institutional stakeholders and which we used in our analysis in this paper, were the aims of this policy and care innovation, interviewees perspectives on older adults as a target group, and the meaning of life cycle robust neighbourhoods. Albeit topic lists were used, all interviews focussed on those elements considered most important by our interviewees. Our interviewees elaborated for example on how they understood participation and citizenship in old age and how these concepts were or should be operationalised in practice. To understand the perspectives of older adults about this innovative care practice, we also interviewed 28 independent living older adults in 18 interviews (partners were interviewed together). Key themes in these interviews were older adults' perspectives on living and ageing in their neighbourhood, their ideals about living a good life, and their ideas about current changes in politics and society. As older adults described their ideals and experiences, we gained insight in the meanings they give to citizenship, participation and ageing. Each interview lasted between 20 and $150 \mathrm{~min}$. Audio recordings were made of 70 interviews and transcribed verbatim in Dutch. Due to practical and technical limitations, during three interviews only notes were taken. The quotes used in this article have been slightly edited for readability.

In addition, the first author made observations during 55 formal and informal meetings, including steering committee meetings, project group meetings and case management meetings, as well as at lunches, handicraft groups and bingo games that included older adults. A few professionals were observed during their daily work, mostly in interaction with older adults or in meetings with other professionals. Six focus groups were organised to gain further information and check for saturation. In these focus groups, professionals, a social neighbourhood team (comprising professionals, civil servants and managers), a project group (comprising managers and civil servants) and a steering committee (comprising policymakers and directors) discussed the collaboration process, successes and failures. The older adults who we interviewed were invited to visit a meeting in their own neighbourhood. Ten older adults attended these meetings, together with five representatives of older adults. 


\subsection{Citizenship in old age: activation policy and celebrating independence}

\section{In need of activation policy}

Policymakers and civil servants, directors and managers of organisations, and care and welfare professionals agreed that the innovative care practice we studied needs an activation policy. Nevertheless, interviewees developed different narratives about activation and articulated this need differently. In this section, we demonstrate how these different actors framed activation of older adults as necessary, while talking about developing life cycle robust neighbourhoods.

\section{'Governmental strategies towards activation'}

The stories of policymakers and civil servants made it clear how they construct the socio-political context of their work. They told us how the national government in the Netherlands promotes an activation approach and expects the local governments to translate the decisions made at a national level into local practices and to reduce their healthcare expenditures by shifting governmental and institutional responsibilities to individuals. Our interviewees argued how they experience a need to be able to serve 'more people with less money', while also managing an increasing demand for care and government facilities. An alderman explained: 'Because no matter how you look at it, the municipality still has to be able to take care of more people with the same amount of money'

On the one hand policymakers and civil servants feel pressed by the assignment to decrease local healthcare expenditures and activate citizens to be self-sufficient and participative. However, on the other hand, they themselves consider a reform to be necessary and they believe that times have changed and the levels of activation and participation should be raised. Although they acknowledged that some people are still frail and in need of care, policymakers and civil servants think the activation of citizens, in their own neighbourhoods, is achievable. In their view an increasing proportion of the current group of older adults is able to participate in society, or rather, in their own neighbourhood. A civil servant argued:

You have groups of people [who are] more vulnerable, need more support and more are, but there are also more and more older adults who are also still active until they are 75 or $80 .$. or for their whole lives... Could you not make use of them for certain things?

These local policymakers and civil servants appropriated the national activation approach, which is illustrated in the way a civil servant specified his expectations of citizenship in old age within society: 
We have always talked a lot about the vulnerable older adults, but of course there are also a lot of older adults who are still very vital. They shouldn't only spend their energy on their grandchildren even if that's a fun and good thing. They should also take some part of the responsibility for the care of the less vital members of their own generation.

In embracing an activation approach, policymakers and civil servants referred to what they now consider to be negative developments from the past. For instance, they explained how former public policies resulted in citizens who became mainly used to certain entitlements, and kept asking for publicly paid help instead of looking for solutions within their own environments. An alderman added:

People are, in the jargon of welfare professionals, pretty much consumption minded. If services are provided, people love to participate. That's not really the problem, but having them organising things themselves is the hard part. In general, people like to bide their time.

In his view, categories like 'older adults' have become obsolete: 'Really, those age categories are pretty random and even somewhat funny. He illustrated how he thought that the category of old age did not really apply to him, although he was almost 60 years old: 'I already belong to the category that's supposed to drive around in a mobility scooter.' Some moments later he added: 'My take is that it's more important to think in terms of limitations.' Many older adults can remain or become quite active, so policymakers and civil servants prefer to make distinctions based on individuals' abilities and disabilities. All people, including older adults, are expected to participate in society in line with their abilities, preferably in activities taking place in people's own neighbourhood, but also by taking care of themselves and each other. A civil servant explained how an older adult who receives a mobility scooter can help the community by driving up to a primary school in the neighbourhood, and read out books to the children. An underlying idea is that by remaining active in society, problems of social isolation can be prevented, while simultaneously expenditures are cut back by making use of volunteering older adults instead of publicly paid professionals.

Although local policymakers identify with the national activation policies and strive for more participation, they also said they feel that they should express themselves cautiously, as they depend on the local electorate. They struggle to find a balance between attuning to their electorate in local accounts of their policies and the actual implementation of participatory policies. During a meeting, one alderman described his frustration as being misunderstood by the citizens he represents:

...you somehow want to make clear that you are actually opposing the policy, the speed with which things are happening, and that people are not understanding that you're also not supporting these things. 
Another alderman tried to explain why older citizens will eventually be pleased as well:

Some people are dissatisfied and others are satisfied because they are receiving some specialised care and responding to that like 'gee, how nice'; [they are happy] because people are visiting them at home and in the past, they were supposed to visit the city hall first...

In this quote, the alderman expressed a desire to please citizens, but also added that the activation approach is necessary: 'Sure, but we are also examining, what you, mister Jansen, can still do yourself.'

\section{'A need to organise care differently'}

Directors and managers of care and welfare organisations said they have to face the consequences of changes based on national and local policies and the financial impulses to change. A care director illustrated this point by saying:

We have almost exhausted our possibilities, but the demand is going to increase. If you don't succeed in finding different creative solutions, you will really end up with a lot of clients [who] you won't be able to serve, or only could serve in a tremendously reduced capacity.

As they are concerned about the consequences of budget cuts to care, like a reduction in jobs and a decrease in quality of care, directors and managers apparently get creative and pursue qualitative improvement. In fact, the initiative for the innovative care practice that we are describing in this study was originally proposed by a healthcare director who was convinced that care should be organised differently.

Directors and managers stress how they think that smart solutions need to combine a decrease in healthcare expenditures while improving the quality of care in a way that does justice to the participation of older adults. They said how they prefer to organise the care system differently, in a way that benefits both the needs of citizens and the needs of the care system. These actors articulated an idea that citizens prefer independence, which can be enabled by encouraging self-management and societal responsibilities of citizens. This will simultaneously help to reduce healthcare expenditures. By focussing on what people really need, more tailor-made care can be negotiated. A care manager explained:

So, on the one hand you have the need, and on the other the vision underlying the fact that people's autonomy is of great value to us. That's not only the case when they start being our clients, but also before and in a time where we might be able to stimulate them somehow so they can move the moment where they enter into our care to a moment far, far ahead or not at all. 
Older adults should be activated to help each other as much as possible, for example, by cooking for each other and sharing a dinner instead of going to organised day-care. A healthcare director described the ultimate result:

that people not only stay home longer, but that they also just want to stay home for a longer period of time, that they won't be coerced, but will be enticed to find solutions within their own environment or neighbourhood... Solutions, which won't result in more severe indications which would result directly in much higher [public] costs.

The stories told by directors and managers make it clear that they believe the ambitions of this transition process build on the idea that the promotion of ageingin-place is genuinely in line with the wishes of older adults.

Directors and managers acknowledged that previous changes in these organisations, like market incentives, have changed care into a bureaucratic financial system and have stimulated people to choose publicly paid care instead of seeking for solutions within their own possibilities. A healthcare director argued: '...In the past couple of years, it used to be extremely easy to obtain certain referrals. And care providers were allowed to renew those referrals. Really, what would you do yourself if you owned a business?' According to a manager of a welfare organisation, the passivity of citizens was caused by the same institutions that now want to change it: 'In the past, we provided care to anyone who had the slightest problem...they stopped working and only played bingo or something like that. We discovered that this didn't make people very happy and that they have much more potential.'

Managers and directors argued that older adults, who have become accustomed to asking for care, now have to become participative. A manager of a welfare organisation said:

the client has to change his or her attitude. It's no longer about claiming rights; no, according to the law you are going to be compensated. If your drive to participate is held back by certain limitations, the Wmo [i.e. the Dutch social support act], in this case the local government, has to tackle this limitation for you.

Directors and managers talked less diplomatically about older adults than policymakers did. One healthcare director explicitly stated that older adults should take more responsibility:

No I think that older adults should notice that it isn't just the government who asks them to take their own responsibility and organise certain things themselves...and that they should actually do that. Which they will take in a bad way, because they don't enjoy having their responsibilities being pointed out to them. Especially in this region, behaviour tends towards leaning and claiming. But done the right way, it will result in a better ability to support themselves it's questionable whether it's the right thing to do to be this paternalistic, but whatever. 
One of the main concerns of directors and managers relates to the assumed success of the activation approach. Sometimes they openly doubted whether the aim of the transition process is practical, whether citizens can be activated as they hope. A director of a welfare organisation stated:

That we won't be able to reach the client, is ultimately still... I'm sure we'll be able to reach the client, but will we be able to mobilise the citizen in reality, and in a way that citizens will have to take responsibility 'For Each Other' [i.e. the name of the transition process] and will we be able to make this happen?

A manager of a care organisation also shared her concerns about the deployment of volunteers, who are needed to take care of people who are no longer able to take care of themselves: 'We are making claims about how we should use volunteers and write a lot of papers about it, that volunteers are very important.' She explained that she thought this to be risky: 'I think it's questionable whether we can find them.' After adding examples of all the fields where volunteers are expected to fill in public gaps she concluded: 'For God's sake, where are we going to find them?'

Directors and managers of welfare organisations found themselves in a difficult position, as they have to carry out the activation policies in practice. Nevertheless, they welcomed the opportunity to reflect on the quality of care again and feel challenged to innovate. In the context of financial limits and the need to activate older adults, quality of care discussions get a new dimension; it is in this context that directors and managers repeatedly discussed the possibility of introducing a quality label for 'life cycle robustness'. The importance of this was explained by one healthcare director:

quality isn't so much defined by, well, if we finish this, then we're done, but more by getting on the same wavelength, agreeing about what is really important. And how are we going to explain what we are doing [i.e. looking for suitable cheaper solutions] to the ordinary citizen and our own employees in a way that makes it clearer and makes it become more tangible?

A quality label was discussed as an instrument that should help to visualise the intended outcomes of this transition, namely a neighbourhood that mediates citizens' independence and tailor-made care arrangements. Directors and managers expressed they expect that citizens will not understand the changes at first, as their access to publicly paid care or help will be limited. Simultaneously, the reductions on publicly paid care necessitate the director to cut back on his employees. He said he finds it hard to tell his employees that the new ideal of healthcare comes with less publicly paid care, which obviously implies that fewer professionals are needed. 


\section{'Love to empower older adults'}

For care professionals, the rise of activation policies is not only a problem, but also an opportunity. While they were used to providing care based on formal and standardised regulations with little room for professional discretion, they are now expected to empower people's citizenship. Professionals expressed to experience the call to activate as an opportunity to demonstrate their professionalism and empowerment capabilities. Their narratives demonstrated they feel challenged, inspired and proud to be 'pioneers': 'what I also really enjoy [as my colleague also said] is that this is the direction everybody is going to move in and in that sense we're at the front of the race.' They said they like to explore new professional empowerment approaches and to develop new professional identities. A neighbourhood nurse explained: 'people always talk about, citizens always talk about having the right that you should be there every evening, from 8:0o until 8:20. But now people are saying 'oh, I'm no longer dependent on the time you show up".

In accounting for the new activating approaches, professionals referred to policy reforms, but they identified with it quite easily. "Yes, they are now brought to talk about their own responsibilities, aren't they? Not the helplessness, but their own power, if I may say so.' Professionals made clear they embrace the activating and empowering approaches as instruments to redefine their professional role, identity and methods. Making older adults more active is considered to be more rewarding than taking care of a person's 'given needs'.

Yes, we assume-that comes with our profession-the ability of the patients to take care of themselves [as soon as possible]. I'm in neighbourhood X, in the centre actually. A lot of older residents are living there on their own and it is our goal to make sure these people maintain their ability to live on their own.

These professionals demonstrated a love to empower citizens and to broaden their repertoire.

However, based on their experiences in daily practices, professionals also pointed to the limits of the activation approach. Although the professionals we observed were very enthusiastic about their new assignment to empower, they thought that local governments and the managers and directors of their own organisations had too-high expectations of their ability to identify new sources of participation. They warned that not all professionals have the capacity to work that way, as they are educated differently, and not all citizens will respond positively to the calls to become more active instead of being nursed. Professionals shared that they expect that some of their peers will feel more comfortable in their former roles: 'It's a rather common thing that people want to please the citizens.' In a discussion about this new professionalism in a focus group with professionals, a neighbourhood nurse elaborated on how professionals struggle with their new role and their assignment to empower 
older adults: 'But you will notice that citizens are willing to keep an open mind about these things. They are willing to discuss this completely different approach, maybe [the citizen] even more so than certain professionals.'

Professionals also stated that the new approach is not suited for very fragile older adults who really need help. In their daily practices, professionals meet a lot of older adults, most of whom pursue independence and will not ask for anything until it is really necessary. One of the downsides of the activation approach is that some older adults, reluctant to ask for help, will be restrained even more. In fact, some professionals question policymakers' assumptions about the claiming of care and the dependent behaviour of older adults. A case manager said:

In my opinion, I think, there are really a lot of older adults who want to be independent as long as possible. Everybody appears to think that every older person thinks, 'I'm entitled to that'. Another professional added: But those are not only older adults. Of course there is a group of people who think, 'hey, that's what I'm entitled to; I have to get that, even if I don't have any use for it.' But of course there is also another group who continue alone to an unbelievable level, practically until they are falling down, yes...

Some older adults do need help, and professionals are afraid that some of those needs will not be identified adequately.

\section{Celebrating independence and a right to remain carefree}

In the care practice we studied, representatives of older adults were invited by organisations and local governments to participate on behalf of older adults. Through our observations, it became clear how their representation of older adults' needs and ideals actually seems to be a bit different than older adults' own stories. Representatives expressed a need for change: in great part, they seemed to support the activation approach and the ideas about the need to encourage older adults to attain an active and independent lifestyle and to help each other. This was clear in the way representatives talked about and responded to older adults. During a meeting with older adults, a representative tried to support an 89-year-old woman by repeatedly saying 'good, good, very good' in approval of all the activities she said she still did, such as singing in a choir and attending a gym class. When the woman explained that she sometimes found it difficult to ask acquaintances for help, a representative responded she should not forget that: 'It's entirely possible that the person you might approach for help would tremendously appreciate being asked; that's how things are. You have to get rid of the notion, which my mother had as well, that 'I dare not ask.' By saying this, he tried to make clear how he thinks older adults need to take more initiative to self-manage.

While policymakers, civil servants, directors and managers of care organisations, professionals, and representatives of older adults discussed the need to activate older 
adults to be less dependent on professional help, the actual practices of older adults are imbued with independence. The statement of an 81-year-old woman, 'I'm happy to be independent and to continue to be that way my entire life', is typical of the way most older adults in our study expressed themselves about ageing and their relationships with family, friends and neighbours. For them, active citizenship is not governmental policy, not a necessary organisational or professional change-it is everyday practice. In narrating their lives, older adults demonstrate how they strive for a meaningful and mainly independent old age. They mentioned the importance of family, good neighbours and friends, but also the importance of being independent, self-sufficient and living in their own homes. Autonomy, independence, participation and ageing-in-place seemed to be as important for the older adults we spoke with as for policymakers and civil servants, directors and managers, and care and welfare professionals. However, their interpretations of these notions are quite different.

\section{'Activated already'}

The older adults interviewed in this study strive for independence in several ways. Some mentioned that they are owners of and responsible for their own lives: 'you have to do it yourself'. They considered independence to be an important element of their identities, describing 'the merits of being independent' and 'being proud to have remained independent'. An 89-year-old woman recalled a German saying to describe how she retains her independence:

Look, I'm still really there, I still take an interest in everything. You have to. It's like the Germans are always saying: 'Age is not the number of years, age is not the grey hair; old is when the capacity to see the funny side of things is gone and nothing interests you anymore'.

She wanted to emphasise that she did not consider herself to be inactive or dependent, since she was trying to live by this motto, trying not to feel old because of her age. She elaborated on how she was staying active by keeping an interest in what happens in society, besides the physical exercises she did on a daily base.

Most older adults demonstrated pride in their independence, but also revealed an anxiety about asking for help, especially from relatives and friends. For instance, the woman quoted above mentioned how her independence determines her relationship to other people. She explained that she had not asked her neighbour for help after she fell out of bed in the night, because this would have been an act of dependency. Instead, she called the alarm service. She considered being able to arrange professional care to be an act of independence: 'When she asked me in the morning, why didn't you call me, I would have done that for you. I said: 'what I can do myself, I will do myself'. Older adults who have watched the transformation of a culture with almost no professional care into a well-organised welfare system with many professionals seeing professional help as a road towards independence, as it 
does not force them to ask their own children or neighbours for help.

The older adults we interviewed have thought about their futures and the way they prefer to live their lives, while being aware of their health situations and specific possibilities and constraints. Most of them who live in urban areas and some of them who live in rural areas had moved several years earlier to apartments designed for senior citizens, and they pointed to the adjustments they had made or could still make to their homes to remain able to live there if they became disabled. Many of the older adults in rural areas had been living for more than 40 years in houses they bought or even built themselves. They also described how they had adapted to their circumstances. The possibility that they might not be able to sell their houses quickly in the current market also affected their future visions.

In narrating their lives, older adults did not present themselves as demanding or dependent, as many of the policymakers, civil servants, directors and managers we interviewed and observed assumed in their stories. On the contrary, they stressed how they would only ask for help if they really could not do without it. They made clear they will postpone doing so as long as possible. Stories about their relationships with their general practitioners are illustrative. While many older adults mentioned the general practitioner as the first professional person they would go to in case of a problem, some of them spoke proudly about how they have not visited their general practitioner in a long time. An 80-year-old woman proudly stated: 'Three weeks ago, I just visited [name of her GP]. 'Finally', he said, 'you're not letting me make any money'. Well. That's how often I go to the doctor.' Most older adults find it hard to ask for help, as explained by an 88-year-old woman: 'You only have to ask, and I'm not the asking type. I'm always afraid to be rebuffed or something, or that they will think of me as... But yes. If you don't ask, they can't help you, of course.'

The older adults we interviewed also explained how they feel urged to contribute to their environment, and how they have a kind of social but also a societal obligation to remain participating citizens. For example, a 76-year-oldwoman spoke about how she struggled on after losing her husband (who passed away when they were both in their early fifties) as well as her son (who committed suicide soon after her husband passed away). She explained that she had to, that you need to move on despite your own private tragedies, although this is not always easy:

But yes, you can't rest on your chair forever, that's not a possibility here. You have to get through things, no matter how difficult that might have been. If just only for the children, the grandchildren and everything, failure is just not an option.

During this interview, she elaborated on the different ways she is and has always been active and participating, caring for others and herself. She spoke about the importance of taking care of others and the way this actually leads to reciprocity. She proudly recounted how she 'had' to knit many scarves for her acquaintances and family during one of the past winters, a way for her to be able to construct her own 
citizenship as it enabled her to be of importance for other people:

That's when it starts to itch, I have to work. She elucidated: no, I can't just sit still, in the winter things are somewhat different, at a time like that you don't, you can't do anything outside, can you... but during the summer... Yes, during the winter, not the last one, the winter before I had to knit 37 scarves.

\section{'We deserve carefree retirement days'}

The older adults we interviewed seem not indifferent to the assumptions made and communicated in media by policymakers and other organisational stakeholders. Although they expressed that they understand that the current policy is perhaps considered to be a solution for an urgent issue, they think that the way it has been communicated and translated into real life practices is unjust. Older adults did not recognise themselves as passive consumers, an image put forth by the media. Most of them explained that they have participated already, and feel like everybody has forgotten what they did in the past. They said that they feel a lack of respect that is expressed in different ways: some people are extremely angry, others are more acquiescent, but all of them expressed a lack of confidence in the current government. A 76-year-old man explained: I'm not complaining, mind you, not at all, but it's true: I earned it and they should leave it alone.

Although these people explained that they do not agree with recent political measures such as cuts in their old age pensions, they also fear for future generations. They are convinced that their children and grandchildren will have much more difficulty in making a living. They spoke about their own experiences, about the way they took care of their own parents for years. The older adults we interviewed explicitly stated that they do not expect, nor want, their children to help them like they did for their parents. One 8o-year-old woman stated: 'No, no, I should, I hope, never see the day that my children have to take care of me.' They also think that in addition to their past contributions, they are still contributing in many ways that are not recognised by policymakers. Most older adults spoke about how their current lives could actually be understood as ongoing working lives: they get up early every day to manage their households, to work in their gardens or to take care of grandchildren or great-grandchildren. An 81-year-old woman said: 'Yes, that's what I've always done. If somebody asks me something, I'm already saying, sure, come to me...'

Recognition and significance in society are important concepts for the people we interviewed. They also felt it was important not to feel pressured, not to feel as if they needed to justify why they have not been working all day long or have not been active as volunteers in their neighbourhoods. The people we interviewed found it important to stress how the things that they do and the things they have done demonstrate that they have actually earned their 'carefree retirement days'. An 81-year-old woman illustrated this argument by describing how she helps her neighbours in her flat. She 
likes to help her neighbours, for example by giving them a voice on the residents' council, by preparing meals and by providing mental support: 'Here they are often claiming, '[own name], you're not the mother of everlasting welfare.' Because I like to cook, to bake and I'm just alone, but I will always make enough so I have something to share.' After sharing a list of exemplary situations, she expressed: 'but I really like doing so.' She repeatedly emphasised that she does not need any recognition: 'I don't want people to put a crown on my head for doing these things, it shouldn't... that's not why I'm doing this.' She illustrated how she thinks remaining active is important for your independence, and she cannot understand why some people choose a more 'passive' life.

Although some of the older adults in this study supported an activation policy in certain cases, they framed this policy differently than local governments and organisations and expressed the need to actually hear the voices of older adults. They defined activity and independence differently than in the institutional activation approach, since they see getting help from a professional as a road towards independence rather than a road to dependency.

\subsection{Conflicting notions of citizenship in old age}

In the sections above we demonstrated different notions of citizenship in old age in a specific public innovative care practice, where policymakers and civil servants, managers and directors, professionals, and older adults and their representatives collectively try to shape life cycle robust neighbourhoods. These neighbourhoods are envisioned as age-friendly places that are meant to enable the pursuing of a participatory society, towards a sustainable care system. Within this practice, a shift of public responsibilities to individuals is being promoted. This is in line with neoliberalist ideals of less state and more individual responsibilities emphasising the importance of being able to manage and regulate own health and well-being (cf. Lamb 2014). Older adults are encouraged to remain independent in their own homes for longer periods of time, to take care of themselves, of others and to participate in society. The reforms did affect the meanings of citizenship and old age. The promotion of an active, participative citizenship within an ideal of a participatory society, assumes that citizenship is a state of being that can be achieved with specific actions or behaviour. Participation has become a tool for defining a citizen's identity. Contrary to existing discourses of positive, successful and active ageing, that build on an idea that citizenship is a given right, our study reveals how citizenship is becoming a negotiable concept, rather than a given right.

Our findings demonstrate how new and conflicting notions of citizenship in old age appear in practice. Although the practice we studied was initiated to facilitate older adults in their ability to live independently, the stories we heard demonstrate a remarkable change in the meaning of old age in relation to citizenship. In the 
narratives of policymakers, civil servants, managers, directors and professionals, it becomes clear the idea is being shared that an activation policy is necessary, although their views contain different meanings of citizenship in old age. Local policymakers and civil servants interpret the political assignment to reduce healthcare expenditures as a policy object and an opportunity to rearrange current systems, to activate people to become independent, self-sufficient, and participative citizens. Directors and managers see the assignment as an object of care, an opportunity to resolve current system errors and improve the quality of care. Professionals experience their assignment as an object of professionalism, an opportunity to demonstrate and explore their new professionalism. In the interviews we conducted, older adults construct their own citizenship completely different. They told stories about their lives that are not even heard by their own representatives and which simultaneously confirm a policy-practice gap on citizenship. Their representatives promote an activation policy in line with the narratives we gathered at local governments and organisations, an activation policy as it is also described in the work of other scholars (e.g. Newman and Tonkens 2011).

In the interviews, older adults do not theorise their citizenship, they do not think of citizenship as an object of policy, care or professionalism, and do not consider themselves to be objects in need of activation. They demonstrate their citizenship in the way they act and talk about their lives. On the one hand, older adults celebrate their independence, but on the other, they also argue that they deserve 'their' carefree retirement days. Older adults feel they have an 'own responsibility' for their independence and for the way they construct their lives in general. Being able to arrange professional help is a road to independence for them, while being obliged to ask people in their social networks for help is considered to be an indication of dependence. They construe their citizenship as 'being able to live as independently as possible, with the possibility to socially participate in a non-obligatory way'. By simply living their lives, older adults often 'invisibly' participate in society, taking consciously care 'not to be a burden to others'. Invisible, as it seems their participation is not being recognised as 'participation in society' by governments and organisations, who describe them as passive and dependent. Governments and organisations construct citizenship in old age as a tool to shape a life cycle robust neighbourhood. There is a presumption that visible active participation of older adults is necessary, that active participation leads to citizenship and therefore older adults are pushed to enlarge their societal contributions. However, these older adults experience the promotion of active participation as a lack of respect for their current and former contributions and feel like old age is being neglected as a phase of life (cf. Milton et al. 2015). The concept of citizenship in old age and of citizenship in general seems to have shifted from an entitlement to be passive towards an obligation to be active (although the notion 'as far as possible' is often added).

It is unclear where the exact boundaries between active and passive lie. There are some general ideas about the activities related to citizenship ('own responsibility', 
'independence') but the specific interpretation differs with each person. Older adults strive for some kind of citizenship through their actions, but they feel that organisations and governments do not recognise their citizenship since the citizenship in practice (in and around the home) differs from ideals in activation policy. What does active citizenship actually mean and are people allowed to choose not to be active (e.g. as in Harbers 2005)? All older adults we interviewed were living independently, and spoke about how they are already active, busy in and around their own homes. They expressed their wish to be able to age in their own homes (ageing-in-place) and within their own neighbourhoods (Dahlin-Ivanoff et al. 2007; Sixsmith et al. 2014). Older adults pursue active and independent lives by reciprocating the help received (cf. Bredewold 2014; Linders 2009; Tonkens and De Wilde 2013).

Although the worlds of older adults shrink as a result of limitations related to ageing, older people present themselves as quite flexible and capable of adapting to their circumstances. The theories discussed in our conceptualisation (Bijsterveld 1995; Gilleard and Higgs 2010; Laslett 1987) distinguished old age as a separate category, consisting of separate subcategories (i.e., the third and fourth age). Our study demonstrates a new development as old age seems to be increasingly neglected as a specific category and older adults' voices seem not to be heard, not even by their own representatives. Because notions of citizenship are narrowed down to a definition of active participation, some older adults might be excluded due to their physical restraints instead of an actual choice. Participation has become more and more necessary to count as a citizen, as it appears that notions of old age are being de-categorised or dismantled in the practice we studied.

Our study suggests that a new distinction is being made between an active, participative citizenship, situated within society, and a non-participative citizenship, which is not visibly situated in society. Consequences of this new distinction are yet unknown. We focussed on one specific practice, which might limit the value of our conclusions about conflicting notions of citizenship in old age in general. However, by using a rather constructivist approach in which we were following the actors, we described the different perspectives and gave independent living older adults a voice. The topics of our analysis, including citizenship and participation, are widely used and interpretable in many ways. Nevertheless, through the way we conducted this study, we learned about the nature of this innovative care practice and were able to describe the different approaches within this practice that aims to activate older adults as citizens. Our analysis allowed us some space to reflect on the question of how citizenship in old age is currently constructed in a care practice, which presumably can also be recognised in similar 'practices'.

The scoping review of literature, which we described in our introduction, revealed that ageing studies have so far put little emphasis on the current relation between ageing, participation and citizenship, as far as we know. Our results suggest that a further exploration of the relationship between citizenship and older adults and the meaning of 'citizenship in old age' is needed to better understand how current policy 
changes fit and affect older adults. As we have only explored the meaning of citizenship within specific boundaries, only investigating the meanings given by a small group of independent living older adults, it might be interesting to investigate the meaning of citizenship for older people who actually seem or feel more dependent. While public policy stimulated the creation of 'old age' as a distinct public problem and a specific policy category in the second half of the twentieth century, the specific public category of 'older adults' appears to be vanishing in the current policy context.

\section{Acknowledgements}

The authors thank the respondents for their willingness to participate in interviews, focus groups and observations for this study. The authors also thank all the people who commented on earlier drafts of this paper. The research reported here was part of a project funded by ZonMw-The Netherlands Organisation for Health Research and Development (grant 314070201). The financial sponsors did not play a role in the design, execution, analysis and interpretation of data, or writing of the study. 


\section{References}

Alvesson, M. and Sköldberg, K., 2009. Reflexive methodology: New vistas for qualitative research. London: Sage.

Bang, H., 2004. Everyday makers and expert citizens. Building political not social capital. Working paper. Canberra: Australian National University.

Bang, H., and Sørensen, E. 1999. The everyday maker: A new challenge to democraticgovernance. Administrative Theory \& Praxis, 21, 03, 325-341. http://dx.doi.org/10.1080/10841806.1999.11643381

Barnes, M., 2005. The same old process? Older people, participation and deliberation. Ageing \& Society, 25, 02, $245^{-259 .}$ https://doi.org/10.1017/So144686X04002508

Bijsterveld, K., 1995. Geen kwestie van leeftijd: verzorgingsstaat, wetenschap en discussies rond ouderen in Nederland, 1945-1982 [No Matter of Age: Welfare State, Science and Debates about the Elderly in the Netherlands, 1945-1982]. Maastricht: Maastricht University.

Black, K., and Dobbs, D., 2014. Community-dwelling older adults' perceptions of dignity: Core meanings, challenges, supports and opportunities. Ageing \& Society, 34, o8, 1292-1313. https://doi.org/10.1017/So144686X13000020

Bond, J., Peace, S., Dittmann-Kohli, F. and Westerhof, G.J. (Eds.), 2007. Ageing in society: European perspectives on gerontology (zrd ed.). London: Sage Publications Ltd.

Bredewold, F., 2014. Lof der oppervlakkigheid: Contact tussen mensen met een verstandelijke of psychiatrische achtergrond en buurtbewoners [In praise of superficiality]. Amsterdam: University of Amsterdam.

Bülow, M. and Söderqvist, T., 2014. Successful ageing: A historical overview and critical analysis of a successful concept. Journal of Aging Studies, 31, 139-149. https://doi.org/10.1016/j.jaging.2014.08.009

Craig, G., 2004. Citizenship, exclusion and older people. Journal of Social Policy, 33, o1, 95-114. https://doi.org/10.1017/ Soo47279403007207

Dahlin-Ivanoff, S., Haak, M., Fänge, A. and Iwarsson, S., 2007. The multiple meaning of home as experienced by very old Swedish people. Scandinavian Journal of Occupational Therapy, 14, o1, 25-32. http://dx.doi. org/10.108o/11038120601151714

Dunn, E., 2005. Standards and person-making in East-Central Europe. In S.J. Collier, and A. Ong (Eds.), Global Assemblages: Technology, Politics and Ethics as Anthropological Problems (pp. 173-193). Malden, MA: Blackwell. DOI: 10.1002/9780470696569.chio

Fraser, N. and Gordon, L., 1994. A genealogy of dependency: Tracing a keyword of the US welfare state. Signs, 19, 02, 309-336.

Gilleard, C. and Higgs, P., 1998. Old people as users and consumers of healthcare: A third age rhetoric for a fourth age reality? Ageing \& Society, 18, 233-248.

Gilleard, C.J. and Higgs, P., 20oo. Cultures of ageing: Self, citizen, and the body. Oxford: Routledge.

Gilleard, C. and Higgs, P., 2010. Aging without agency: Theorizing the fourth age. Aging \& Mental Health, 14, 02, $121-128$. http://dx.doi.org/10.1080/13607860903228762

Harbers, H., 2005. Inside the politics of technology: Agency and normativity in the co-production of technology and society. Amsterdam: Amsterdam University Press.

Higgs, P., 1995. Citizenship and old age: The end of the road? Ageing \& Society, 15, 04, 535-550. https://doi.org/10.1017/ So144686Xoooo2890

Huisman, F. and Oosterhuis, H. (Eds.), 2014. Health and citizenship. Political cultures of health in modern Europe. London: Pickering \& Chatto.

Isin, E. and Turner, B., 2007. Investigating citizenship: An agenda for citizenship studies. Citizenship studies, 11, ol, 5-17. http://dx.doi.org/10.1080/13621020601099773

Jasanoff, S., Markle, G., Petersen, J. and Pinch, T. (Eds.), 1995. Handbook of science and technology studies. California: Sage Publications Inc.

Jasanoff, S., 2004. Science and citizenship: A new synergy. Science and Public Policy, 31, 02, 90-94.

Kampen, T., Verhoeven, I. and Verplanke, L. (Eds.), 2013. De affectieve burger. Hoe de overheid verleidt en verplicht tot zorgzaamheid [The affective citizen]. Amsterdam: Van Gennep.

Kymlicka, W. and Norman, W., 1994. Return of the citizen: A survey of recent work on citizenship theory. Ethics, 104, 02, 352-381. https://doi.org/10.1086/293605

Lamb, S., 2014. Permanent personhood or meaningful decline? Toward a critical anthropology of successful aging. Journal of Aging Studies, 29, 41-52. https://doi.org/10.1016/j.jaging.2013.12.006

Laslett, P., 1987. The emergence of the third age. Ageing \& Society, 7, 02, 133-16o. https://doi.org/10.1017/So144686Xooo12538 Lassen, A. and Moreira, T., 2014. Unmaking old age: Political and cognitive formats of active ageing. Journal of Aging 
Studies, 30, 33-46. https://doi.org/10.1016/j.jaging.2014.03.004

Linders, L., 2009. De betekenis van nabijheid: een onderzoek naar informele zorg in een volksbuurt [The significance of being close: A study of informal care in a working-class neighbourhood]. The Hague: Sdu Uitgevers.

Lloyd, L., Calnan, M., Cameron, A., Seymour, J. and Smith, R., 2014. Identity in the fourth age: perseverance, adaptation and maintaining dignity. Ageing \& Society, 34, o1, 1-19. https://doi.org/10.1017/So144686X12000761

Marschall, M., 2004. Citizen participation and the neighbourhood context: A new look at the coproduction of local public goods. Political Research Quarterly, 57, 02, 231-244.

Marshall, T., 1949. Citizenship and social class and other essays. Cambridge: Cambridge University Press.

Milton, S., Buckner, S., Salway, S., Powell, K., Moffatt, S. and Green, J., 2015. Understanding welfare conditionality in the context of a generational habitus: A qualitative study of older citizens in England. Journal of Aging Studies, 34, 113-122. https://doi.org/10.1016/j.jaging.2015.06.002

Minkler, M. and Holstein, M., 2008. From civil rights to ... civic engagement? Concerns of two older critical gerontologists about a "new social movement" and what it portends. Journal of Aging Studies, 22, 196-204. https://doi.org/10.1016/j. jaging.2007.12.003

Muehlebach, A., 2012. The Moral Neoliberal: Welfare and Citizenship in Italy. Chicago: The University of Chicago Press.

Newman, J., and Tonkens, E., 2011. Participation, responsibility and choice: Summoning the active citizen in western European welfare states. Amsterdam: Amsterdam University Press.

Persson, T. and Berg, S., 2008. Older people's “voices”-on paper: Obstacles to influence in welfare states-A case study of Sweden. Journal of Aging \& Social Policy, 21, o1, 94-111. http://dx.doi.org/10.1080/o8959420802539118

Petriwskyj, A., Gibson, A. and Webby, G., 2014. Participation and power in care: exploring the "client" in client engagement. Journal of Aging Studies, 31, 119-131. https://doi.org/10.1016/j.jaging.2014.09.007

Rmo, 2013. Rondje voor de publieke zaak. Pleidooi voor de solidaire ervaring [Doing something for the public cause]. The Hague: Raad voor de Maatschappelijke Ontwikkeling. The Council for Social Development.

ROB, 2012. Loslaten in vertrouwen. Naar een nieuwe verhouding tussen overheid, markt én samenleving [Trusting and letting go. Towards a new relationship between government, market ánd society]. The Hague: Raad voor het openbaar bestuur. The Council for Public Administration.

Rudman, D., 2015. Embodying positive aging and neoliberal rationality: Talking about the aging body within narratives of retirement. Journal of Aging Studies, 34, 10-20. https://doi.org/10.1016/j.jaging.2015.03.005

RVZ, 2013. Het belang van wederkerigheid... solidariteit gaat niet vanzelf! [The importance of mutuality......solidarity takeswork!]. The Hague: Raad voor de Volksgezondheid en Zorg. Council for Public Health and Care.

RVZ, 2012. Redzaam Ouder. Zorg voor niet-redzame ouderen vraagt om voorzorg door iedereen [Self-sufficiency in old age. Care for dependent elderly people requires precautionary measures by everyone]. The Hague: Raad voor de Volksgezondheid en Zorg. Council for Public Health and Care.

Scourfield, P., 2007. Helping older people in residential care remain full citizens. British Journal of Social Work, 37, 07, 1135-1152. https://doi.org/10.1093/bjsw/bclo86

SCP, 2013. Met zorg ouder worden. Zorgtrajecten van ouderen in tien jaar [Ageing with care Care trajectories of older persons over a decade]. The Hague: Sociaal Cultureel Planbureau. The Netherlands: Institute for Social Research.

Sixsmith, J., Sixsmith, A., Malmgren Fänged, A., Naumanne, D., Kucseraf, C., Tomsone, S., Haak, M., Dahlin-Ivanoff, S. and Woolrych, R., 2014. Healthy ageing and home: The perspectives of very old people in five European countries. Social Science \& Medicine, 106, 1-9. https://doi.org/10.1016/j.socscimed.2014.01.0o6

Tonkens, E., and de Wilde, M. (Eds.), 2013. Als meedoen pijn doet. Affectief burgerschap in de wijk. [If participation hurts. Affective citizenship in the neighbourhood]. Amsterdam: Van Gennep.

Tonkens, E., 2008. De bal bij de burger. Burgerschap en publiekemoraal in een pluriforme, dynamische samenleving [The ball is in the citizen's court]. Amsterdam: Vossiuspers UvA.

Townsend, P., 1981. The structured dependency of the elderly: A creation of social policy in the twentieth century. Ageing \& Society, 1, ol, 5-28. https://doi.org/10.1017/So144686X81000020

Speech from the Throne Troonrede, 2013. September 17th. Retrieved from http://www.rijksoverheid.nl/documenten-enpublicaties/toespraken/2013/o9/17/troonrede-2013.html (October 31, 2014)

Verba, S., Schlozman, K. and Brady, H., 1995. Voice and equality: Civic voluntarism in American politics. Cambridge: Cambridge University Press.

Walker, A., 2008. Commentary: The emergence and application of active aging in Europe. Journal of Aging \& Social Policy, 21, o1, 75-93. http://dx.doi.org/10.108o/08959420802529986

Wharf-Higgins, J., 1999. Citizenship and empowerment: A remedy for citizen participation in health reform. Community Development Journal, 34, 04, 287-307. https://doi.org/10.1093/cdj/34.4.287

WHO, 2002. Active ageing: a policy framework. Geneva: World Health Organization. 
WHO, 2007. Global age-friendly cities: A guide. Geneva: World Health Organization.

Van de Wijdeven, T., de Graaf, L., and Hendriks, F., 2013. Actief burgerschap: Lijnen in de literatuur [Active Citizenship: Streams of literature]. (Tilburg/The Hague: TSPB/BZK).

WRR, 2012. Vertrouwen in burgers [Confidence in citizens]. Amsterdam: Amsterdam University Press/Wetenschappelijke Raad voor het Regeringsbeleid [Scientific Council for Government Policy]. 



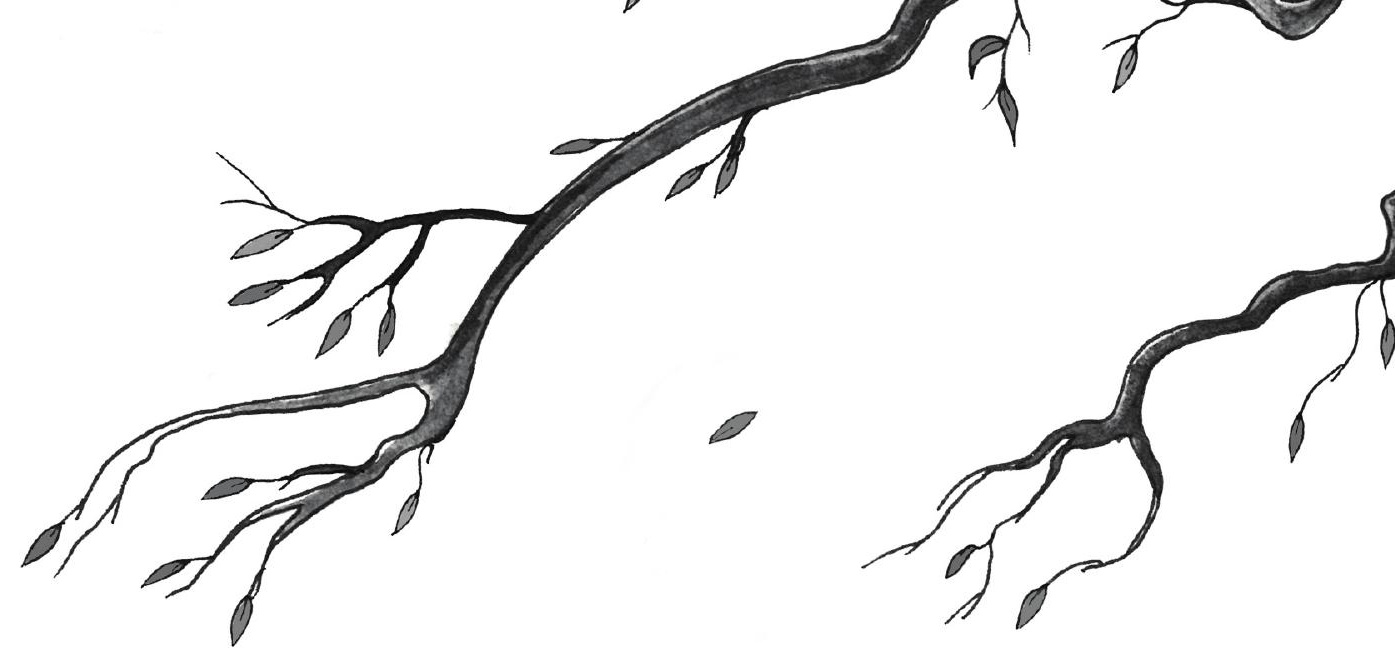

Chapter 3

How does an ageing policy translate into professional practices?

An analysis of kitchen table conversations in the Netherlands

\section{Submitted:}

Susan van Hees, Klasien Horstman, Maria Jansen and Dirk Ruwaard. How Does an Ageing Policy Translate into Professional Practices? An Analysis of Kitchen Table Conversations in the Netherlands. 


\begin{abstract}
In the context of the transformation of welfare states into participatory societies, care and welfare professionals are assigned new roles. In the Netherlands, they are tasked with activating and empowering older adults, as well as negotiating customised care. For this purpose, policymakers introduced the kitchen table conversation as a social technology to assess needs and abilities in an informal setting, at home or in public places. The notion of a kitchen table refers to the idea that an informal sphere may increase the professionals' ability to attune to the needs and abilities of citizens. This paper discusses the findings of a qualitative study, in which several ethnographic methods were used to examine kitchen table conversations with older adults in practice. Our study demonstrates that, although the tool aims to increase attunement between professionals and citizens, it actually creates tensions between policy, professionals and citizens. Professionals struggle with the issue of how other policy expectations - such as cutting the costs of care - resonate in the conversations, a phenomenon which becomes even more awkward in the private domain of older adults. In practice, kitchen table conversations do not so much create discretionary space, but mainly generate ambiguity in professional work.
\end{abstract}




\subsection{Introduction}

Enabling opportunities to remain living independently for longer is the key element of current ageing policies. The World Health Organization (WHO) advises governments to develop age-friendly environments for active, healthy ageing (2017). These WHO-policy concepts fit in a broader activation development to confront challenges induced by an ageing population and increasing healthcare expenditures in Western welfare states (Liebenberg, Ungar and Ikeda 2015; Newman and Tonkens 2011). To enable citizen participation, the Dutch government has decentralised many responsibilities to organise healthcare and welfare services towards municipalities. In 2012, the government's coalition agreement stated: 'the decentralisation of many assignments to municipalities enables a more tailor-made [policy] and an increased citizen involvement'. However, this decentralisation-process also has to help municipalities 'to do more with less money'.

Discourses of citizen participation also create new challenges for professionals (Ellis 2014; Liebenberg et al. 2015; McDonald and Chenoweth 2009). Until recently, provision of care and welfare services in the Netherlands was based on legal entitlements. Requests for help were examined by special indication officers who were guided by criteria in policy documents. For long-term care needs, individuals could appeal to the 'Exceptional Medical Expenses Act' (Algemene Wet Bijzondere Ziektekosten, ABWZ), for welfare services (e.g., domestic help, a mobility scooter, adjustments to the home) the 'Social Support Act' (Wet Maatschappelijke Ondersteuning, Wmo) was applied. Basically, policy documents acted as decision-making tools to assess individuals' eligibility for care and welfare (cf. Høybye-Mortensen 2015). When eligible, an individual received an indication that was an official approval for the specific service or provision requested. The complete verification procedure often took place behind a desk, relying on information that was provided in the individual's request.

Since 2015, formal, standardised criteria are no longer used to verify an individual's eligibility for help. Now, instead of verifying an individual's entitlement to at-home care or welfare services, municipalities verify whether they must compensate individuals for their 'participation abilities and wishes'. Therefore, municipalities make arrangements when individuals are 'actually and continuously lacking' informal solutions in their immediate environments (Dutch Social Support Act 2015). While care and welfare professionals formerly provided care when it was requested, they must now control their urge to help, as the new ageing policy encourages them to help people to take care of themselves. Professionals have to stimulate people to search for help in their informal circle and facilitate them in remaining self-sufficient. Everett, Homstead and Drisko (2007) note that, with an assignment to empower, the role of a professional changes from being 'the expert authority' to becoming 'a collaborator' (p. 169). This role comes with a promise that professionals' discretionary space will increase, a trend which is called 'the new professionalism'. However, in their study of the discretionary space of professionals as activators of social assistance recipients, 
Van Berkel, Van der Aa and Van Gestel (2010) conclude that these professionals, though they hold the keys to citizenship - by providing access to care or welfare provisions that can increase autonomy for instance -, do not have the abilities or tools to judge an individual's situation fairly.

To facilitate the new, empowering role of care and welfare professionals in the Netherlands, a new tool has been introduced: the kitchen table conversation. In this paper, we explore this tool and how it is used in professional practices involving older people (from age 70). The aim of our study is not to evaluate this tool in terms of its effectiveness, but to investigate how it works out in practice, affects conversations, and enables professionals and older citizens to attune to each other when negotiating needs and abilities. First, we explain how the kitchen table conversation was introduced as a professional tool and the theoretical background of our study. Next, we describe the design of the study. After presenting four in-depth descriptions of kitchen table conversations, we conclude by reflecting on what this tool entails for ageing policies that aim to stimulate participation and ageing-in-place.

\subsection{Kitchen Table Conversations as a Participatory Technology}

In the context of current participatory societies, participation can be considered 'a moral obligation'. This issue also concerns older adults who have to remain active and live independently for as long as possible, while the organisation of care in their own informal networks takes priority over formal care. In this context, professionals have to mediate between these policy ideals and the ideals of older adults, as they have to assess and negotiate the needs and participation abilities of older people in order to legitimise care provision when necessary. For this purpose, the technology of the kitchen table conversation has been devised. In September 2008, the Dutch State Secretary for Health, Welfare and Sport wrote a letter to introduce 'the initiative of the so-called $<<$ kitchen table conversation $>>$ with citizens, where the situation is explored using an integrated approach and an inventory is made of the extent to which citizens can still contribute themselves'. A guideline of the Association of Netherlands Municipalities (2010) added that kitchen table conversations represent

a careful investigation, an adequate analysis, the application of a wider perspective, a collective search for solutions. It requires abandoning a claim culture and taking one's own strength and responsibility as a point of departure.

As many municipalities felt that further regulation was desired, they introduced additional technologies to structure the kitchen table conversations. These technologies include intake and consent forms, questionnaires and the self-sufficiency matrix, a tool that is used to measure and monitor an individual's self-sufficiency. The notion of the kitchen table to symbolise a good dialogue is not new. In a variety 
of fields, including human geography, social and healthcare, history, feminist studies and political science, scholars have identified different meanings that people attribute to the kitchen (Abram 2007; Bennett 2006; Kohl and McCutcheon 2015; Sarkissian, Shore, Vajda and Wilkinson 2012; Smith 1989). The kitchen is represented in their work as a place which articulates patriarchal and unequal power relations (as the work-place of servants, for instance), which empowers people in the kitchen who 'control' the food, and offers opportunities to create a community of care, to communicate and to organise actions (such as the development of feminist activities). In a considerable number of studies kitchens are constructed as safe spaces for interactions (Bennett 2006; Kohl and McCutcheon 2015; Smith 1989) and for informal and in-depth conversations.

However, the connection between 'kitchen table' and 'conversation' can be made in different ways. In policy and politics, the kitchen table is used both literally and metaphorically as a place to inform citizens, engage communities and facilitate public dialogues (Abram 2007; Sarkissian et al. 2012). By contrast, Kohl and McCutcheon (2015), distinguish the kitchen table as a safe space for self-reflexivity in scientific research, as it helped them to openly reflect on their positionality in race and gender studies. Furthermore, the kitchen table is known as a negotiation tool; for example, in the case of shared decision-making processes in healthcare (Norlander and McSteen 2000; Truglio-Londrigan 2013). The kitchen table discussion was introduced for instance as a tool to enable conversations about end-of-life issues as part of advance care planning in palliative home and hospice-care (Norlander and McSteen 200o). The kitchen table symbolises 'the familiar and comfortable setting of the home', and should help mediate possibly 'the most important' but also 'one of the most difficult conversations' (Norlander and McSteen 2000, p. 532). Truglio-Londrigan (2013) explains in her study about professionals in palliative home-care situations, how home-visits enable professionals to spend more time talking about a person's needs and desires, than during a formal office-visit. In addition, relatives and friends can attend more easily, while personal issues can be discussed outside the context of acute care. Because the kitchen table offers more space for dialogue, it also requires professionals who can 'forge their own path'. While institutions offer formal structures to be followed, such as time-limits and care procedures, the at-home-setting both requires and enables professionals to respond to the personal setting.

While these studies consider kitchen tables as safe places where stories can be shared and common actions can be planned, Kohl and McCutcheon (2015) argue that the kitchen table is also a place for dialogue where no consensus needs to be reached. As is explained by Sarkissian et al. (2012, p. 7), the kitchen table is used as a metaphor and does not necessarily refer to actual kitchen tables. Instead, it represents

the place where we have casual but important conversations, we share meals and where people, even in a busy world, frequently come together. (...) a place where many feel comfortable to speak openly about their real perspectives, ideas and concerns. 
In general, the kitchen table is presented as a place that invites people to share ideals, ideas, fears and dreams. By introducing the kitchen table as part of an ageing and activation policy, policymakers expect that these characteristics of the kitchen table will help translate their policy into practice.

By introducing the kitchen table as a place where care is discussed, however, the relationship between professionals and older people changes. Instead of only entering the home solely as a care provider, professionals now enter the private domain at an earlier stage to discuss the need for care. As a result, the home also plays a role in deciding whether care is necessary and, if so, what kind. Several scholars studying relationships between care and place, demonstrated how healthcare and nursing practices change when they take place outside formal care institutions (e.g., Andrews 2003; Kearns 1993; Poland, Lehoux, Holmes and Andrews 2005). According to Dahlin-Ivanoff, Haak, Fänge and Iwarsson (2007), who studied meanings of ageing-in-place, the home changes at the moment that a professional enters, becoming a place of care in addition to being a home. Because of this 'complex relationship between power, technology, culture, and place', Poland et al. (2005) state there should be more attention to place-sensitivity, to explore the way that the uniqueness of a place affects professional work. In short, the kitchen table is described as a place that enables professionals to have more personalised conversations, but also needs professionals who can adjust to all these different kitchen tables.

\subsection{Theorising Kitchen Table Conversations}

The kitchen table conversation in the policy we studied was introduced as a tool to help professionals negotiate the activation of older adults. Drawing on insights from Science and Technology Studies (STS), we understand this tool as a social technology. Social technologies are characterised by Derksen and Beaulieu (2011) as technologies that consist of human actions or depend on social interactions. Mol, Moser and Pols (2010, p. 174) argue that technologies do not fail or work on their own: 'Devices get their particular shape, value and functions in the practice in which they are used, and users creatively negotiate the scripts that technologies carry'. In other words, although technologies are designed to serve a specific purpose, they do not achieve this function in isolation, which means that technologies need humans and thereby become social. Technologies are designed with expected and prescribed behaviour in mind; a machine does not work without human intervention, nor can a questionnaire be completed without any human activity either. Following this line of argument, technologies must interact with humans to be 'activated' and to work in practice. In practice, however, technologies might work differently from the designer's original intention. A brick might be used to block a door rather than to build a wall, while a questionnaire can become a checklist instead of a helpful tool to collect information. 
From this perspective, it is not surprising that social technologies introduced to facilitate professional work are not automatically facilitative in practice. Нøyby-Mortensen (2015) demonstrates that tools designed for a specific purpose are used differently in different contexts. In studying decision-making tools, she concludes that tools that require a great deal of interpretation have less impact on a professional's discretionary space than tools that are more predefined. She demonstrates that using a tool analytically, during an assessment to guide and mediate a decision - such as a decision tree -, means that the tool basically defines the professional's discretionary space. Conversely, considering it as a documentation-tool to structure the advice afterwards, means that the space is defined during the conversation. Based on this reasoning, the impact of technologies is greater when they are more clearly prescribed. By contrast, Evans (2011) makes the opposite claim that the elaborateness of a procedure creates a greater need for discretion from the professional. Because there are so many different guidelines and it is impossible to follow them all, professionals have to negotiate their own by choosing which guidelines they want to follow. To make their assignments workable, they have to choose between different technologies while they tinker to make them applicable (Mol, Moser and Pols 2010). In the Netherlands, kitchen table conversations are introduced as a social technology to enable professionals to come up with customised care arrangements and decisions with respect to care. We aim to unfold how the tool of the kitchen table conversation translates policy into practice and what this entails for professional work.

\subsection{Methodology}

Our study took place in Parkstad, an area in the Southern part of the Netherlands. We studied kitchen table conversations, that were introduced in this area as part of an ageing-in-place policy. Our observations are part of a larger qualitative study that we conducted between 2011 and 2015, using several ethnographic methods to explore how this ageing-in-place policy was developed and worked out in practice. The kitchen table conversation has been formally included in Parkstad's regular procedures since 2014, but in preceding years, professionals already experimented with the tool. Kitchen table conversations take place at people's own home, but also at other places, such as a community centre. During intake and follow-up meetings professionals (appointed as case managers) often use intake forms or questionnaires to describe a person and the reason for the visit. In a social neighbourhood team professionals can reflect on their cases and appointments can be made with other professionals who need to be involved. If a case manager lacks specific expertise for instance, a back-up option is organised within this team.

In this paper, we follow a social-constructivist approach in which we explore the use of these kitchen table conversations. Therefore, we draw on observations of fifteen kitchen table conversations that took place in 2012 and 2014 . These conver- 
sations were employed by a neighbourhood nurse, an advisor of older adults, two social workers, a care manager, and three Social Support Act servants (executers of the Dutch Social Support Act, regulating the delivery of welfare services, such as a domestic help). Eleven observations took place at people's homes in two separate neighbourhoods (one urban, one rural), three at a community centre and one at a consultation room in a Town Hall. To organise these observations, the first author explained the study during formal meetings of professionals and asked for consent to observe professionals when 'doing' kitchen table conversations. Further agreements were made in-person with professionals who agreed to be observed. Sometimes only one kitchen table conversation was observed; in other cases, multiple (but maximal three). At the beginning of conversations, professionals asked individuals for consent to be observed. All professionals participated in different pilots with kitchen table conversation designs and were familiar with this method of activation. Field notes were taken during all observations and were then elaborated on extensively and promptly. In this paper, we highlight some of our observations that are exemplary for the huge variety between conversations, professionals and older people in practice.

During the conversations, professionals had to collect as much information as possible about the citizen, before writing an advice about a customised arrangement. Although a project leader expressed a kitchen table conversation 'should be a very open conversation', they also 'developed an intake-form with quite specific questions', which was deemed necessary to guarantee that professionals have comparable kitchen table conversations. These questionnaires included a variety of topics, among which: daily activities, social activities, physical condition, and informal care providers. Questions could be: 'how do you usually spend your days?'; 'how do you manage your household?'; and 'what activities do you enjoy?' but also how people organise their personal care, whether they have children, and if so, if they live nearby and how they provide assistance. To preserve their anonymity, all names of professionals mentioned in our observations are pseudonyms.

\subsection{Professional Kitchen Table Practices}

\section{Negotiating a Predefined Need}

Most professional home visits are scheduled when people ask for help. If a request is submitted, a professional in a neighbourhood is appointed to 'do' a kitchen table conversation during a home visit. In some of these cases, individuals already have a valid indication for help based on the previous policy. Because it is a transitory phase, the municipality decided that these indications remain valid until their expiration dates. However, during a home visit, professionals are still expected to negotiate activation opportunities. 
Jenny visits an older woman who received an indication for a mobility scooter some years ago, but soon after returned the device. Now, the woman wants 'to get her mobility scooter back'. The woman opens the door and Jenny introduces herself and me [first author]. She explains how things have changed 'in our policy as you might have heard already' and that she wants to talk about the life of the woman in a more extensive way than she might have been used to: 'Just to be able to help you towards our best abilities, so let us talk about your life in general'. The woman agrees, we enter her living room, and join her and her daughter-in-law around a table. Jenny puts a questionnaire for her to complete on the table. She says they will discuss the request for a mobility scooter, but that she first wants to know more about the woman's daily and social life. The woman says, 'that's okay'. However, when Jenny formulates her first question, she replies by elaborating on why she really does need 'her mobility scooter'. Jenny states she understands that the woman wants to talk about the mobility scooter, but that she really must know some other things in advance.

Although the woman indicates that she understands this, she continues to respond to Jenny's questions that 'she really does need her mobility scooter'. She talks about her physical constraints, her medication, why she would like to use the mobility scooter, and the misunderstanding that led her to return her scooter a few years ago because she thought she was not allowed to drive on the pavements. She searches for medical information in a sideboard to prove that her claims about her physical condition are justified. Jenny says she does not need to know these details, but both the woman and her daughter-in-law continue to provide examples of difficulties that the woman faces in her daily life. Jenny tries to move on, pointing at her list, but the woman repeats: 'I just need my mobility scooter'. Jenny looks at her watch and says it is time to round up this conversation. After leaving the house, Jenny bursts out: 'This is not how it is supposed to go'. She says that she feels like she has failed, because she was not able to have a conversation or complete the questionnaire. She explains how these conversations give her mixed feelings because they are very complicated in comparison to how she would have dealt with this situation in the past. 'I would not have scheduled this visit then, maybe I would not even make a phone call.' She argues that this woman obtained approval for her claim a few years ago, and, since then, nothing has happened that could have improved her physical health. 'She has obtained a formal indication, which I would just renew.' She has a right to use a mobility scooter, and although she returned the scooter when she believed that she could not handle the device correctly, 'her claim is still legitimate'.

In this case, a request was made to 'get a mobility scooter'. A professional is expected to have a kitchen table conversation that is consistent with the ideals of a negotiation of activation opportunities. In the woman's home, the professional wants to assess needs and abilities and organises the conversation by following her questionnaire. While this questionnaire covers many domains of life, varying from the personal health status, daily activities and mobility, to voluntary activities and the social network, the woman refused to answer questions about her life; she only wants to prove the legitimacy of her request. The professional struggles with her assignment to negotiate activation while knowing there is a valid legitimation for the request. 
Eventually, the professional experiences a feeling of failure because she was unable to complete the list, as the woman was not willing to give up her agency in her own living room, seeking to ensure that her needs would be heard.

\section{Negotiating a Need Proactively}

Within some neighbourhoods, it is common practice that when inhabitants turn eighty years old, they receive a home visit. During these visits, a professional must 'do' a typical kitchen table conversation, although there is no formal request to assess. The idea is that conversations can be preventive, detecting problems at an early stage, while simultaneously helping to activate people, for instance to become volunteers. Previously, visits would only take place if there was an explicit personal request.

Sitting on the couch in the living room of an older couple, Annette explains that she is here today to determine if the man needs any support now that he has turned eighty. Immediately, the couple replies they do not need anything at all, as they are both perfectly healthy. Nevertheless, they answer all of Annette's questions during the next hour. Annette apologises several times for the length of her questionnaire (the same list Jenny used), but the couple repeats: 'it does not matter at all'. For instance, Annette asks them about their physical constraints, as well as how they spend their days. After the couple explains that they are often busy taking care of their grandchildren and that they often provide meals for their children, Annette wants to know what they receive in return. Only when she asks them about their financial situation, they refuse to answer: 'this information is private'. Annette takes notes about all of the details that are shared during the conversation, including intimate information concerning the relationship with their son and daughter-in-law. Afterwards, I talk with Annette about how she feels about this conversation and the use of a questionnaire that includes private questions about people's health, finances, daily activities and social network, while these people obviously did not want any help. Annette explains that, although these conversations are time consuming, they are also important to 'stay in touch with the everyday feelings of regular older people'.

In this case, there is no request for help. The professional assignment is to find out whether there are any problems or activation opportunities. There are no restrictions to which professionals should shape their conversations, although they are expected to use a questionnaire. Professionals expect to gain legitimacy when asking questions as these are listed. The couple in this fragment is very cooperative, allowing a professional to enter their home and to ask many questions, although they were not willing to share details they consider private. According to the professional, the conversation does not reveal any problems, but she considers the conversation useful as a means to 'stay in touch' with older inhabitants. 


\section{Negotiating an Undefined Need}

In a pilot project, a professional visits an older couple. Beforehand she explains that she visits people after receiving a request for help, but that she has no further instructions or guidelines. In this pilot, there are no time limits nor questionnaires that she needs to complete. If she considers it necessary, she can immediately organise specific care. However, she has to have a kitchen table conversation and she needs to provide the municipality with a recommendation based on an extensive report. The older woman whom we are visiting has a husband suffering from Parkinson's' disease. A care manager involved with this man has asked to verify whether his wife is eligible to receive any extra help now her husband's care demands are increasing rapidly. The woman is coping with some infirmities that occur with old age.

An older woman opens the backdoor and invites us in. She apologises for her husband's current absence, but she assures he will join us later, although it is difficult for him to stay in one room and to remain focussed. The woman says that she is nervous because she is afraid that she will not get any help. In the past, a physician has 'interrogated' them, [as part of the verification procedure for an indication] and rejected their care claim for a domestic help. Laura reassures the woman that it will be all right and that she understands that the situation is different now. She adds that she is aware that the couple has to cope with a great deal at the moment and that it is probably difficult for them to understand everything at once, but that she will do what she can to help them. In the meantime, the husband has joined us. When asked to tell something about their physical abilities, the woman retrieves some documents that contain both their medical histories. She starts to read the information out loud, which takes some time as the information dates back to the 1970s. Sometimes, Laura looks for some explanations regarding medication or medical conditions on her tablet and makes notes on her form. After having written everything down, she asks whether the woman could show us their house, as this will help to understand how they live and what kind of help might be suitable. During the tour, the woman explains specific adjustments which they made for her husband, including a special chair in the kitchen that enables him to get around, handles beside the toilet and an additional balustrade next to the stairs, adding that they can move a bed to the living room when necessary. Laura interrupts the woman occasionally to ask for additional details, such as how they get out of bed in the morning or how they deal with a higher threshold in one of the rooms. Back in the living room, Laura explains that she intends to advise the municipality at least to adjudge a domestic help to the couple. She tells them that she can also organise some extra support if desired, although she understands all this can be a bit overwhelming. In the end, she proposes for now to start with the procedure for a domestic help, which will take a couple of weeks and will offer the couple some time to adjust to the idea of having a help around their house.

In this case, there is an unspecified request for help. It is up to the professional to find out what the request actually entails, why it is made and how the couple can be facilitated. Although the professional is able to structure the conversation in the 
way she thinks is appropriate, it follows a similar structure to conversations in which questionnaires are used. The professional already anticipates the advice which she has to write and which has to meet a certain structure, but she also tries to combine the collecting information with providing reassurance to the couple.

\section{Negotiating a Need for Support}

Some activation practices take place outside the home, during consultations in more or less public places, such as a neighbourhood community centre. All inhabitants can walk-in to discuss whatever they choose during a short conversation of fifteen minutes. These consultation hours are introduced to enable people who do not know what to do or where to go to meet a professional. At times, there are no visitors; at other times, there are plenty. Professionals 'do' these conversations in a way similar to the kitchen table conversations. While professionals mostly, do not know anything about visitors in advance, they need to collect specific information about their request for accountability.

Anne is waiting for visitors during today's consultation hour. An older woman enters the room. Anne knows she must encourage a dialogue about actual needs of visitors. She asks the woman for her name, while she points to a form and explains that she wants to write it down. The woman hesitates, trying instead to talk about a letter she received from the municipality. However, Anne says she cannot discuss this letter when she does not have her name. During the following minutes, Anne repeats her argument that she needs a signature to make her time accountable, while the woman replies that she feels disrespected and that she has only 'a small question for which no registration is needed'. Eventually, the woman becomes angry and walks away. Anne tells me that she feels confused. While she only wants to help people, they must understand that receiving their consent is part of her job.

During another observation at this community centre Peter, a colleague of Anne, welcomes a woman who asks him to help her gain some insight into what she must do if she wants to emigrate, while she still has financial debts. Peter asks the woman to elaborate on her situation, because without any background knowledge, he will be unable to advise her. Together, they discuss the woman's wishes. Peter explains that he still needs some additional information to be able to help her. He says he thinks the best thing to do is to make a new appointment to have a more in-depth discussion. However, he first needs her to sign an informed consent. He suggests, 'Why don't you just fill in this form, while I check my calendar to schedule a follow-up consultation?' The woman writes down her details and signs the form. Peter quickly checks the form for her details while proposing a day for their appointment. In preparation for their next appointment, he asks the woman to search for some information on the Internet. After the woman has left, Peter explains that he thinks 'getting a signature' is just part of his activation assignment. He even aims to use signatures as a way 'to make visitors a participant in the conversation by giving them a specific task'. 
The two conversations described above differ from most kitchen table conversations because they do not take place at home. This gives citizens an opportunity to meet professionals in a more anonymised way. But if they want actual help, they must reveal their identities. Professionals have some flexibility in the ways that they do the conversation, but they are bound by time limits and administration rules that oblige them to obtain written informed consents. They also are required to activate visitors to look for solutions in their own social networks. Although using the same technology of the kitchen table conversation, the conversations work out differently. The first conversation is a discussion about unveiling one's identity, while in the second conversation, identity is used as an activation strategy.

\subsection{Discussion and Conclusion}

In this paper, we explored the kitchen table conversation, introduced as a new social technology to facilitate care and welfare professionals as regards their assignment to encourage ageing-in-place. Policy expectations concerning this technology draw on notions of a kitchen table as a symbolic place for informal, open, and in-depth dialogues. Whereas such a dialogue implies an equal power balance in which consensus does not have to be reached (Kohl and McCutcheon 2015), in fact the kitchen table conversation is introduced as a policy tool to activate older people in an unequal professional/citizen relationship. While citizens do not exactly know what they stand to gain or lose in these conversations, they are usually aware that professionals also have an assignment to cut costs, and that it is not only about being eligible for help.

The expected role of professionals in helping to cut back on care costs adds to the tensions which professionals experience in practice. Though professionals are formally expected to come to a good care arrangement with citizens, their assignment is combined with a message that less formal care is preferred, as policymakers strive to increase older citizens' independence in this manner. While the government increasingly withdraws from society by shifting responsibilities to individuals, it paradoxically expects professionals to activate these individuals by entering their private sphere (home). When professionals enter a home as representatives of the government, the home becomes a place where publicly provided care is negotiated. Kitchen table conversations illuminate tensions between policy (a withdrawing government) and practice (professionals invading the privacy of the home). The home changes from a safe and private place into a place where care and independence are discussed (cf. Dahlin-Ivanoff et al. 2007), affecting the role of professionals and turning them into gatekeepers and care negotiators. Where they would previously enter a private space as a care provider, they now enter before any care arrangements are made.

Places mediate relationships between professionals and citizens. Yet while participative policies outline the kitchen table as an informal, warm and safe setting, our observations demonstrate something else: the professional's decision on which an 
individual depends is tied to the setting of that individual's private home. In the first case, we observe that the woman uses her home to demonstrate her needs. This context empowers her to determine the agenda, to stick to the subject that she finds important, and to refuse to talk about other suggestions made by the professional. The second case shows a couple that, despite being in their own home, may feel obliged to share private information without knowing for what purpose it is going to be used. The third case shows how the home-setting plays a role in helping the professional to decide what care is possible, as the tour of the home helps to visualise the daily challenges faced by the couple. Although the setting of the private home may offer opportunities for citizens to control the agenda, and to invite relatives or friends to attend the meeting to support them, it might also make it harder to end the conversation. Consequently, our final observation is that the professional is now a visitor in citizens' own homes, making it more difficult for them to walk away.

Our study demonstrates that professionals who are having kitchen table conversations, struggle to find a balance between their ideals of good care and their interpretation of current policy expectations. The professional in our first case literally says that she experiences a sense of failure because she could not complete her questionnaire. For her, completing the questionnaire is necessary to be able to discuss other things than merely the physical need for a mobility scooter. As part of the new policy ideal, she wants to be able to find out how she can empower the woman whom she is visiting and what opportunities for assistance are available within the woman's own network. However, she is unable to convince the woman of the importance of discussing these other things. Professionals endeavour to make their conversations fit within the policy ideal, seeking opportunities to convince citizens of the benefits of activation and ageing-in-place, while being simultaneously aware that policymakers expect them to cut the costs of formal care. However, this dilemma further complicates an informal, open and in-depth dialogue between professional and citizen. Completing a form or a questionnaire becomes a goal in itself, though such tools - clearly visible as policy-instruments - impede an open dialogue based on equality.

Ideally, the professional and the citizen reach a consensus on a customised care arrangement. In the current policy context, the dependence of older people on the professional's verdict precludes an equal relationship. In the third case, the older woman expresses her fears that her own needs and those of her husband will not be acknowledged (yet again). Instead of a dialogue about their needs and possibilities based on an activation ideal, the home-visit results in a reassuring talk based on what opportunities the professional considers to be available for care provision. In the last case, the conversations take place within a public domain. This creates other tensions, as when a visitor decides to run away and the professional is left with the issue that she cannot account for the time spent. The cases that we analysed illustrate that kitchen table conversations articulate different kinds of tensions between policy and practice, demonstrating the ambiguity of the 'new professional' role in partic- 
ipatory regimes and of a social technology introduced to mediate ageing-in-place.

Within STS, Mol, Moser and Pols (2010) demonstrated that although social technologies that are used in caring practices contain an inscribed purpose, they acquire their eventual meaning in use. Our analysis indicates that the social technology of the kitchen table conversation not only affects professionals' activities and space in interactions with individuals, but also their definitions of good care, and of what is public or private. Our research calls into question whether the kitchen table conversation is actually a social technology, as it lacks the characteristics that define a tool, such as a certain predictability and standardisation. Other tools, such as questionnaires and forms, are added to the conversation to stimulate standardisation, which is at odds with the idea of customised care and which creates ambiguity in professionals' assignments. Instead of facilitating the informal, warm and open setting for which they are intended, these tools are used to structure the conversation into an assessment of a citizen's needs and opportunities, to help professionals decide whether the person is eligible for a care arrangement. Although the idea of a well-designed tool is that the acts and behaviour of the user are prescribed in the technology, our observations demonstrate that this tool lacks a predictability required to prescribe the actual conversations between professionals and citizens.

While kitchen tables are chosen because they signify the importance of a safe place, our analysis suggests that kitchen table conversations in a Dutch ageing policy impedes the development of an open dialogue because of the inherent inequality of knowledge and power. Whereas the professional has decision-power, it is unclear to citizen how they can affect decisions. Home-visits organised proactively to negotiate possible care needs might help to detect loneliness or care risks which can subsequently be addressed, but the ambiguity of the tool makes its use problematic. Despite a small sample, our analysis shows that new participatory regimes create new and complicated assignments for professionals. The conversations offer opportunities for professionals to increase their space, but the responses to this space differ from one professional to another. The fact that some are in search of firmer footing, while others feel free to create their own ideal conversation, further emphasises the ambiguity of the kitchen table conversation as a social technology. 


\section{Acknowledgments}

The authors thank the respondents for their willingness to participate in interviews, focus groups and observations for this study. We also would like to thank everybody who commented on earlier drafts of this paper, especially participants of the EASST 2014 conference in Torun and participants of the WTMC-dissertation day in May 2015. The research reported here was part of a project funded by ZonMw - the Netherlands Organisation for Health Research and Development (grant 314070201). The financial sponsors did not play a role in the design, execution, analysis and interpretation of data, or writing of the study. 


\section{References}

Abram, R., 2007. Kitchen Conversations: Democracy in Action at the Lower East Side Tenement M. The Public Historian, 29, o1, 59-76. doi:10.1525/tph.2007.29.1.59

Andrews, G., 2003. Locating a geography of nursing: space, place and the progress of geographical thought. Nursing Philosophy, 4, 03, 231-248. doi: 10.1046/j.1466-769X.2003.00140.x

Bennett, K., 2006. Kitchen Drama: Performances, patriarchy and power dynamics in a Dorset farmhouse kitchen, Gender, Place \& Culture, 13, 02, 153-160. doi:http://dx.doi.org/10.108o/09663690600573775

Berkel, R. van, Aa, P., van der and Gestel, N. van, 2010. Professionals without a profession? Redesigning case management in Dutch local welfare agencies. European Journal of Social Work, 13, 04, 447-463. doi:http://dx.doi. org/10.1080/13691451003603455

Dahlin-Ivanoff, S., Haak, M., Fänge, A. and Iwarsson, S., 2007. The multiple meaning of home as experienced by very old Swedish people. Scandinavian journal of occupational therapy, 14, 01, 25-32. doi:http://dx.doi. org/10.108o/11038120601151714

Derksen, M. and Beaulieu, A., 2011. 'Social technology'. In Jarvie I. and Zamora-Bonilla, J. (Eds.), The Sage handbook of the philosophy of social sciences, 703-720. Sage: London.

Ellis, K., 2014. 'Professional Discretion and Adult Social Work: Exploring Its Nature and Scope on the Front Line of Personalisation', British Journal of Social Work, 44, 2272-2289. doi:https://doi.org/10.1093/bjsw/bcto76

Evans, T., 2011. 'Professionals, Managers and Discretion: Critiquing Street-Level Bureaucracy', British Journal of Social Work, 41, 368-86. doi:https://doi.org/10.1093/bjsw/bcq074

Everett, J., Homstead, K. and Drisko, J., 2007. Frontline worker perceptions of the empowerment process in community-based agencies. Social Work, 52, 02, 161-170.

doi:https://doi.org/10.1093/sw/52.2.161

Høybye-Mortensen, M., 2015. 'Decision-Making Tools and Their Influence on Caseworkers' Room for Discretion', British Journal of Social Work, 45, 6oo-615. doi:https://doi.org/10.1093/bjsw/bct144

Kearns, R., 1993. Place and health: towards a reformed medical geography. The Professional Geographer, 45, 02, doi:139147. 10.1111/j.0033-0124.1993.00139.x

Kohl, E. and McCutcheon, P., 2015. Kitchen table reflexivity: negotiating positionality through everyday talk. Gender, Place \& Culture, 22, 06, 747-763.

doi:http://dx.doi.org/10.108o/o966369X.2014.958063

Liebenberg, L., Ungar, M. and Ikeda, J., 2015. 'Neo-Liberalism and Responsibilisation in the Discourse of Social Workers', British Journal of Social Work, 45, 1006-2021.

doi:https://doi.org/10.1093/bjsw/bct172

McDonalds, C. and Chenoweth, L., 2009. '(Re)Shaping Social Work: An Australian Case Study', British Journal of Social Work, 39, 144-16o. doi:https://doi.org/10.1093/bjsw/bcmo94

Mol, A., Moser, I. and Pols, A. (Eds.), 2010. Care in practice: On tinkering in clinics, homes and farms. Transcript Verlag: Bielefeld.

Newman, J. and Tonkens, E. (Eds.), 2011. Participation, responsibility and choice: summoning the active citizen in western European welfare states. Amsterdam University Press: Amsterdam.

Norlander, L. and McSteen, K., 20oo. The kitchen table discussion: A creative way to discuss end-of-life issues. Home Healthcare Now, 18, o8, 532-539. Retrieved from http://journals.lww.com/homehealthcarenurseonline/ Abstract/200o/o9ooo/The_Kitchen_Table_Discussion_A_Creative_Way_to.12.aspx

Poland, B., Lehoux, P., Holmes, D. and Andrews, G., 2005. How place matters: unpacking technology and power in health and social care. Health \& Social Care in the Community, 13, 02, 170-180. doi:10.1111/j.1365-2524.2005.00545.x

Sarkissian, W., Shore, Y., Vajda, S. and Wilkinson, C., 2012. Kitchen table sustainability: Practical recipes for community engagement with sustainability. Routledge: London.

Truglio-Londrigan, M., 2013. Shared decision-making in home-care from the nurse's perspective: sitting at the kitchen table-a qualitative descriptive study. Journal of clinical nursing, 22, 19-20, 2883-2895. doi:10.1111/jocn.12075

WHO, 2017. World report on Ageing and Health. World Health Organization: Geneva. Retrieved from http://apps.who. int/iris/bitstream/10665/186463/1/9789240694811_eng.pdf?ua=1 



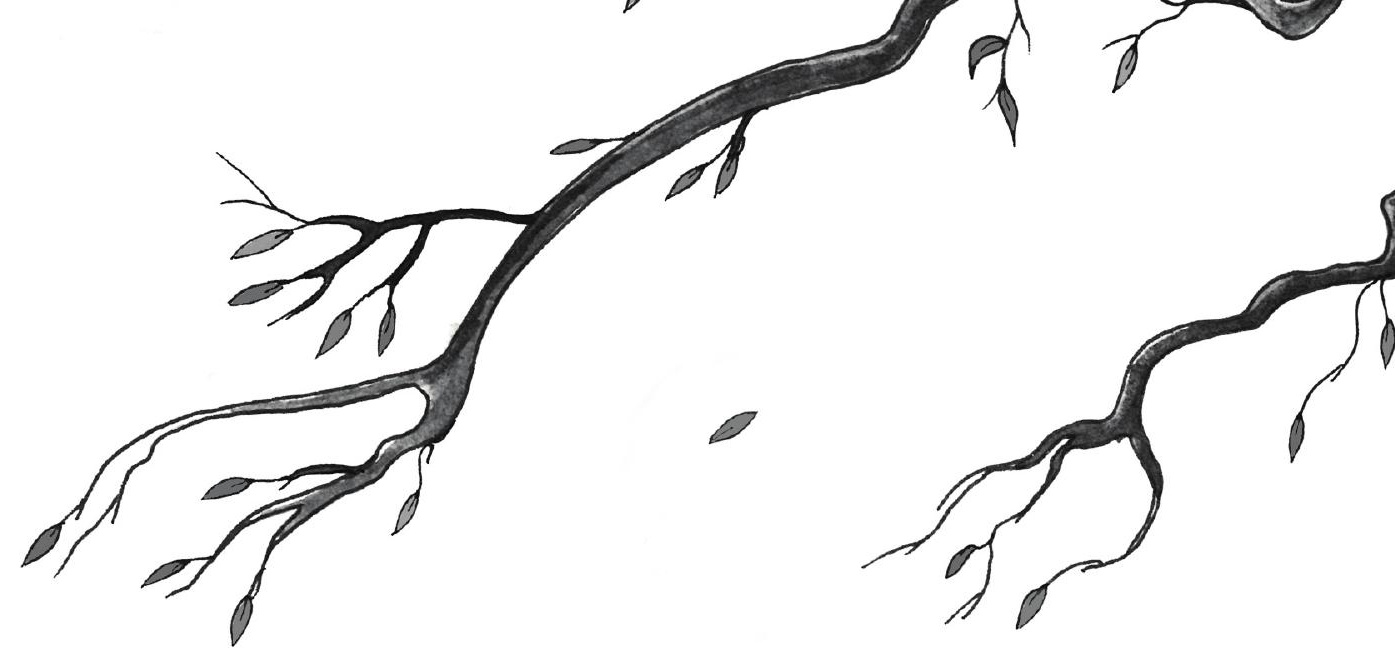

Chapter 4

Meanings of 'lifecycle-robust neighbourhoods'

Constructing versus attaching to places

Published as:

Susan van Hees, Klasien Horstman, Maria Jansen and Dirk Ruwaard, 2017. Meanings of 'lifecycle-robust neighbourhoods': constructing versus attaching to places. Ageing \& Society, Published online: 23 January 2017, 1-26. doi: https://doi.org/10.1017/So144686X16001483 


\begin{abstract}
In Western welfare states, notions of age-friendly communities and ageing-inplace are increasingly important in new health policies. In the Netherlands, care reforms are modifying the former welfare state to be more participatory; local governments are seeking collaborative solutions. Municipalities and housing, care and welfare organisations in the southern part of the country developed the concept of 'lifecycle-robust neighbourhoods', envisioned as places where older people can agein-place. Although many scholars have used the concept ageing-in-place in their studies of neighbourhoods, we aim to unravel this concept further by exploring how this particular ageing policy plays out in practice. This paper explores what the development of 'lifecycle-robust neighbourhoods' means in relation to notions of ageing-in-place and age-friendly communities. We used ethnography (interviews, observations and focus groups) to reveal how, on the one hand, the policymakers, housing, care and welfare directors and representatives of older people, as developers of 'lifecycle-robust neighbourhoods' and, on the other hand, older people, give meaning to places to age-in-place. It becomes clear that ageing-in-place has a different meaning in policy discourses than in practice. While developers mainly considered place as something construable, older people emotionally attached to place through lived experiences.
\end{abstract}




\subsection{Introduction}

Referring to ageing populations and associated public healthcare expenditure, increasing numbers of Western welfare states shifted health responsibilities (partly) from the state to individuals (Bond et al. 2007). Simultaneously, care and welfare services have become decentralised (Hacker 2009; Kroneman, Cardol and Friele 2012; Nowak et al. 2015; Singh 2008). In the Netherlands, the Social Support Act (Wet maatschappelijke ondersteuning) is playing an important role in national reforms. Though the Act (2007) evolved due to several amendments, its aim remained to enable older people to live independently for longer periods of time. The Dutch act is in line with the aim of the World Health Organization (WHO 2007) to make the world more age-friendly, as was expressed in the 'Global Age-friendly Cities: A Guide'. This guide draws on the WHO's active ageing framework, which defined active ageing as 'a process of optimizing opportunities for health, participation and security in order to enhance quality of life as people age' (WHO 2002, p. 12). In 2015, Zeitler and Buys added that encouraging the development of communities that enable people to remain engaged and participative was also central to the active ageing concept. In 1993, gerontologist Rowles already explained how 'a belief [is] gradually being subsumed within public policy, that older people, particularly as they grow more frail, are able to remain more independent by, and benefit from, ageing in environments to which they are accustomed' (Rowles 1993, p. 65); Olsberg and Winters (2005) also argued that people increasingly wish to age-in-place. In this paper we aim to unravel meanings of a Dutch policy to construct ageing-in-place, by exploring how this policy plays out in practice.

How meanings of ageing evolved in relation to ageing policies in the past decades, becomes clear in the literature review of age-friendly communities in Western welfare states of Lui et al.'s (2009). They observe a counter-movement between 2005 and 2008, where ageing was no longer being interpreted as a social problem: it was considered a positive starting point. Notions of age-friendly places were used to promote the development and exploration of what age-friendly cities and communities meant (Lui et al. 2009). The concept of age-friendly communities has even been used as a governmental strategy (to make places age-friendly) (Menec et al. 2015), but different governmental strategies have different foci. Walton (2014) for instance described a strategy aiming to develop 'vital places', nearby destinations that affect residents' vitality and health. Other authors mention notions of belonging, identity, (in)dependence and use of space as elements of ageing-in-place strategies (Peace, Holland and Kellaher 2011; Phillipson 2007; Sixsmith and Sixsmith 2008; Wiles et al. 2011). Furthermore ageing-in-place is associated with concepts of healthy, successful, productive or active ageing (Boudiny 2013; Bülow and Söderqvist 2014, Lassen and Moreira 2014; Sixsmith et al. 2014; Walker 2008). In line with the heterogeneity of ageing, there are many definitions of successful ageing (Depp and Jeste 2006; Nosraty et al. 2015). Depp and Jeste (2006) concluded that it is too complicated to fit these ideas in one single theory or model. 
While many studies have already explored the meanings older people give to place, we have not yet found discussion of a comparison between how ageing-in-place policies relate to older people's lived experiences of ageing-in-place. In our study, we aimed to fill this gap by analysing different meanings of ageing-in-place within a public innovative care practice in the Netherlands called 'Voor Elkaar in Parkstad' ('For Each Other in Parkstad'). In this practice policy makers, directors of housing, care and welfare organisations (including a healthcare insurer), and representatives of older people, aimed to develop a policy to 'make ageing-in-place' (representatives are appointed by formal older adults' organisations to represent older adults' interests, for instance by participating in policy boards and panels). They introduced what they called 'lifecycle-robust neighbourhoods', as places that enable ageingin-place. These neighbourhoods can be considered as 'ageing technologies'. In our study we explored how both developers (the initiating policy makers, directors and representatives) and users (older adults) give meaning to neighbourhoods as places for ageing-in-place. The distinction between developers and users is introduced in literature aimed at understanding how new technologies are incorporated in everyday practices (Oudshoorn and Pinch 2005).

We first discuss the theoretical background of the study. Subsequently, we present the case we studied and explain the methodology used. We then present our analysis; discussing how developers (policy makers, directors and representatives of older people) and users (older people, inhabitants) experience the places that are an object of the ageing-in-place-policy. Finally, we will reflect upon our analysis and discuss how it contributes to current ageing-in-place discourses.

\subsection{Defining ageing-in-place}

Ageing-in-place has become an important element within Western reform policies. In this section we will examine theoretical notions of place and place attachment and ageing-in-place policies.

\section{Place}

To enhance our understanding of how places matter, we used the work of social constructivist Gieryn (2000). He explained that instead of using demographical, geographical and historical quantifiable characteristics, his task was 'to reveal the riches of a place-sensitive sociology' (Gieryn 200o, p. 464). He wanted to understand why and how places matter and are unique, even if they increasingly look alike. While 'clones of places' are built everywhere (e.g. similar shopping malls and office complexes), places remain meaningful and unique because of: (a) geographic location ('unique spot in the universe', (b) material form ('the physicality of place'); and (c) 
investment with meaning and value (naming, identification, or representation by ordinary people). These features resonate with those referred to in spatial sciences by Cresswell (2004, p. 7) as 'location', 'locale' and 'sense of place', and in gerontology by Rowles' (1993) components of place attachment: (a) physical (e.g. repetitive routines of use); (b) social (e.g. shared habitation, being familiar with neighbours); and (c) autobiographical (e.g. the personal history built over time that helps to identify with a particular place). Gieryn argued that a combination of these three features make places meaningful as they construct the sensitivity of a place. Place in itself is not important he argued, but the way place mediates social life is; people emotionally attach to a place because of social relations and history associated with it.

Attachment to place is difficult to explain in words. When walking through the Dutch city Maastricht Gieryn struggled to articulate differences and similarities to his hometown Bloomington, Indiana. Comparisons in terms of demographic characteristics or historical facts are not able to 'capture the sociologically significant characteristics' of both places (Gieryn 2000, p. 483). Only qualitative characteristics can help to understand why specific places matter to some people and not to others. Thrift (2009) and Trell and van Hoven (2010) also argued that places are constructions or reconstructions in people's imaginations, memories, emotions and feelings, both positive and negative.

Although Gieryn demonstrated how places are constructed through meanings, he also demonstrated how places are agents themselves and influence the environment and social life (Gieryn 200o). For example, Jacobs' (1961) work 'The Death and Life of Great American cities', illustrates how a location to create a safe environment, away from traffic, for children to play and for others to meet, simultaneously contributes to its dangerousness as the isolated location also attracts criminal behaviour.

\section{Place attachment}

To understand what place means in relation to age and how people attach to place, theories on the relation between ageing and place are helpful.

Many different environmental factors contribute ageing-in-place. Gardner (2011) elaborated on the meaning of places for ageing, when trying to understand the effect neighbourhoods have on places when people age, whilst exploring the public life of older people living independently. Social networks in neighbourhoods and the neighbourhoods themselves influenced the experience of ageing and wellbeing. Gardner distinguished three key places where older people make social connections and experience informal public life: near the home (first place), work (second place), and in several third places. Third places, Gardner explained, are places with a specific destination, such as the park, a community centre or a shop. She also distinguished thresholds, so-called 'hybrid third places', like driveways, backyards and elevators; and transitory zones, like places between places, such as, streets and sidewalks. Gardner showed how these different places can affect people's behaviour differently. 
Apart from places, flexible transport options enable people to remain independent in later life, especially in remote and rural areas (Plouffe and Kalache 2010; Zeitler and Buys 2014). Additionally, Walton (2014) emphasised the importance of specific places to ensure vitality and health (like the availability of healthy food sources). Furthermore, influences on health in general (not specifically related to later life) can also depend on different socio-economic neighbourhood areas, neighbourliness (the 'hi-factor'), greenness of environment and the proximity to Gardner's 'third places' (Eriksson and Emmelin 2013).

Places matter, but why are people attached to specific places? Some authors point to a functional relationship with the personal environment (e.g. Lawton and Nahemow 1973), drawing on the idea that individuals' competences enable them to make rational choices with respect to their environments (also Rowles 1993; Peace, Holland and Kellaher 2011). Lawton and Nahemow (1973) argued that the more competent individuals are, the more proactively they will be able to deal with possible challenges in later life (mobility issues for instance), and the less place-dependent they will be. Peace et al. (2011) added the concept of 'option recognition', which basically means that it is not necessarily remaining in-place that is important, but the opportunity to independently select the best option where to age (or the only realistic one).

Other authors point to an experiential, affective relationship which is distinguished based on personal affections towards a place (Hillcoat-Nallétamby and Ogg 2014; Rubinstein and Parmelee 1992), for instance because it provides opportunities to keep the past alive and to build a shared identity as a community (Means and Evans 2012). Yet while communities can stimulate attachment to places, they can also stimulate withdrawing from their own neighbourhood (Gilleard and Higgs 200o; Means and Evans 2012).

In his work, Rowles (1993) criticised the notion of ageing-in-place for its romanticised associations. He argued that the choice to remain in-place is often based on pragmatic reasons (e.g. a mortgage that has to be paid, convenience), instead of on emotional and experiential attachments. In addition, generic places are also increasingly able to invoke a sense of 'familiarity and identification': an ordinary McDonald's restaurant could evoke memories of a precious moment (e.g. a first kiss) that took place in another McDonald's. Furthermore, older adults do use strategies to re-make place after a relocation, both physically (using the same furniture) and socially (developing tactics to connect with new neighbours) (Rowles 1983).

In a study exploring the meaning attributed to homes, neighbourhoods, and communities when ageing-in-place, Wiles et al. (2011) argued that the latter can help to delay or even prevent the institutionalisation of older adults, as the home setting can offer a sense of connection, and feelings of security and familiarity. Even when their own environment changes, older adults are able to adapt to these changes (Lager 2015). Although many older adults might prefer to remain in-place, Keyes et al. (2014, 
p. 128) concluded in their study 'lifelong community cannot be forced upon people; rather, it must be crafted with input and guidance from those whom it is intended to serve'.

Against the background of arguments that suggest that place attachment is increasingly less related to specific places, it is interesting to consider Gieryn's (2000) place-sensititvity: What is it, in particular, that makes a place meaningful for people living and ageing there? Places reflect and constitute social relations, and they can simultaneously include and exclude individuals (Lamont and Molnár 2002). This is important when examining why and how places are regarded meaningful to older people (Gardner 2011; Joseph 2008; Joseph and Chalmers 1995; Lamont and Molnár 2002). In their work on growing old-in-place, located in rural New Zealand, Joseph and Chalmers (1995, p. 81) illustrated how some older people chose to age where they had a 'lifetime of experience' over what was considered the most suitable place to age in terms of healthy ageing or over what could be considered the rational chosen better option (Peace, Holand and Kellaher 2011).

\section{Ageing-in-place policies}

One of the underlying assumptions of new policies that promote agefriendly cities and communities is that they will provide the context to enable or encourage active ageing: they are places 'where policies, services, settings and structures support and enable people to age actively' (WHO 2007, p. 5). The current changes in how old age and ageing-in-place are understood resonate with similar changes in notions of citizenship, independence and individual responsibility (Newman and Tonkens 2011). Menec et al. (2011) describe how most governments consider social participation to be pivotal when searching for strategies in dealing with the implications of ageing populations. Although the WHO started to promote the concept of agefriendly cities by focusing on urban areas (Plouffe and Kalache 2010), increased attention has now been given to rural and remote areas, as the highest proportion of their residents are older people (Buffel, Phillipson and Scharf 2013; Coleman and Kearns 2015; Menec et al. 2015). According to Buffel et al. (2014), different communities need different approaches to become agefriendly, and a one-size-fits-all approach cannot be applied. They state that local needs and desires (e.g. fresh air, travel opportunities, healthcare, sports) have to be taken into account (see also Winterton and Warburton 2011).

In current social policies, one can observe a shift in responsibility from the state to individuals and their family and friends, and in that context the meaning of home has changed (Roberts and Mort 2009; Wiles et al. 2011). The home is reconstructed as a place of care. For instance, Milligan (2009, p. 71-72) observes 'a continuous renegotiation of the meaning of home as a site of care and a place of social relations and personal life'. 
However, while policy makers consider ageing-in-place mainly from the perspective of health and care, older adults might want other things (Milligan 2009; Roberts and Mort 2009). The number of older people who remain independent for longer is increasing, and it is important their views on where they want to age are heard (Dahlin-Ivanoff et al. 2007; Wiles et al. 2011) rather than to assume they are infirm (Heathcote 2011). Instead of focusing on opportunities for health and care provision, other elements are distinguished as important to enable ageing-in-place 'regardless of age, income or ability level' (Satariano, Scharlach and Lindeman 2014, p. 1374). Several scholars mention the importance of living in a private home based on feelings of safety, independence (freedom) and comfort (Eriksson and Emmelin 2013; Satariano, Scharlach and Lindeman 2014). Although ageing-in-place can be a choice for some, for others (especially low-income individuals) it can be the only option, as they are not able to choose (or buy) other options (Kohon and Carder 2014; Morenoff and Lynch 2004; WHO 2002). To enable independence in old age, communities (social networks) remain important in policy making as they are considered to be able to fulfil informal care and welfare services (Means and Evans 2012). In short, these studies on ageing-in-place policies illuminate that a combination of physical and social capital is vital to enable ageing-in-place.

\subsection{Methodology}

In this paper, we explore concepts of ageing-in-place by unravelling meanings of so-called 'lifecycle-robust neighbourhoods' in the case 'Voor Elkaar in Parkstad'. Parkstad is located in the southern part of the Netherlands and in 2012 it had almost 250,000 inhabitants, spread over eight municipalities, which varied from rural places with fewer than 8,ooo inhabitants, to urban areas with almost 88,ooo inhabitants. 'Voor Elkaar in Parkstad' was developed not only in response to the regional challenges of a shrinking, as well as ageing, population with associated increasing healthcare expenditure, but also, as a care director stated: 'to undo bureaucratic and other flaws in the system' [i12]. 'The idea as discussed during meetings of the steering committee in 2011 was to develop 'lifecycle-robust neighbourhoods' where people could live independently for longer. In this paper, we explore meanings of lifecycle-robustness in relation to age and place by unravelling the way(s) in which actors who are involved in devising the 'Voor Elkaar in Parkstad' policy (developers) or affected by it (users) understand ageing-in-place.

In our qualitative study, we used ethnographic methods (Alvesson and Sköldberg 2009), as these enabled us to collect insightful in-depth data examining the different constructions of 'lifecycle-robust neighbourhoods'. Data collection took place within a broader study, which ran from July 2011 until September 2015 and explored con-

1 After each quote a code is mentioned, with which we refer to the particular interview source. Codes start with an i (interviews with developers) or io (for interviews with older people). 
structions of among others ageing and lifecycle-robustness. We did not only study the constructions of policy makers, housing, care and welfare directors, older people and their representatives, but also those of civil servants, as well as managers and professionals located in housing, care and welfare. This paper does not specifically discuss the constructions of ageing-in-place of these civil servants, managers and professionals, but it is important to understand how meanings given to place by developers and users are situated.

Firstly, we analysed documents, such as, project plans and steering committee, project group and working group meeting minutes, to get an idea of the underlying principles of this innovative public care practice. Secondly, we conducted 76 interviews. 28 took place with developers (policy makers, directors and representatives of older people). To explore how older people understand their neighbourhood as users, we interviewed 28 older people who lived independently in 18 interviews (partners were interviewed together). In the interviews, we asked the interviewees to share their experiences of and thoughts on ageing, their homes and their neighbourhoods. Each interview lasted between 20 and 150 minutes and all interviews were transcribed verbatim (except three in which only notes were taken due to practical and technical reasons). Thirdly, we observed all interviewees in 72 formal and informal meetings, including steering committee meetings, project group meetings, case management meetings, home-visits of care and welfare professionals, as well as at lunches, handicraft groups and bingo games. Field notes were taken during all observations and were then elaborated on extensively and promptly. Fourthly, we organised six focus groups to get feedback on our preliminary findings and explore further some topics. One focus group took place with policy makers, one with project members, two focus groups were held with housing, care and welfare professionals and two focus groups were with older people. All focus groups were audio recorded and transcribed verbatim. In our analysis merely direct quotes from interviews are used. However, our findings were confirmed by the observations and focus groups.

All research activities were conducted in Dutch. We coded recurring topics in documents, interviews, observations and focus groups. Focus groups were used to verify preliminary findings, after which we refined our coding if needed, seeking the elements that made neighbourhoods suitable for ageing-in-place that participants considered important. We translated all quotes in this paper from Dutch to English: these were then checked by an English editor and the editing was subsequently checked by us to ensure the original meaning had been retained.

\subsection{Meanings given to lifecycle-robustness}

Participants in our study gave different meanings to ageing-in-place. Below we illustrate how developers and older people (users) living in these places give meaning to 'place'. 


\section{Constructing enabling places}

As previously mentioned, to address the challenges of an ageing population, policy makers, directors of housing, care and welfare organisations and representatives of older people in Parkstad initiated a plan to develop (or re-construct) 'lifecycle-robust neighbourhoods' that enable older adults to live independently and remain self-sufficient (Transition Plan Voor Elkaar in Parkstad 2011). In discussing this they imagined what would be important for ageing-in-place and came up with different ideas and arguments.

Private homes were considered important facilitators of ageing-in-place. An alderman mentioned for instance the importance of 'creating care homes' [i15]. In his view, when people face health problems, care should be provided in private homes. Representatives of older people elaborated on this when talking about wheelchair and walker friendly corridors and entrance access: 'when building or renovating you need to consider that doors need to be wider for instance ... when building, you need to consider whether there is a possibility to add a grip [rail in the] toilet' [i3]. Another representative of older people further elaborated on what a suitable home meant:

I would not say that we need to demolish everything and build only similar houses. But in construction work, it should be considered that within 25 years, half of our population will need a suitable home [i7].

According to the views of developers, 'lifecycle-robust neighbourhoods' should include houses that enable home care provision, including telecare. Places that can be described as convenient places. A housing director elaborated: 'that is why it is important for us that good home care is possible in our houses' [i17].

However, several directors we interviewed, pointed out that feeling unsafe at home was an important barrier to remaining in-place.

As people age, their houses become fortresses. They become more afraid, six-double-locks, I don't know, security systems, you cannot name it. Because they create a kind of cocoon of security inside their own home [i4].

Here, the concept of 'lifecycle-robust neighbourhoods' is strongly related to feeling secure, and according to another care director this started at home:

You cannot resolve that by sending someone by every day, for half an hour. You cannot resolve it with a security system either, because if you have a security system, you know that you are actually unsafe. Because otherwise you would not need that security system, it is an existential insecurity. For those people, and I have known plenty, in my work and in my private life, a caring home is a blessing. They do no longer need to be afraid of burglars, they do not need to be afraid of loneliness, being alone, no longer afraid to fall and that no one will find them. Not afraid of 
forgetting their pills [i5]. Simultaneously, this director wondered: 'I am curious whether there [is] ... actually [not] that many ... 'lifecycle-robust neighbourhoods', little attention is actually paid to whether [they are] ... actually ... age-unfriendly' [i5].

In short, in their narratives aldermen and representatives of older people mentioned the physical characteristics of a private home that can enable or disable ageingin-place, while care directors are rather pessimistic about the opportunity to make people feel safe in their own homes.

Feeling safe and happy in a place was not only related to the private home, but also to the neighbourhood in which people age. Public health service advisors, an insurance company and a regional consultancy agency, mentioned how characteristics of neighbourhoods should be taken into account when developing an environment to age-in-place. For instance, an insurance company representative mentions the importance of social status:

There are, of course, different socio-economical status-scores, in this neighbourhood you have to organise completely different things [than in another], there are simply other needs in a luxury residential area. Or an area full of care institutions for older adults. In that sense, it is impossible to explain how a 'lifecycle-robust neighbourhood' looks like [ig].

Public health services point to other facilities:

Perhaps there [is a] need [for] ... some characteristics [to be] in there later. There needs to be ... minimum ... facilities, or a minimum scale ... number of inhabitants, or at least a ... neighbourhood platform [structure] or whatever. But at least things, that help to keep things going.' [i2o].

Other developers struggled with the assumed diversity of needs and desires amongst people and how hard it is to specify why some people want to live in one place and not in another. Some communities attracted people to remain in-place, but developers found it hard to specify exactly what makes these communities so appealing. When talking about this a housing director described of one specific neighbourhood:

[There] is ... such an entrance [i.e. the respondent referred to the atmosphere you could immediately experience when visiting the neighbourhood], that I would almost say that the quality of the house is subordinate to that. This is not entirely the case. It is [attractive] for one ... [group of residents], the other ... does not even want to be found there when dead [i17].

People do attach to neighbourhoods, even if a place no longer suits their needs. An alderman elaborated on the attitudes he experienced in a community where people were determined to stay-in-place: 
People are extremely ... determined to stay-in-place. Meaning people who are disabled, or [are] hardly able to move up and down the stairs ... [are] very difficult to encourage ... to move. They would, so to speak, rather go down the stairs while sitting on their bum, than that they would move to a beautiful apartment, with an elevator and everything, which is not situated in their neighbourhood. But even if it is two streets away, for some people that would be an invincible obstruction [i16].

Unique and often unidentifiable characteristics are considered to be important for people and make them postpone a decision to move out and to avoid thoughts about approaching the end-of-life stage:

Sometimes you see that people stay too long ... that last step, people find it very difficult. Their perspective is often something like, this is our last step and then we will die. ... Sometimes, because of that, people stay, too often, too long, in-place [i17].

Developers are convinced that elements of place attachment - important for ageing-in-place - are somehow embedded in communities. However, according to them, social cohesion was not only embedded in communities, but could also be constructed. They stressed the importance of neighbourliness and activity. A representative of older people explained: 'it should be a neighbourhood where something happens ... that needs to be a bit incentivised, try to create some ambiance, with neighbourhood parties and whatever else' [i7]. An alderman thought that neighbourliness is possibly already available:

The possibility exists that small communities have such a strong social cohesion, that they might actually be able, with minimal resources, to keep it viable and [enabling] ... for the ageing population [i18].

By referring to festivities, a representative of older people touched upon an often-expressed desire for neighbourly atmosphere, mainly described as neighbours helping each other with their needs. Other developers additionally talked about how they could facilitate this kind of social cohesion. A care director asked for instance: 'Can we ... enable people to do as much as possible in their own neighbourhood, their own home?' [i12]. This director interpreted 'lifecycle-robust neighbourhoods' as:

The fact that you as a client, an older adult in the neighbourhood, are participating, taking part, [and] are doing things for the neighbourhood, for people, but that you also get something back, and that you are facilitated to [stay] ... there [i12].

However, not everybody thought neighbourliness can be organised, a care director (again more pessimistic) warned: 
In those ... 'lifecycle-robust neighbourhoods', there is a certain social pressure not to turn your back on your neighbour. But we know, because we are all human, that in those neighbourhoods, it will always be the same people who help [i4].

As mutual help in neighbourhoods will not always be realised, policy makers, directors and representatives identified a need for what they called a signalling function. This is a professionally organised function, embodied in a person, not a professional per se, who works or lives close to the older person, and notices when things go wrong. A care director explained:

The person who often first notices [such] things is a concierge. He sees the garbage is not taken away, a garden is no longer being kept, how someone starts to get more difficulties walking with his walker and opens the door only once in a while to ... [let] the dog out, unable to do it himself. ... It is possible to organise the signalling function in ... chain[s] of care providers differently [i11].

An insurance company representative envisioned a similar function:

Do you have a problem, and it can be very simple, but also, I need to do a request [for help] and I do not know where I need to be. I can no longer do my groceries because it is icy ... we can organise that in one person [ig].

While discussing the importance of having a signalling function to enable ageingin-place, developers discussed how organisations could jointly facilitate residents' participation, eventually resulting in residents taking over the signalling function. A welfare director explained: 'eventually it is all related to participation and to the neighbourhood taking over tasks of the professional' [i14]. However, developers agreed that to achieve such a participative neighbourhood patience is needed. A care director added how structure, method and culture are important in creating an environment that enables ageing-in-place:

If we start to understand again that it is sensible to know whether my neighbour gets help from the home care or from family-members, and if I have a signalling function there as well, if that becomes common practice, then all changes will be sustainable ... the needs of an older adult will change, but ... the environment can be flexible [i.e. the environment has to become able to fulfil people's needs] [iro].

'Lifecycle-robust neighbourhoods' are constructed in different ways, but overall these neighbourhoods were considered by developers as places that can be constructed top down. Most of the developers were rather optimistic about the possibilities to realise ageing-in-place: 'no formalising, no organising; only facilitating. You just know who needs a nail in the wall, and you know who is able and willing to do that' [i24]. Others described their aims as being idealistic. A care director explained this ambiguity: 
If I look at lifecycle-robustness, I suppose these are neighbourhoods where people can live from cradle to grave, but with the current movement of the next generation [where many people do not longer remain in the same place for a lifetime], I would not put my money on this [lifecycle-robustness] as a future development [i4].

\section{Experiencing attachment to place}

While the developers' narratives mainly considered neighbourhoods as places that can be constructed to enable ageing-in-place, older people had different narratives. Although they shared the idea that ageing-in-place is valuable, they did not consider place as something that could be made, but rather as something that just is. Many mentioned how they liked being in their own place. A woman aged 82 said: 'I am fine here. By now, [I] know everyone, this is anyhow a cosy place to live' [ioz]. Others stressed that 'you should not move an old tree', which is a Dutch saying that implies things will go wrong if older people have to move. Among our interviewees there were people who have moved to what are considered as age-friendly apartments, a couple that was considering moving because they thought a new place might be more age-friendly, and people living in homes they bought or even built decades ago and intended to remain living there. Although people expressed worries about the new social policy as it discouraged people from moving to care institutions, they also relied more or less on getting help if they really needed it.

From the narratives of older people it became clear that they experienced, rather than constructed their place. Similar as developers they liked practically convenient places, like homes that offered home care opportunities and were located close to facilities and services, for instance a woman aged 76 said:

my general practitioner is there... the physio therapist, I only say, there should be a pharmacy as well. Her husband, aged 77 then added: ... but that is also nearby ... that is why we moved here... that we have everything, yes, we age a bit, we still drive a car, but if you no longer have a car, you do not need to go anywhere here, you are already there, you have everything you want in place [io18].

Although older people liked to have facilities nearby, most people considered mobility and travel opportunities to be essential as well. Being able to drive a car, having good bus connections, or neighbours/family members nearby who can assist with transport, helped older people to remain in-place. They worried about having no shops nearby, whilst simultaneously explaining how they would manage. Often there was a 'hidden', emotional attachment to the place where people lived, like having lived there with their partner for many years. By using the word 'hidden' we wish to illustrate that although it is considered to be very important by people themselves, they do not share these attachments explicitly with other people. It is an attachment 
that becomes visible when they start talking about their history and the meaning of their home and neighbourhood. A woman aged 88 explained that she decided not to move to another place, as she valued the time she spent there together with her late husband, although she could move to a place closer to facilities and her children:

Those circumstances, that moving out, my children cannot do everything and then I need to bother them and they work... I am fine here. I will not get such an apartment [as this one]. Those are all smaller with small windows and we have beautiful windows, everything here is big [iono].

Another woman aged 89 explained: 'I say, I will remain home as long as possible. My husband is buried at the cemetery here; I could not leave him' [i1]. An important reason why people eventually move is to remain independent. An older woman aged over 75 appraised the convenience of her new apartment and added there should be more houses like hers:

I think they have to build more. For the older people ... something like this is lacking ... most people are bunched upon each other and would love to have another home, an apartment, those are unavailable ... From the moment I lived here I felt at home, because I loved to live here ... the environment and the house itself, beautiful ... everything is nearby [ioz].

In line with the ideas of care directors, older people also stressed the importance of feeling safe in their neighbourhood. They mentioned, for example, how they valued being able to choose a safe and protected route to the supermarket (there are sometimes private pathways between the apartment buildings and facilities) or having a security system. For instance, one woman aged over 75 explained: 'I do have a security system you know, to push. In the beginning I did not wear it that often, but after a while I became a bit anxious'[io8/9]. Others explained how they felt safe because there were people in their environment who watched out for them. A couple both aged 83, discussed their neighbourhood's safety: The man said 'we are not easily frightened you know, not at all'. The woman added '[there is] just a bit of drug dealing here', then the man said 'and otherwise, we can call [name cousin]' [io13]. Several people experienced some criminality in their neighbourhood, mostly drug dealing, vandalism or trouble caused by younger people. Some people felt their freedom was limited and were afraid to walk in certain area, for example a couple discussed their neighbourhood. The woman aged 76 said: 'Currently, it is reasonably quiet in this neighbourhood, it has been really bad here, people did not dare to go out anymore'. Her husband aged 77 explained it was: 'because of those young people...' and the woman added that it was the 'nuisance of young people ... also in the park. A man who lives here went there, letting his dog out ... he had his umbrella with him and almost hit them ... they did push him down' [io18]. Some older people thought the same as a man aged 86, who said: 'many older adults do not remember they have been young' [io14]. He tried to explain the so-called 'Soccer-act' that was implemented 
in his neighbourhood. It placed a ban on public group meetings and aimed to keep younger people off the streets.

Whether older people felt safe was affected by another element that resonated with an earlier distinguished factor, social cohesion. People felt protected by their neighbours or by having someone in the neighbourhood they could rely on, like the couple's cousin. A woman aged 80 imagined it was possible to stay in her own home, because all her neighbours watched out for her, she added:

Also because of the whole neighbourhood, by chance a cousin lives there, the neighbours always watch whether I have the window open in the morning ... he has got a key, because I have got an additional lock on the door now. They said ... to me that I needed to lock the door. So now I am used to lock[ing] the door ... but he cannot get in otherwise, if something is wrong. Here is a roller shutter, there, well, nobody can get in ... I have a phone inside, so I can always... that is all taken care of, yes, they do watch over me [io4].

It was important for the older adults we interviewed, that someone noticed when they were absent for a day. A couple remarked this was different to their former residence. The woman aged 76 said:

Here it is really, you sit together, and if you have not seen someone for a day or so, you will ask ... There [in our former place] I did not see them [neighbours] for fourteen days, but here, if you have not seen someone than you go out to ask, how are you, what is wrong? And I like that [io18].

Her husband aged 77 added: 'Here we watch out for each other' [io18]. People also emphasise how they are helped by their neighbours when facing practical problems. A woman aged 89 said that she was still mad because a local journalist wrote in her neighbourhood there was a lack of solidarity. She explained that she actually experienced the opposite:

If I did not have such good neighbours, I would no longer live here ... for some months ago I had a leak in my basement, because of the shower ... the drain was clogged. Two neighbours, him and him, have made a brand new drain, I did not have to hire anyone [io1].

The fact that social cohesion is valued also becomes clear when people talk about things they miss. Many older adults think that younger people in their neighbourhood have become strangers, because 'they are busy all day with their work and they have their own lives'. Older adults share feelings of nostalgia about a lost sense of community and no longer being surrounded by contemporaries. A woman aged 89 said:

We don't have that many genuinely old people. Yes, we have enough of them, in a village there are plenty of old people, but many are dead also. But many, the new people, yes, you do not [have 
children any] longer ... at school. You no longer know them, you have no contacts anymore... yes, it is [not] ... as nice as it used to be ... The old people sat outside at their door, but now, everything is inside. [ion].

Male respondents specifically mentioned the companionship they experienced between miners. A man (aged 85) in a couple stated: 'if you are together, in the same neighbourhood, the connection will endure forever... that will not go away. But, so many strangers have come here, now the connection is vanishing a bit'. His wife (aged 8o) added: 'Yes, and all people are on their own here' The man said: 'Yes, what has been will be no more' [io17].

Neighbourliness was an important topic in many interviews, during meetings observed and in focus groups, either because people enjoyed it, or because people experienced a lack of it. An older man aged 86 explained how he had lived in the city-centre for a few years, together with his now deceased wife. They moved there together because of her health condition. He explained how he felt out-of-place there, especially after she passed away: 'I came into the isolation, you understand?' [io14] and how he missed the neighbourliness he had always experienced when he was living in another part of the city (where he lives again now): '... My wife had passed away six months earlier, then the woman [a neighbour] asked: 'How is your wife?' [io14]. Although his apartment in the city-centre was a 'beautiful apartment', he missed being acknowledged by neighbours, and moved back in his original neighbourhood: 'When I leave my home I just walk and come across familiar faces. I sit outside, there are benches and I sit on a bench sometimes with the people, chatting' [io14]. Even though he thought his neighbourhood consisted of 'too many stones' he planned to remain there: 'I love to live here and I said it, I know so many people, and I would not want to leave' [io14].

Neighbourliness was not just associated with knowing and helping each other, it was related to the 'familiarity' of strangers, as in being known and acknowledged by other community-members via your neighbours. In this region, it was considered normal to not pay visits to neighbours. They visited friends at home, but friendly neighbours were preferably met at what we named 'private-public meeting-places'. In some of the apartment buildings there were meeting-places, in the corridor or on the balcony, where residents met and drank coffee together in the evening, or celebrated festivities like Christmas. A woman aged 78 described the daily ceremony at her place:

If the weather is normal we sit there with say five, six people in the afternoon, and we drink a cup of coffee and talk a bit. And in the evening we sit there, sometimes with ten, twelve people. And there is always one woman, she lives closest by, she makes the coffee [ion1]. 
Public places sometimes enabled similar meetings for people, for example, the mention of the game pétanque terrain recurs in several interviews in different places [pétanque is a ball game played outdoors, it is also known as boules or bowls]. People liked how they could watch the game and talk with neighbours. For instance, a woman aged 82 said:

It is nice to live here, during the summer, we all sit outside there, with the whole club... they have made a pétanque terrain there. And in the afternoon, I always wait until a woman goes there, and then I also go, no sooner. [io2]

However, not everybody liked to only meet in public places, a couple talked about how they found it difficult to connect with neighbours in their current living-place. They moved there, some years ago and they think it's a pity that nobody has accepted their invitation for coffee at their place, the woman aged 8o said: 'Listen, in this neighbourhood, we do not relate with anyone.' The man aged 85 added: 'we talk with everybody. The woman agreed: 'we talk with everybody, but no one visits us, but we don't go anywhere either ... At the beginning I have invited them to come over for a cup of coffee, but they did not do that. My husband already told you'. The man reiterated, 'yes, come by one time ... but nothing' [io17]. Another woman (aged 8o) missed her former place as well, she felt acknowledged and surrounded by friendly people there:

I live here [sic] now for three years in September. But the people here are not that ... everybody says that you need to watch out for each other and help each other, but they all just shut the door behind them and that's it [io12].

The appreciation of private-public meeting-places versus people missing friendships revealed that people experience places and neighbourliness differently. Some valued their privacy, while others felt unacknowledged when invitations for coffee were ignored or when it seemed hard to find friendship.

\subsection{Conclusion}

In this paper we explored meanings of ageing-in-place, as they are articulated by developers of 'lifecycle-robust neighbourhoods', and by older people who live in these neighbourhoods. We investigated how this concept of lifecycle-robustness relates to more widely known concepts such as ageing-in-place and age-friendly places. We found that developers tried to construct places and make them meaningful by listing 'enabling' and 'disabling' elements, while older people as users did not construct, but experienced places, while living and ageing there. They often appreciated the elements that developers thought were important, but did not necessarily con- 
sider places with these characteristics desirable to age in. Although we unpacked understandings of rural and more urban areas, the differences between them did not influence the overall findings.

The idea of 'lifecycle-robust neighbourhoods' resonates with ideals of age-friendly places to enable ageing-in-place. All these concepts embed a similar ideal, which is to encourage and enable older people to remain in-place as long as possible, by improving the age-friendliness of people's environment. Although the developers in our study talked about 'lifecycle-robust neighbourhoods', their policy and narratives mainly focused on older people and the role of the home and neighbourhood; they struggled to clearly define lifecycle-robustness. When they talked about age-friendly places and ageing-in-place policies, they envisioned neighbourhoods as mediators for remaining in-place. This implied they expected that places could be constructed and could act as ageing technologies. They felt enabling elements, such as services, facilities and suitable homes needed to be available in these places and the introduction of a signalling function could stimulate social control and cohesion.

A signalling function refers to a specific officer (volunteer or professional) who is appointed as a 'signaller' to provide preventive care and help people remain in-place. The signaller's role is to notice things when they go wrong, so that organisations can react to situations immediately. They presumed older people needed to be activated as participative citizens who could help each other, for instance by volunteering as the signalling function. Although demographic characteristics of a place did play a role in their ideas of place (referring to the socioeconomical status for instance), in general most developers viewed lifecycle-robustness as a malleable concept, a malleability they expected to further encourage by adding this signalling function.

Developers shared expectations of how a signalling function could help construct a more participative neighbourhood, as this was supposed to play a preventive role, as well as provide support. Although the narratives of older adults do reveal a desire for increased social cohesion, in general they also valued their privacy. This became particularly clear in the way many looked for social interactions outside the privacy of their homes, often in what we distinguished as private-public meeting-places. The importance of the home in social interactions is individually determined. Means and Evans (2012) refer to how Depres (1991) argues that homes do not only reflect individual values and help develop social interactions, but also offer 'a refuge from the outside world'. An added, constructed signalling function does not guarantee an increased independency or interaction and each individual will respond differently. Making someone responsible for signalling possible problems may seem like a good idea based on the premise that this enables ageing-in-place, but this ignores heterogeneity among older adults. In practice some older adults shared how they felt more secure and at home when they knew they were being watched by neighbours, friends or relatives, while others explained that they preferred their private space to remain private. 
The existence of private-public meeting-places illustrated how people can experience new places as meaningful, because of the new opportunities they provide to attach. The buildings in which people lived and also places outside, such as, pétanque terrains, acted as agents in creating meeting-places (cf. Gieryn 2002), although the existence of such places did not automatically create these interactions. This resonates with ideas of inclusion and exclusion, which can be found, for instance, in the work of Lamont and Molnár (2002), which basically say that places include some people while simultaneously excluding others. Although according to Peace et al. (2011) and Rowles (1993) the function or meaning of place is more important than a particular, unique place, our findings show that many older adults attach to particular places because of their unique meaning. In exploring the importance of communities and wondering whether communities of interest can substitute communities of place, Means and Evans (2012) argued that interests cannot simply replace place, but need to exist beside place. This argument is confirmed by the way older men in our study talked about how they missed the companionship they experienced when working in the mines, which lasted for years after the mines were closed, as their co-workers did initially continue to live in the neighbourhood they shared, showing the importance of place for these communities.

Places are meaningful because they create interactions, but these interactions depend on the availability of space and on the interpretation of this space as a possible enabler of interactions. Our study reveals how differently the same place can be experienced by different people, how expectations vary, and how expectations of places do not necessarily guarantee spaces will be used and become meaningful places for social interactions. The private-public meeting-places older people talked about all already existed, and some people only use a place if they know they will not be the first user (e.g. the woman who waits for other pétanque spectators to arrive). Others expect to be invited to participate, and some do not consider these places to be a valid substitute for social interactions in private.

Local characteristics played a role in how developers gave meaning to the role of place in 'making ageing-in-place', but did not seem to hinder their visions of lifecycle-robust places. As users of these 'lifecycle-robust neighbourhoods under development', older people expressed their ideas about their own places differently. They shared stories about how they experience places. Some older people talked about how there should be more suitable homes and convenient places (shops, care and welfare facilities) in the environment, but their narratives mainly revealed how personal their experiences of places are. Each older person attached to specific places but experienced his or her place in their own way.

Place attachment is based on a personal connection, such as friendly neighbours, relatives, a (deceased) partner, or because of treasured past memories, often related to personal relationships. Their stories revealed an emotional attachment to place, real connections made via connections with other people. While some users had 
ideas about improvements, they often also added 'you need to adjust', because places are the way they are. Some will choose to remain in-place even if there are places available that they consider more suitable for their health, for instance because they are located close to informal caregivers, stores and services. In a similar way as described by Joseph and Chalmers (1995) some people prefer 'a lifetime of experience' over the best suitable place for care or over what might be better, or over what in pragmatic approaches might be considered better or more realistic options (cf. Peace et al. 2011). Sometimes new places offer new experiences, when people are, as Rowles (1993) described, able to use strategies to connect with other people and make themselves at homes, other times new places confirm feelings of loss ('the good old days').

In constructing 'lifecycle-robust neighbourhoods', developers seemed to have forgotten to ask what place means for the older people who lived there, which is interesting when considering that Gieryn (2000) argued how places are constructed through people's interpretations. Older people attach to place for individual reasons, and when relaying their experiences they all referred to the three features summarised by Gieryn (200o) that make places meaningful: the geographic location of home and 'things' in the neighbourhood, the physicality of the place and they attached to place through experiences that held meaning for them. This attachment is affected sometimes by Joseph and Chalmers' 'lifetime of experience', other times by experiences of other places in the past as well. Each individual attached meaning in his or her own way, although they are often convinced that they just 'need to adapt'.

Places gave people feelings of being acknowledged or ignored, but also helped to protect their privateness (offering opportunities for meetings in safe and private environments). In fact, people experienced Gardner's (2011) 'third places' within their own private spaces and environments. By creating opportunities to feel at home in places, it excluded other people, who longed for the realisation of another ideal of neighbourliness. One person can interpret a place as age-friendly, while their neighbour thinks it is not. Gieryn (2002) mentioned buildings play an important role, when interpreting places as being meaningful; they can affect the way people feel in or out of place. The things people experience as important make these places meaningful and enable older people's positive experiences of ageing-in-place. They often concentrate on the 'ability to live in one's own home and community safely, independently and comfortably...' (Satariano, Scharlach and Lindeman 2014, p. 1374). Older people attach to places, but also cherish opportunities to move if desired. Conceptions of 'lifelong communities' differ and are based on individual experience, which makes developers' ideas of one definable place based on a building with a few basic elements challenging. We therefore argue that they should genuinely listen to the experiences of older people living in these places, as the success, of a concept such as, lifecycle-robustness is related to the experiences of its users. 
This study is obviously situated in a particular policy-practice setting that we chose to examine, but as it demonstrates that situatedness and ideas about an ideal environment for ageing-in-place are intermingled with cultural aspects (e.g. illuminated by the ideas on private-public meetings); we would expect similar experiences in other places. During interviews, in observations and during focus groups we experienced how interviewees found it difficult to concretise a visual conceptualisation of ageing-in-place, often only emphasising particular elements. They mentioned points of improvement, but found it difficult to demonstrate what makes a place good. Methods from visual sociology might help to overcome this obstruction, and therefore we organised a photovoice project as a follow-up to this study (Wang and Burris 1997). We presume photovoice will help to facilitate a conversation about lifecycle-robust conceptualisations between developers and users. This seems necessary because we experienced how older adults' voices and experiences were not properly heard by policy makers, directors and representatives of older people when developing a new ageing-in-place policy.

\section{Acknowledgments}

The authors thank the respondents for their willingness to participate in interviews, focus groups and observations for this study, in particular all older adults who were willing to share their personal stories on ageing-in-place. The authors also thank everyone who commented on earlier drafts of this paper. The work was supported by ZonMw - the Netherlands Organisation for Health Research and Development (grant number 314070201, 2011). Although no formal ethical approval was required for this study, we did follow the ethical guidelines in anthropological research. The main researcher introduced herself and explained the purpose of the study and of the specific activity at the beginning of each independent research activity. It was explained to participants that participation during all research activities was voluntarily and anonymous, participants were allowed to end their participation at any moment without further explanation. Verbal consent was asked for all voice recordings made and participants were allowed to reflect on preliminary findings afterwards. 


\section{References}

Alvesson, M. and Sköldberg, K., 2009. Reflexive Methodology: New Vistas for Qualitative Research. Sage: London.

Bond, J., Peace, S., Dittmann-Kohli, F. and Westerhof, G. (Eds.), 2007. Ageing in society: European perspectives on gerontology. Sage Publications Ltd.: London.

Boudiny, K., 2013. 'Active ageing': from empty rhetoric to effective policy tool. Ageing \& Society, 33, 06, 1077-1098. doi: https://doi.org/10.1017/So144686X1200030X

Buffel, T, Donder, L. de, Phillipson, C., Dury, S., Witte, N. de and Verté, D., 2014. Social participation among older adults living in medium-sized cities in Belgium: the role of neighbourhood perceptions. Health Promotion International, 29, 04, 655-668. doi: 10.1093/heapro/datoo9

Buffel, T., Phillipson, C. and Scharf, T., 2013. Experiences of neighbourhood exclusion and inclusion among older people living in deprived inner-city areas in Belgium and England. Ageing \& Society, 33, o1, 89-109. http://dx.doi.org/10.1017/ So144686X12000542

Bülow, M. and Söderqvist, T., 2014. Successful ageing: A historical overview and critical analysis of a successful concept. Journal of Aging Studies, 31, 139-149.

doi:https://doi.org/10.1016/j.jaging.2014.08.009

Coleman, T. and Kearns, R., 2015. The role of bluespaces in experiencing place, aging and wellbeing: Insights from Waiheke Island, New Zealand. Health \& Place, 35, 206-217. doi:http://dx.doi.org/10.1016/j.healthplace.2014.09.016

Cresswell, T., 2004. Place: A Short Introduction. Blackwell Publishing: Oxford.

Dahlin-Ivanoff, S. Haak, M., Fänge, A. and Iwarsson, S., 2007. The multiple meaning of home as experienced by very old Swedish people. Scandinavian journal of occupational therapy, 14, o1, 25-32. doi:10.1080/11038120601151714

Depp, C. and Jeste, D., 2006. Definitions and predictors of successful aging: a comprehensive review of larger quantitative studies. The American Journal of Geriatric Psychiatry, 14, o1, 6-20. doi:https://doi.org/10.1097/o1.JGP.oooo192501.03069. bc.

Duff, C., 2010. On the role of affect and practice in the production of place. Environment and planning. D, Society and space, 28, 05, 881-95. doi:https://doi.org/10.1068/d16209

Eriksson, M. and Emmelin, M., 2013. What constitutes a health-enabling neighborhood? A grounded theory situational analysis addressing the significance of social capital and gender. Social Science \& Medicine, 97, 112-123. doi:https:// doi.org/10.1016/j.socscimed.2013.08.008

Gardner, P., 2011. Natural neighborhood networks-Important social networks in the lives of older adults aging in place. Journal of aging studies, 25, 03, 263-271. doi: https://doi.org/10.1016/j.jaging.2011.03.007

Gieryn, T., 200o. A space for place in sociology. Annual review of sociology, 26, o1, 463-496. doi:10.1145/annurev.soc.26.1463

Gieryn, T., 2002. What buildings do. Theory and Society. 31, 01, 35-74. doi:10.1023/A:1014404201290

Hacker, B., 2009. Hybridization instead of clustering: Transformation processes of welfare policies in Central and Eastern Europe. Social Policy \& Administration, 43, 02, 152-169. doi:10.1111/j.1467-9515.2009.00653.x

Heathcote, E., 2007. Old age and the city. BMJ, 343,1-3. doi:10.1136/bmj.d4418

Hillcoat-Nallétamby, S. and Ogg, J., 2014. Moving beyond 'ageing in place': older people's dislikes about their home and neighbourhood environments as a motive for wishing to move. Ageing \& Society, 34,10, 1771-1796. doi: https://doi. org/10.1017/So144686X13000482

Jacobs, J., 1992 [1961]. The Death and Life of Great American Cities. Vintage Books Edition: New York.

Joseph, A. and Chalmers, A., 1995. Growing old in place: a view from rural New Zealand. Health \& Place, 1, 02, 79-9o. doi:https://doi.org/10.1016/1353-8292(95)ooo11-A

Joseph, L., 2008. Finding space beyond variables: An analytical review of urban space and social inequalities. Spaces for Difference: An Interdisciplinary Journal, 1, 02, 29-50.

Keyes, L., Phillips, D.R., Sterling, E., Manegdeg, T., Kelly, M., Trimble, G. and Mayerik, C., 2014. Transforming the way we live together: A model to move communities from policy to implementation. Journal of aging \& social policy, 26, 1-2, 117-130.

doi:http://dx.doi.org/10.108o/o8959420.2014.854646

Kohon, J. and Carder, P., 2014. Exploring identity and aging: Auto-photography and narratives of low income older adults. Journal of Aging Studies, 30, 47-55. doi:https://doi.org/10.1016/j.jaging.2014.02.006

Kroneman, M., Cardol, M. and Friele, R., 2012. (De)centralization of social support in six Western European countries. Health policy, 106, o1, 76-87.

doi:https://doi.org/10.1016/j.healthpol.2012.03.003 
Lager, D., 2015. Perspectives on ageing in place: Older adults' experiences of everyday life in urban neighbourhoods. University of Groningen: Groningen.

Lamont, M. and Molnár, V., 2002. The study of boundaries in the social sciences. Annual Review of Sociology, 28, 167-195. doi: https://doi.org/10.1146/annurev.soc.28.110601.141107

Lassen, A. and Moreira, T., 2014. Unmaking old age: Political and cognitive formats of active ageing. Journal of Aging Studies, 30, 33-46. doi: https://doi.org/10.1016/j.jaging.2014.03.004

Lawton, M. and Nahemow, L., 1973. Ecology and the aging process. In Eisdorfer, C. And Lawton M. (Eds.), The psychology of Adult Development and Ageing. American Pscyhological Assocation, Washington DC, 619-674.

Lui, C., Everingham, J., Warburton, J., Cuthill, M. and Bartlett, H., 2009. What makes a community age-friendly: A review of international literature. Australasian Journal on Ageing, 28, 03, 116-121. doi:10.1111/j.1741-6612.2009.00355.x

Means, R. and Evans, S., 2012. Communities of place and communities of interest? An exploration of their changing role in later life. Ageing \& Society, 32, 08, 1300-1318. doi:https://doi.org/10.1017/So144686X1100o961

Menec, V., Means, R., Keating, N., Parkhurst, G. and Eales, J., 2011. Conceptualizing age-friendly communities. Canadian Journal on Aging/La Revue canadienne du vieillissement, 30, 03, 479-493. doi: https://doi.org/10.1017/ So714980811000237

Menec, V., Hutton, L., Newall, N., Nowicki, S., Spina, J. and Veselyuk, D., 2015. How 'age-friendly' are rural communities and what community characteristics are related to age-friendliness? The case of rural Manitoba, Canada. Ageing \& Society, 35, 01, 203-223. doi:https://doi.org/10.1017/So144686X13000627

Milligan, C., 2012. There's No Place Like Home: Place and Care in an Ageing Society. Ashgate Publishing, Ltd.: Farnham

Morenoff, J. and Lynch, J., 2004. What makes a place healthy? Neighborhood influences on racial/ethnic disparities in health over the life course. In: National Research Council (US) Panel on Race, Ethnicity, and Health in Later Life, Anderson, N., Bulatao, R. and Cohen, B. (Eds.). Critical perspectives on racial and ethnic differences in health in late life. National Academies Press, Washington DC, 406-449.

Newman, J. and Tonkens, E., 2011. Participation, responsibility and choice: Summoning the active citizen in western European welfare states. Amsterdam University Press: Amsterdam.

Nosraty, L., Jylhä, M., Raittila, T. and Lumme-Sandt, K., 2015. Perceptions by the oldest old of successful aging, Vitality 90+ Study. Journal of Aging Studies, 32, 50-58. doi:https://doi.org/10.1016/j.jaging.2015.01.002

Nowak, S., Molema, C., Baan, C., Oosting, S., Vaandrager, L., Hop, P. and Bruin, S. de, 2015. Decentralisation of longterm care in the Netherlands: the case of day care at green care farms for people with dementia. Ageing \& Society, $35,04,704-724$. doi:https://doi.org/10.1017/So144686X13000937

Olsberg, D. and Winters, M., 2005. Ageing in place: intergenerational and intrafamilial housing transfers and shifts in later life. Australian Housing and Urban Research Institute, UNSW-UWS Research Centre.

Oudshoorn, N. and Pinch, T., 2003. How users matter: the co-construction of users and technology (inside technology). The MIT Press: Cambridge, Massachusetts.

Peace, S., Holland, C. and Kellaher, L., 2011. 'Option recognition' in later life: variations in ageing in place. Ageing \& Society, 31, 05, 734-57. doi:https://doi.org/10.1017/So144686X10001157

Phillipson, C., 2007. The 'elected' and the 'excluded': sociological perspectives on the experience of place and community in old age. Ageing \& Society, 27, 03, 321-342. doi:https://doi.org/10.1017/So144686Xo6005629

Plouffe, L. and Kalache, A., 2010. Towards global age-friendly cities: determining urban features that promote active aging. Journal of urban health, 87, 05, 733-739. doi:10.1007/s11524-010-9466-o

Roberts, C. and Mort, M., 2009. Reshaping what counts as care: Older people, work and new technologies. ALTER-European Journal of Disability Research/Revue Européenne de Recherche sur le Handicap, 3, 02, 138-158. doi:https:// doi.org/10.1016/j.alter.2009.01.004

Rowles, G., 1983. Place and personal identity in old age: Observations from Appalachia. Journal of Environmental Psychology, 3, 04, 299-313.

Rowles, G., 1993. Evolving images of place in aging and 'aging in place'. Generations, 17, 2, 65-70.

Rubinstein, R. and Parmelee, P., 1992. Attachment to place and the representation of the life course by the elderly. In Altman, I. and Low, S. (Eds.), Place Attachment. Plenum Press: New York and London, 139-163. doi:10.1007/978-14684-8753-4-7

Satariano, W., Scharlach, A. and Lindeman, D., 2014. Aging, Place, and Technology Toward Improving Access and Wellness 
in Older Populations. Journal of Aging and Health, 26, o8, 1373-1389. doi:https://doi.org/10.1177/o898264314543470 Singh, N., 2008. Decentralization and public delivery of health care services in India. Health Affairs, 27, 04, 991-1001. doi: 10.1377/hlthaff.27.4.991

Sixsmith, A. and Sixsmith, J., 2008. Ageing in place in the United Kingdom. Ageing International, 32, 03, 219-235. doi:10.1007/s12126-008-9019-y

Sixsmith, J., Sixsmith, A., Malmgren Fänged, A., Naumanne, D., Kucseraf, C., Tomsone, S., Haak, M., Dahlin-Ivanoff, S. and Woolrych, R., 2014. Healthy ageing and home: The perspectives of very old people in five European countries. Social Science \& Medicine, 106, 1-9. doi:http://dx.doi.org/10.1016/j.socscimed.2014.01.006

Thrift, N., 2008. Space: the fundamental stuff of geography. In: Clifford, N., Holloway, S., Rice, S. and Valentine, G. (Eds.). Key Concepts in Geography. Sage: London, 95-107.

Trell, E. and Hoven, B. van, 2010. Making sense of place: exploring creative and (inter)active research methods with young people. Fennia-International Journal of Geography, 188, o1, 91-104.

Walker, A., 2008. Commentary: The emergence and application of active aging in Europe. Journal of Aging \& Social Policy, 21, o1, 75-93. http://dx.doi.org/10.1080/08959420802529986

Walton, E., 2014. Vital places: Facilitators of behavioral and social health mechanisms in low-income neighborhoods. Social Science \& Medicine, 122, 1-12. doi:https://doi.org/10.1016/j.socscimed.2014.10.011

Wang, C. and Burris, M., 1997. Photovoice: Concept, methodology, and use for participatory needs assessment. Health Education \& Behavior, 24, 03, 369-387. doi: 0.1177/109019819702400309

Werlen, B., 1993. Society action and space: an alternative human geography. Routledge: London.

Wiles, J., Leibing, A., Guberman, N., Reeve, J. and Allen, R., 2011. The meaning of “ageing in place" to older people. The gerontologist, 52, 3, 357-366. doi:http://dx.doi.org/10.1017/So144686X12000621

Winterton, R. and Warburton, J., 2011. Models of care for socially isolated older rural carers: barriers and implications. Rural and remote health, 11, 03, 1678.

World Health Organization, 2002. Active Ageing: A Policy Framework. World Health Organization, Geneva. Available online at

http://apps.who.int/iris/bitstream/10665/67215/1/WHO_NMH_NPH_02.8.pdf [Accessed 29 October 2015].

World Health Organization, 2007. Global Age-friendly Cities: A Guide. World Health Organization: Geneva. Available online at http://www.who.int/ageing/publications/Global_age_friendly_cities_Guide_English.pdf [Accessed 29 October 2015].

Zeitler, E. and Buys, L., 2015. Mobility and out-of-home activities of older people living in suburban environments: 'Because I'm a driver, I don't have a problem'. Ageing \& Society, 35, 04, 785-808. doi: https://doi.org/10.1017/So144686X13001086 



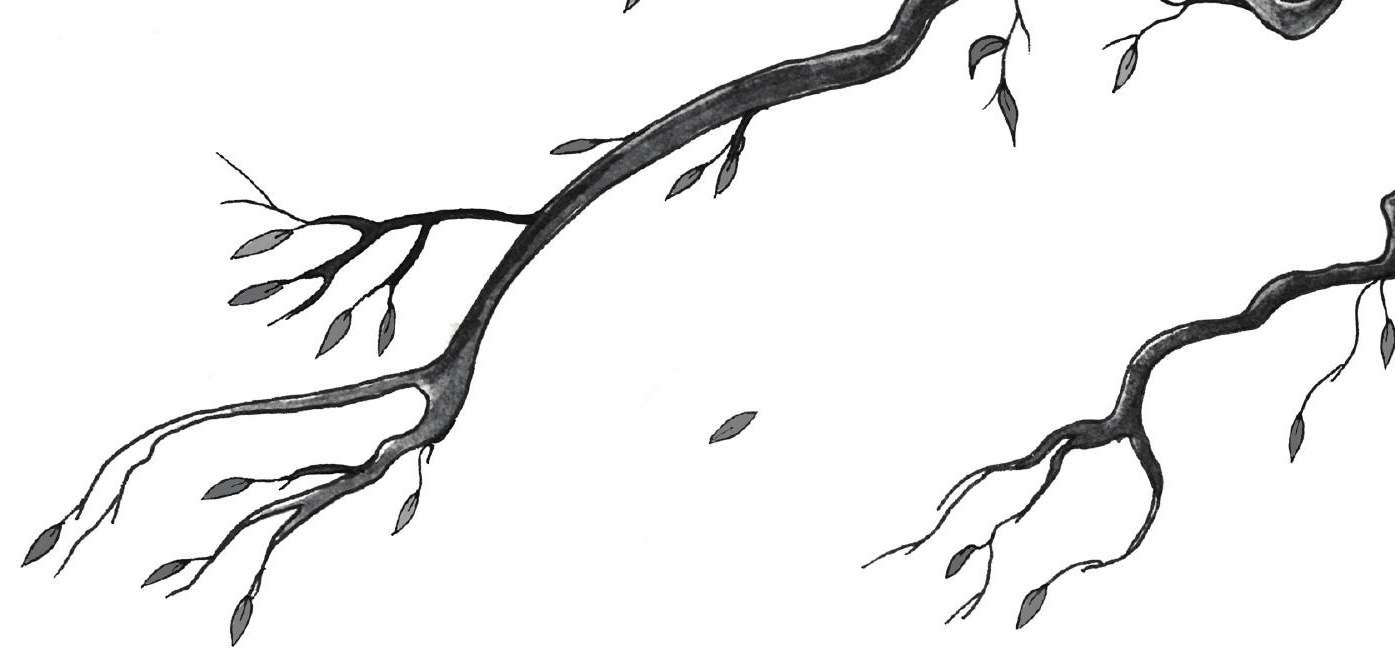

\section{Chapter 5}

\section{Photovoicing the neighbourhood}

Understanding the situated meaning of intangible places for ageing-in-place

\section{Published as:}

Susan van Hees, Klasien Horstman, Maria Jansen and Dirk Ruwaard, 2017. Photovoicing the neighbourhood: understanding the situated meaning of intangible places for ageing-in-place. Health \& Place, 48C, 11-19.

doi: https://doi.org/10.1016/j.healthplace.2017.08.007 


\section{Abstract}

Ageing-in-place is considered important for the health of older adults. In this paper, inspired by a constructivist approach to ageing-in-place, we unravel professionals' and older adults' constructions of ageing-in-place. Their perspectives are studied in relation to a policy that aims to develop so-called 'lifecycle-robust neighbourhoods' in the southern part of the Netherlands. We conducted a photovoice study in which 18 older adults ( $70-85$ years) living independently and 14 professionals (social workers, housing consultants, neighbourhood managers and community workers) were asked to photograph and discuss the places they consider important for ageing-in-place. Based on a theoretically informed analysis of the data, we found that professionals primarily consider objective characteristics of neighbourhoods such as access to amenities, mobility and meeting places as important enablers for older adults to remain living independently. Analysis of older adults' photographs and stories show that they associate ageing-in-place with specific lived experiences and attachments to specific, intangible and memory-laden public places. We conclude that exploring these experiences helps to increase current knowledge about place attachment in old age. 


\subsection{Introduction}

Place is considered increasingly important in ageing policies of Western welfare states. The World Health Organization (WHO, 2015) advises governments to encourage the development of age-friendly places, described as places that facilitate a healthy lifestyle, social participation and security. According to the WHO, providing age-friendly places will help people to age actively and thereby enhance their quality of life. Governments choose these approaches to confront the challenges of rapidly ageing societies and increasing healthcare expenditures (Menec et al., 2015). By increasing opportunities to remain living independently for longer, governments aim for people to remain healthier for longer. Although ageing-in-place is presented as a solution for governmental challenges, a great variety of studies on this topic over the past decades has demonstrated the complexities of the ageing-in-place processes (Andrews et al. 2007; Wiles et al. 2012). We studied the meanings of ageing-in-place in the development of so-called 'lifecycle-robust' neighbourhoods. These were introduced in a Dutch policy initiative, as a response to demographic trends and rising costs of healthcare. Although the term 'lifecycle-robust' appears to be synonymous with the notion of 'age-friendly', and the current stress is on enabling ageing-in-place, the idea of lifecycle-robust neighbourhoods is that they enable people of all ages from cradle to grave - to live there.

Studying the meaning of ageing-in-place, Wiles et al. (2012) demonstrate how ageing-in-place ideals as articulated in policy papers differ from those expressed by older adults. They argue that the phrase 'ageing-in-place' is not as fixed or transparent as assumed in policies. Most older people were not familiar with the term and some even had negative associations, like "being trapped" in a place without the ability to move' (p. 360). Buffel, Phillipson and Scharf (2013) and Van Hees, Horstman, Jansen and Ruwaard (2017) observed similar differences between policies and everyday practices. According to these authors, older adults' experiences of place were not heard by policymakers, and those living independently experienced difficulties in explaining why places matter to them. Buffel et al. (2014) concluded that older adults often abstain from participatory approaches concerning housing issues, neighbourhood design and planning, because they feel their voice is being neglected on these topics. Kenkmann et al. (2017) compared perspectives of older adults and care professionals in care homes and found that professionals construct these homes primarily as workplaces, while the older adults who live there construct them as their homes. In addition, older adults expressed feeling more at home when they have greater autonomy and choice in how to use space, while professionals believed that elements such as order and cleanliness would contribute to a 'homely' environment. In studies exploring meanings of ageing-in-place among policymakers, professionals and older adults, very different perspectives and experiences come to the foreground. 
Many studies on ageing-in-place already emphasise the importance of older adults' voices and discuss specific meanings given by them to places relating to place attachment versus barriers created by places (e.g. Kohon and Carder 2014; Novek and Menec 2014). Elements of ageing-in-place that are generally considered important are mobility, social relations, and the environment as enablers of mobility and social relations (e.g. the importance of benches on which to rest and as enablers of social interactions) (Gardner 2011; Menec et al. 2011; Ottoni et al. 2016; Vogelsang 2016). We want to advance the investigation of ageing-in-place by not only focusing on which constraints and regulators older adults recognise in their environment, but by also exploring how their constructions of ageing-in-place connect or interact with those of local professionals (social workers, housing consultants, neighbourhood managers and community workers) who translate ageing-in-place policies into daily practices. We therefore chose photovoice as an alternative method, to explore untold stories about place and to obtain insights into the experiences of older adults. Photovoice provided us with an opportunity to explore how older adults and professionals both construct ageing-in-place. It helped unravel lived experiences and stories that, according to Coleman and Kearns (2015), remain untold when relying only on interviews, because: '... "ageing-in-place" is not only a demographic or political issue but also an emotional and lived experience that inherently involves the broader place of residence'. In interviews, people expressed difficulties in elaborating why and how places matter to them. Photovoice provides participants with an opportunity to show instead of tell.

Below, we first sketch the theoretical background to this study and explain the constructivist approach used, which frames ageing-in-place as the situated dynamics of place attachment and sense of place. We then describe the methodology used in this ethnographic study and introduce our case, which involves the introduction of lifecycle-robust neighbourhoods, after which we present a visual analysis. Finally, we reflect upon the ways in which older adults and professionals visualise and share their perspectives, and discuss how these relate to prior discussions of place attachment and ageing-in-place.

\subsection{Theorising ageing and place}

Ageing-in-place has been thoroughly investigated and discussed within geography, public health and gerontology during the past decades. This notion closely relates to place attachment, which is elaborated below. First, we discuss two major approaches used to explore how older adults relate to place: (a) an empirical-rationalist approach and (b) a social-constructivist approach. Scholars using the first approach often draw on an ecological perspective (Lawton and Nahemow 1973), focusing on an environment-person fit. They identify characteristics of place that optimise individual functioning. Tangible characteristics, such as proximity and access to amenities, 
mobility opportunities, security and attachment through personal items are demonstrated as important for ageing-in-place (e.g. Dahlin-Ivanoff et al. 2007; Eriksson and Emmelin 2013; Hillcoat-Nallétamby and Ogg 2014; Ottoni et al. 2016; Rowles 1983, 1993; Peace, Holland and Kellaher 2011; Plouffe and Kalache 2010).

However, while 'objective' but static demographic, geographical and historical characteristics provide insight into meanings of place, this approach does not help to understand what specifically makes place meaningful for people when living there. In our study, inspired by Science and Technology Studies (STS) we draw on the social-constructivist approach that was introduced to understand how places become meaningful (Andrews et al. 2013; Gieryn 2000; Milligan 1998). This approach considers the meaning of place not as a sum of objective characteristics, but as a dynamic process in which meaning construction is situated and contingent upon historically shaped experiences. Place is not considered to be a static context, but an integral and meaningful part of peoples' social lives that is constructed by past experiences and desired futures (Andrews et al. 2007). STS is a discipline that studies how science, technology and society interact based on the idea that there is no activity that is not technologically mediated (Hackett, Amsterdamska, Lynch and Wajcman 2008). Places can be considered as such mediating technologies when they affect society and invoke relations between people using or relating to them. Accessibility, design and the stories people share about a place create meaning. A pub needs visitors, but subsequently visitors interpret the pub based on their experiences and through other users. Via this example, Gieryn (2000) explains how one pub had become a symbol for class distinction as it attracted the 'moneyed'. A constructivist approach to place points to the importance, not of objective characteristics as such, but to how places generate experiences, and how they enable people to connect to other people and thereby to place.

Constructivist studies first nuanced the idea that older adults all have a desire to remain in-place and demonstrated that ageing-in-place is also about agency and choice in how to use place (Van Hoven and Douma 2012). The maintenance of autonomy, independence, identity and feelings of belonging is crucial (Coleman, Kearns and Wiles 2016: Heatwole-Shank and Cutchin 2016; Peace, Holland and Kellaher 2011; Van Hoven and Douma 2012). Stones and Gullifer (2016) studied the refusal of very old people to leave their homes. They found that being able to maintain one's home is not only important because the physical setting represents independence, but also because of an attachment to 'things, experiences, memories and expectations embodied therein' (p. 453). Through these experiences people develop collective identities, memories and histories, which create feelings of belonging and place attachment. This adds to Rowles's (1983) argument that place attachment is constructed by how people in everyday life talk about their life experiences in their environment. He argues that environments embody such experiences and can be called 'incident places'. In her study of collective and relational experiences of place, Degnen (2015) explains that by sharing memories and experiences of place the meaning of place continually changes. 
Social-constructivist studies on meanings of ageing-in-place demonstrate how not only the home, but also places outside the home such as green (and blue) spaces, historical buildings, monuments, and opportunities for social interactions affect place

attachment (Coleman and Kearns 2015; Coleman, Kearns and Wiles 2016; Gardner 2011; Wiles et al. 2012). Gardner (2011) studied how such public places can create opportunities to connect, to maintain connections and how places subsequently create feelings of belonging and a sense of community. In addition to home (first places) and work (second places), Gardner recognises the importance of so-called third places, which refer to somewhat open, public places (such as pavements, parks and squares) and public buildings (such as grocery stores, libraries, bars, restaurants and churches). These are places that offer opportunities for people to interact in diverse ways. Apparently, the simple everyday interactions invited by public places, such as observing, calling or waving to a neighbour, are of special importance in constructions of place attachment. In addition, Coleman and Kearns (2015) demonstrate how places do not necessarily need to be actively used to be meaningful. In their study of what ageing-in-place means for older adults living on an island, they give an example of an older woman who explains how she gets pleasure, meaning and satisfaction in her daily life from the view from her home. A man living on the same island has the opposite experience; the island makes him feel as if he is in exile. In literature about safe neighbourhoods, Blokland stressed the importance of public places to stimulate 'public familiarity' among 'familiar strangers' (Blokland 2009).

Here, we adopt a constructivist approach. Through photovoice we explore processes of meaning construction with respect to lifecycle-robust neighbourhoods for older adults. We aim to give them a voice in relation to the experiences of professionals who work in these neighbourhoods and aim to enable ageing-in-place. We advance our understanding of ageing-in-place not only by presenting yet untold stories and experiences, but also by exploring how third places relate to meanings of place.

\subsection{Materials and methods}

This paper draws on a photovoice study, a method used in the social sciences and based on the idea that photographs add new (visual) information about our society because they induce alternative modes of thought (Pink 2013). Using visual information to collect information in research, is considered an opportunity to 'give voice' to unique perspectives, experiences and meanings (Novek et al. 2012). Photographs (existing photographs, or photographs taken by researchers and/or participants) are considered visualisations of experiences and meanings given to objects (or places) by participants (Catalani and Minkler 2010; Lockett, Willis and Edwards 2005; Wang and Burris 1997; Wang and Redwood-Jones 2001). These are the main data according to which participants can share their stories. Most scholars ask participants to reflect 
upon the images in interviews (and sometimes in additional dialogue meetings) (Kohon and Carder 2014; Novek et al. 2012). The advantage of this method is that it allows for collection of data about how people interact with places without interfering in their daily structures and schemes, as participants can collect this material independently at a preferred time (Carpiano, 2009; Cele, 2006). In interviews, people are limited to talking about places, while the use of photographs can help to visualise their ideas (Carpiano, 2009). Photographs provide an opportunity for them to show why places are meaningful, while they also maintain agency over which experiences to share.

For this study we created a design that would not only help to give voice to older adults' meanings of place, but also enable a dialogue between older adults and local professionals about ageing-in-place. We assumed that residents know how best to improve the quality of life in their neighbourhoods, because they have what is called 'place-bound, experiential knowledge' (Henke and Gieryn 2008; Hergenrather et al. 2009). As the area in which our study was conducted is known for having a less educated population, we also expected that photovoice would improve opportunities for less articulate participants to express themselves. By facilitating dialogue meetings and by reporting on their experiences, we created an opportunity for people to share their perspectives. Dialogues induced insight with yet untold, unique meanings.

\section{Photovoice in Parkstad}

This photovoice study was conducted from July 2015 to November 2015 in Parkstad. Parkstad is an area in the southern part of the Netherlands with almost 250,000 inhabitants (in 2012), consisting of eight municipalities ranging from rural communities with less than 8,ooo inhabitants to urban areas with almost 88,ooo inhabitants. The area is known for its relatively abundant greenery (Parkstad means 'Park City'), its touristic attractiveness, a history of mining (several coal mines were operational in the post-World War II period), and its geographic position on the Dutch-German border. Parkstad is also known for its demographics (it has a rapidly ageing and shrinking population); the prospective impact on health has induced a sense of urgency in policymakers to change former policies. Our study was conducted in two separate neighbourhoods that were selected because the civil servants and neighbourhood managers employed there were seeking opportunities to increase the neighbourhood's experienced lifecycle-robustness. The policy in both neighbourhoods emphasises the encouragement of community-sense over changes in physical constructions. Furthermore, both neighbourhoods are situated directly on the Dutch-German border and consist of mainly Dutch residents; about 20 percent of the population are (mostly Western) immigrants. We chose neighbourhoods A and $B$ based on the assumption that experiences would be different in each because $\mathrm{A}$ is situated in a (more) urban area, while B spreads into a rural area. 
We asked 14 professionals and 18 older adults in A and B to photograph a maximum of 25 objects and places which they considered important with regard to ageing-in-place. All professionals worked on a daily basis in these neighbourhoods. Participating professionals informed older adults about the study, and invited them on behalf of the authors to participate. The professionals were instructed to ask people approximately 70 years and over who were living independently. We offered to provide customised solutions for people who were willing to participate, but felt unable to do so independently (owing to mobility limitations, for instance). Although this method of selection has led to purposive sampling, our inclusion coincidentally contained an equal gender mix, with all but one person (63 years) within an age range of $70-85$ years. We did not ask participants for specific personal details, but it became clear from their stories that a mix of people had been included, some of whom had lived in the same neighbourhood (or even the same home) for their entire lives, while others returned to their neighbourhood after retirement or because they were looking for more appropriate, age-friendly homes.

Because the policymakers in our case introduced lifecycle-robustness as a mediator of independently ageing-in-place while maintaining a good quality of life, we explained the concept of lifecycle-robust in an instructional meeting for the participants as 'places to age in a good way'. Participants were asked to keep a logbook in which they answered five questions per photograph: 1 . What is displayed in the photograph? 2. When was the photograph taken? 3. Where was the photograph taken? 4. Why do you consider this specific object or place important when you think about ageing in this neighbourhood? 5. What does the object or place you photographed mean for you personally? What does the photograph symbolise for you? All participants signed a consent form, granting permission to use all anonymised photographs taken for this study. After one to two weeks, the photographs and logbooks were collected. We then asked people to choose their three most important photographs that should definitely be used during a subsequent dialogue meeting. Based on which photographs participants prioritised and on recurring themes, we selected 50 (out of 218) photographs in A and 54 (out of 237) in B for the dialogue meetings. Because some older adults worked together, and some only participated in a dialogue meeting, this resulted in 13 photosets made by older adults (six in A and seven in B) and ten by professionals (six in A and four in B). Where necessary, we asked for additional information in a short interview (nine interviews with 11 older participants) when collecting the photographs, or in an e-mail or phone follow-up. Questions for clarification about the photosets of professionals were asked immediately after they were received (during a social neighbourhood meeting in A and via e-mail in B). We wanted to organise the dialogue meetings within two weeks after the photographs were collected, to ensure the stories behind the photographs were still vivid in people's minds. 
In the dialogue meetings participants reflected on the photographs, and shared the underlying stories in small groups of three to five participants (a mix of one or two professionals and three or four older adults). These dialogues were audio-recorded and transcribed verbatim. A researcher guided these dialogues (the first author and four colleagues). Each researcher was instructed beforehand to make sure each group discussed the photographs according to three questions: 1 . What do you like about living / working in this neighbourhood and what makes it age-friendly? 2. What do you like less about this neighbourhood? What makes this place not age-friendly? 3. Make a poster of how you would describe or visualise an ideal neighbourhood where you can 'age-in-place'. Participants were encouraged to use the photographs in their dialogues and to add a description or drawing of the stories they felt were not represented in the photographs. Eventually the groups shared their ideas by giving a short poster presentation.

Data-analysis commenced prior to the dialogue meeting. The trustworthiness of the study was increased by using multiple methods and sources, and by continually refining codes and categories during the process. A preliminary selection of topics was based on the photographs that were given priority by the participants in addition to the places or things that recurred in different photographs of different participants (e.g. nature, formal and informal meeting places, memories). After the dialogue meetings, the topics that were given the most attention during these meetings were discussed with the co-authors until consensus was reached. Corresponding journal entries, interview transcripts and transcripts of the dialogue meetings were examined and re-examined by the first author for these recurring topics. A photo-report including these topics was sent for verification to all participants, to ensure a reliable representation of their perspectives. To obtain a complete picture of the results, they were discussed with the co-authors and via this consensus-building the dependability of the results was increased.

\subsection{Constructions of ageing-in-place}

Our findings are presented in this section. Quotes from interviews and dialogue meetings are used to report participants' experiences, as we prioritise their voices and participation in the study. By using their own words, we strive for an honest representation of participants' experiences and perspectives, and consider this an opportunity to give them a broader voice. 


\section{Professionals' constructions of ageing-in-place}

Figure 1: 'a care zone' photographed by a housing professional

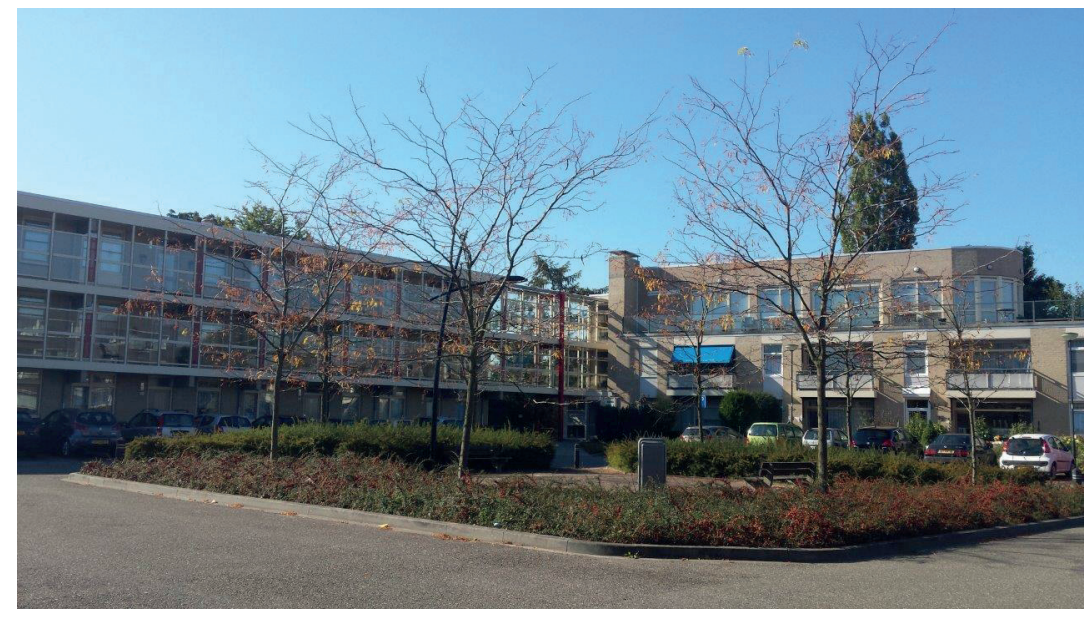

Figure 2: a bus stop photographed by a housing professional

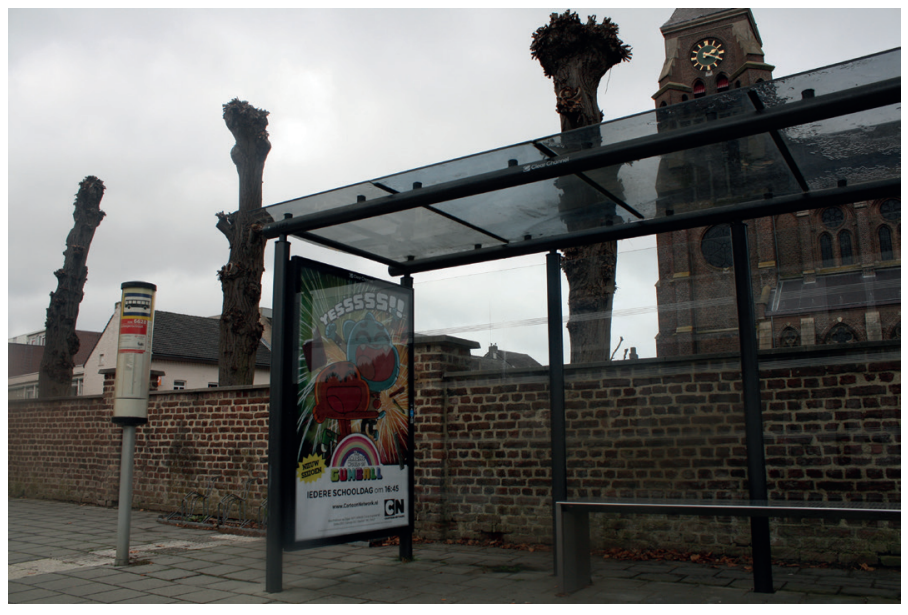

'I actually started looking at buildings [...] for instance this [Figure 1] "care zone" where actually all kinds of housing are available, independent living, assisted living, luxury homes, whatever you want, all care related [...] one care centre facilitates, in my view, an opportunity to remain living [independently] for longer', a housing professional explained during one of the dialogue meetings. How this professional gives meaning to his perspective on place for ageing-in-place exemplifies how many of the participating professionals give meaning to ageing-in-place. Photographs, 
logbook details and stories demonstrate that the professionals articulate a somewhat objectivist approach to ageing-in-place, mainly focusing on static elements in a neighbourhood which, from their perspective, address the needs of older adults. Most professionals photographed buildings and services they considered convenient for older adults, such as bakeries and butchers, grocery stores, bus stops and meeting centres for older adults and age-friendly houses or buildings. In talking about such places (Figures 1 and 2), professionals explained that they consider good housing facilities with transport, care, welfare, and daily needs services in the environment to be conducive to ageing-in-place. However, they simultaneously worried that these places are no longer sustainable, because, as a neighbourhood manager expressed: 'resources are severely cut, the trick is to maintain these services with constrained budgets. That is why we are trying to think of other possibilities, there is some tension there'. In other words, to enable ageing-in-place, professionals think age-friendly environments are needed, although there are no means to build them. Therefore, they aim for alternative solutions, for instance by promoting the use of public spaces in apartment buildings as meeting places for older adults.

Figure 3: a community centre, photographed by several professionals in neighbourhood A

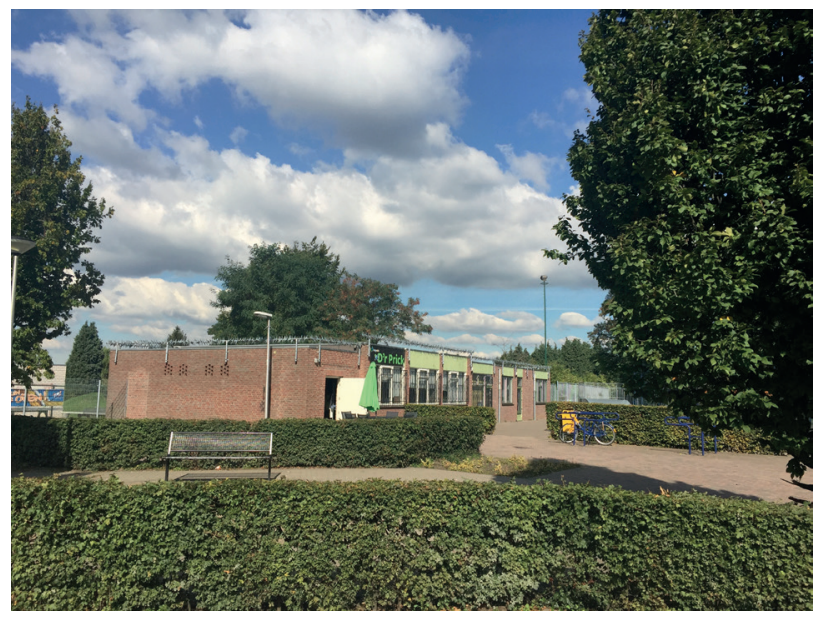

Professionals find communities and community centres important, as these are considered to increase social cohesion to encourage ageing-in-place. They argued that loneliness is an important issue obstructing ageing-in-place: 'because, in our social work, we see much loneliness. However, we do not see it literally. Because those people are not waiting at their front door, saying: we are lonely. [...] the way you [addressing older people attending the dialogue group] live, should be exemplary for others'. Some others agreed that increasing the role of the community would be 
a good strategy to redesign the neighbourhood as lifecycle-robust. They highlighted how they want to create centrally located community places, for instance by (re) making the community centre (Figure 3) into a formally organised meeting-place run by volunteers. By promoting informal help, professionals also aim to improve older people's coping mechanisms to address problems of loneliness. Another barrier for ageing-in-place that was stressed (in neighbourhood A in particular) was safety. Many places were photographed to symbolise dangerous situations, neglect or criminal behaviour (e.g. Figure 4).

Although professionals in both neighbourhoods mainly emphasised the importance of functional characteristics of a neighbourhood that are directly related to health (including social participation), they noticed that there may be other reasons for older adults to become attached to the environment. Some professionals in both places included historical buildings, monuments and parks in their photographs.

Figure 4: the assumed residence of a motorcycle club, photographed by civil servants

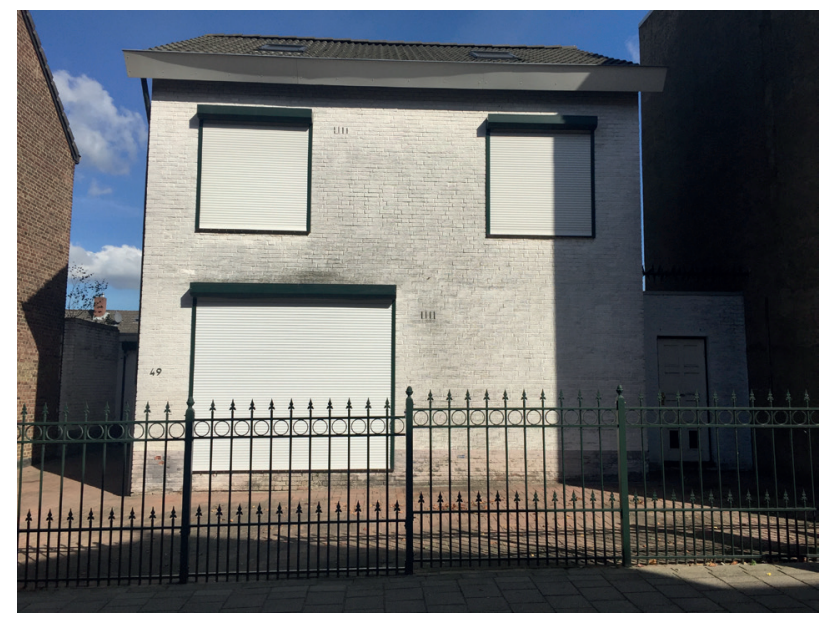

\section{Older adults' constructions of ageing-in-place}

Turning to perspectives of older adults demonstrates different ideas of place. The photographs and background stories below illustrate that older adults confirm a need for tangible characteristics in place, but that they give meaning and value to these places differently. When talking about photographs such as Figures 1 and 2, older adults confirmed that functionality is elementary for ageing-in-place, but they described functionality differently by emphasising how places are functional for them. During the dialogue meetings, it was explained that only a selection of all photographs would be discussed, but that participants could use other photographs that display similar places to those shown in their own photographs (e.g. 'a' bus 
stop could be represented as 'their' bus stop). However, it became clear that photographs of other participants that seemed similar did not represent similar stories for participants, and that they missed discussing their own specific photograph (or place). Instead of seeing such photographs as symbolic of characteristics that enable or constrain ageing-in-place, older adults talked about that specific bus stop they use when they need to go to the hospital, or that specific store they use to do their daily groceries. Participants living in more remote areas with fewer services in their immediate environment shared how they were afraid to lose these functional places, while people living in central areas photographed such places as useful places for themselves or their neighbours. At the same time, the people in remote areas were convinced that everyone will eventually find a solution when services disappear. One older man argued: 'If you have no help at home and need a bus [...], people [neighbours] will take care of it. In this place, nobody will die because he has no food. They [neighbours who need help] arrange it in another way, also if they need to get some money [the nearest cash dispenser is located in another village], they arrange something'. However, if you really are in need of care, he thinks that living in remote places might no longer be sufficient, owing to a lack of services: '[...] people should live independently for longer periods of time [...] which would be good, but some support has to be available'.

\section{Figure 5: a garden as a symbol of taking care of one's own neighbourhood,} photographed by an older woman

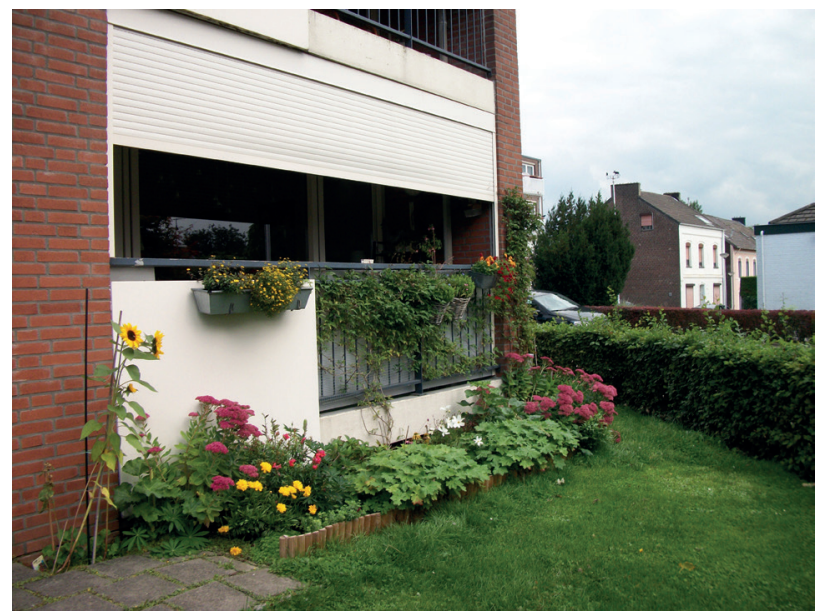

Besides functional places, older people photographed places that symbolise the value and meaning of their place's appearance for their environment. The photograph in Figure 5 was taken by a woman to demonstrate the beauty of the neighbourhood for herself and her husband, but also to demonstrate how residents care about and 
take care of their neighbourhood. She explained how they loved their own wellkept garden as well as the garden of their neighbour and that they thought it was important that people take care of their place. A man shared how, for him, the way neighbours take care of their place is meaningful in a similar way, but he feels powerless at not being able to improve how his neighbourhood looks: 'One small example, my wife cleans the pavement every day, she cleans the window frames. However, next to us, young people are living there, it [their pavement] is green as grass, they never do anything about it, maybe once a year'.

Older adults also mentioned the value of access to social activities and participation, either at formal meeting places, or in public places. Living in a more urban environment with access to a variety of facilities and services is appreciated by people living in age-friendly apartment buildings. Some mentioned how they like the specific meeting places for older people inside some apartment buildings (so-called living-room projects), but benches in a park or at a square, within walking distance (i.e. for some, this means within 100 metres) also represent opportunities for social participation. An older woman described her own apartment building as a good place to age, stating that it is essential 'that you own a real cosy home [...] where you can live safe and secure'. By safe and secure she meant that the place offers her additional security because neighbours can easily keep a close eye on her while strangers are kept out.

Interestingly, participants not only considered opportunities for social participation as important for themselves, but also mentioned the importance of spaces for younger people. A woman said that she did not like the vandalism in front of her apartment building, but that she thought this was partly due to a lack of meeting places for younger people: 'I think it is sad that these young people are driven away everywhere [...] yes, they create tumult, but that is not what this is about, I think they need to have a place where they can meet'. By driving the younger people away, an older man warns, the neighbourhood will lose diversity and cohesion: 'Our biggest problem is that the school has been closed [...] consequently, these children go to different places, different schools, they are no longer together [...] they make their own friends, sometimes they join the soccer club. [...] a school is very important for a neighbourhood in that sense'.

Although older adults' constructions of meaningful places are mostly related to their individual experiences and personal use, the characteristics they mentioned as elementary for a lifecycle-robust neighbourhood are largely the same: an attractive functional place that offers opportunities for social interaction. Although older adults confirmed the importance professionals ascribed to place in enabling social and physical activities, they also photographed other kinds of places and shared other kinds of stories, such as those about places they are attached to for reasons that are less tangible. In both neighbourhoods, participants shared photographs and stories about places they deemed specifically valuable for individual experiences. The photograph of a cemetery (Figure 6) exemplifies such a story. 
Figure 6: the community cemetery, photographed by an older woman to demonstrate the sense of community in the neighbourhood

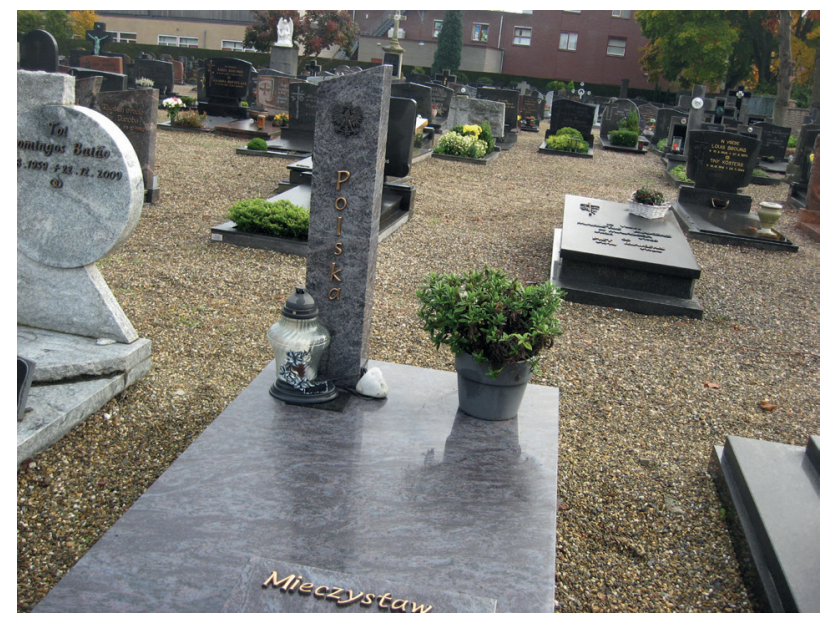

A woman photographed this place to illustrate how the community has always accepted foreigners, like her Polish husband who is buried there, and how immigrants and local citizens lived together harmoniously in the past. 'Next to my husband, there lies a Portuguese, and what I wanted to note is that during the war, and in the years after the war, when the Poles came and later those others as well, we have never had the idea he was approached wrongly. And that is what I wanted to prove with that'. For her the cemetery is not only a place to visit her late husband, but also a place that symbolises a sense of community.

Figure 7: the former location of a dancing bar, photographed by an older woman and an older man in neighbourhood $A$

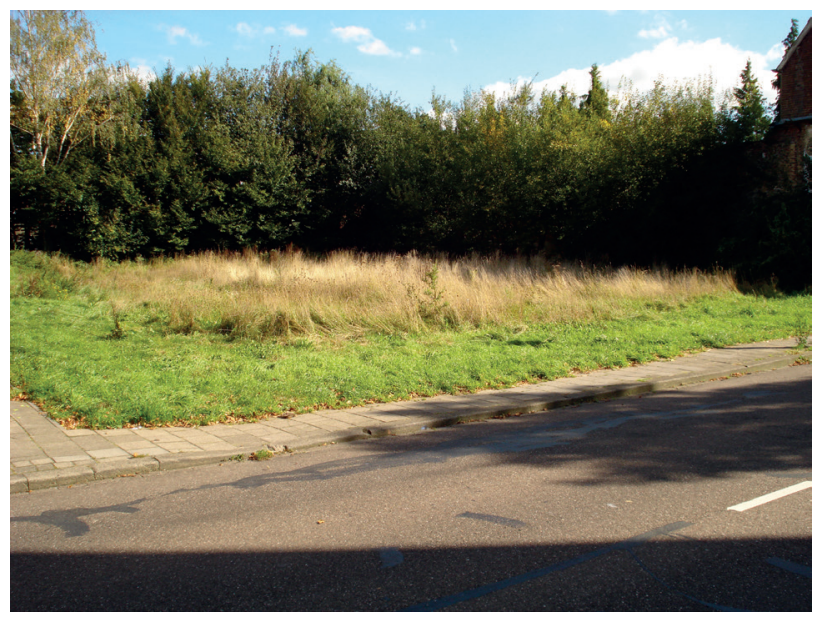


Another example of this is 'hidden' in Figure 7. An older man said: 'That place [...] a wilderness, [...] that is just filthy to see, but well, probably the municipality does not own the place. However, it could be a bit, that they just use a lawnmower one time, to make it look a bit more attractive. That is what I think, for many older people, that is a thorn in the side. In the past, there used to be a bar with a ballroom, there was a vibrant life, then, well, now they have demolished it [...]'. There used to be a famous dancing bar where many older adults went when they were younger; this was 'the' place to go and to meet other people. That this location is currently not taken care of is frustrating for some people who are nostalgic about the place. Similar (childhood) memories recurred in many photosets. People feel nostalgic or sad about these places because the original places have vanished or are neglected. When talking about this neglect, participants shared the sentiment that the value of their neighbourhood that they experience is not recognised by others.

According to older people, specific places contain untold (or unheard) memories and stories that professionals and policymakers are not aware of. An example is a large flat that is scheduled for demolition because it no longer fits current housing requirements but that is well known in the neighbourhood for its social cohesion. The flat has become a place that represents an ideal of qualitative ageing, as an older woman explained: 'That has been a big advantage for many people, that flat, if you think of the cohesion there, incredible. All those years [...] that flat, it was marvellous, the things that happened there'. When talking about these places, older adults emphasised that it might be good to retain the vividness of these places by maintaining these memories, even when reconstructing places.

\section{Older adults and professionals discussing ageing-in-place}

In dialogue meetings (Figures 8a and 8b), older people and professionals shared stories about their prioritised photographs, and added stories about other places they deemed important. A particularly important topic in neighbourhood A, but also discussed in neighbourhood $\mathrm{B}$, was safety and how it affects a desire to remain in a place (Figure 4). During the meetings professionals explained that there were safety issues in the neighbourhoods because their location on the Dutch-German border not only offers opportunities for leisure trips or to buy (cheaper) products, such as gas, but also for all kinds of criminality. Both residents and professionals mentioned that the neighbourhood attracts drug dealing and robbery. In picturing the criminal behaviour they were facing, older adults attempted to give nuance to its influence on their experience of place. An 85-year-old woman, who shared a story about how she stood up during an attempted robbery at the cemetery, stated: 'They will not chase me away'. Older adults explained that they attempt to look away and ignore the ugly parts of their neighbourhoods if possible. A woman photographed a building used for drugs across from her place, but when talking about the building and what she did not like about it, she tried to give nuance to her experience by saying that her 
windows are on the 'good' side of the building (where this building cannot be seen), which enables her to ignore the ugliness.

Figures 8a and $8 b$ : impressions of the dialogue meetings
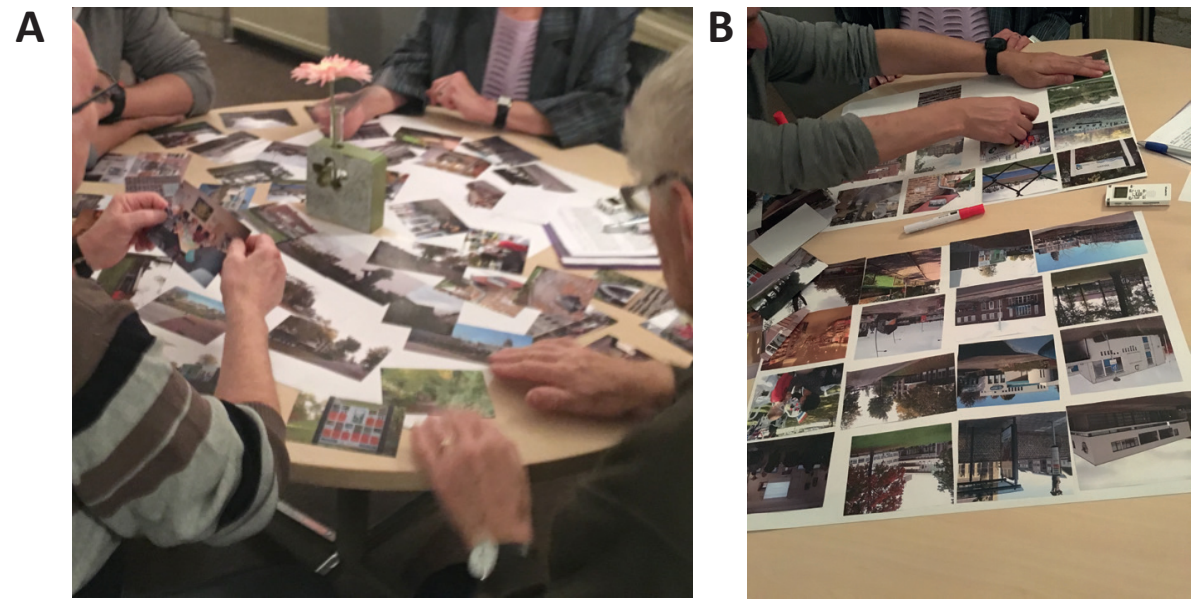

While professionals mainly emphasised the importance of places to enable physical and social activities for ageing-in-place, older adults shared many stories about other kinds of places.

Figures 9 and 10: a wooden witch photographed by one man and one woman and a path in the forest. The forest was part of four photo-sets in Neighbourhood B

\section{9}

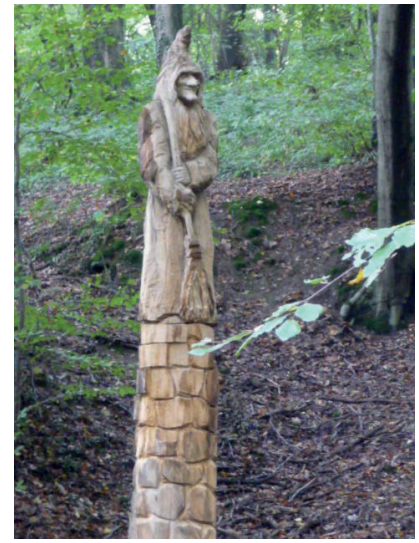

10

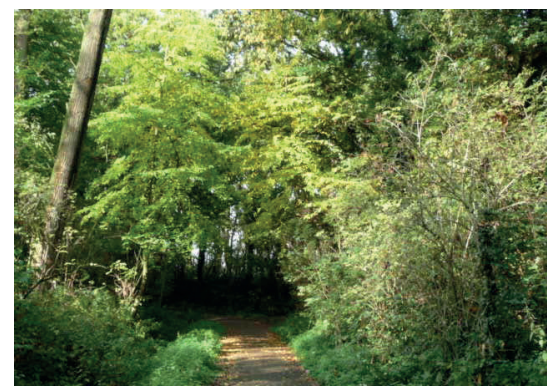


'That witch' an older woman said when she showed the photograph in Figure 9, 'has been carved out of one tree, and it is placed at the former location of an open-air theatre ... An explanation about the history of the theatre follows, which dates back decades. The wooden witch can be found in a forest that is attached to neighbourhood B. Professionals were surprised that older people consider this and similar places as important for ageing-in-place. When talking about Figure 10 a neighbourhood manager expressed wonder: 'I think it is remarkable, if we talk about lifecycle-robustness, that you take a photograph of [such a steep path], which you can hardly climb', while older adults argued that 'the environment, that is phenomenal' and appreciated that 'you see everybody there, walking, cycling'. Talking about their photographs confirmed that people become attached to places through experiences, memories and history. Monuments and monumental buildings or places like the wooden witch were portrayed many times, and participants explained how these places give their neighbourhood its own identity and acknowledge events that happened in the past (e.g. a mining history, World War II).

Despite barriers to ageing-in-place, older participants prefer their current place and even shared photographs of their own homes to emphasise its importance. Before the meeting, some older adults thought of it as an opportunity to share their feelings of displeasure with their municipality's policy. During the meetings, some topics of concern were shared, including unsafe traffic situations (a dangerous crosswalk), neglected vacant buildings, criminal activities and absence of services (public transport). However, in the main, participants shared how proud they were to be able to live where they live. Professionals, who identified with the municipal policy much more than older adults, shared their surprise about the resilience that was articulated in the experiences of older people, such as the stories about the forest path. 


\subsection{Discussion and conclusions}

In this study, we investigated the meanings of ageing-in-place by exploring professionals' and older adults' experiences of place using a photovoice method. In this section, we discuss our findings and demonstrate the usefulness of photovoice in exploring place experiences as well as the limitations and implications of the study. The neighbourhoods that we studied are the homes of the older people who participated. Professionals give meaning to ageing-in-place in these neighbourhoods based on their daily practices and professional experiences. These professional perspectives imply that ageing-in-place is based on tangible characteristics, which resonate with characteristics illuminated in previous studies (e.g. Coleman and Kearns 2015; Eriksson and Emmelin 2013; Gardner 2011; Ottoni et al. 2016; Plouffe and Kalache, 2010), but also with the ideas of policymakers that ageing-in-place can be constructed physically (Van Hees, Horstman, Jansen and Ruwaard 2017). These characteristics include the availability of age-friendly homes, proximity to facilities and services, transport opportunities and spatial opportunities for social participation and feelings of security. There were some differences between professionals' perspectives in both neighbourhoods; professionals in A stressed the lack of safety due to criminality, while in B disappearing services were emphasised. But in general, professionals' perspectives were similar and in line with current policies. However, their ideas about how older adults attach meaning to ageing-in-place differ from those of the older adults themselves.

Older adults consider these characteristics to be important, but when talking about their photographs and the places they think are important, their stories confirm the findings of earlier studies as they demonstrate that the meaningfulness of neighbourhoods is situated and individually defined (Coleman, Kearns and Wiles 2016). People feel particularly attached to places that are embedded in history and which give nostalgic feelings - such as a steep forest path - and are not willing to let themselves 'be chased away'. They also explained that the neighbourhood community can compensate for a lack of services and facilities only to a certain extent. Older adults wanted to pick places that symbolised certain experiences that are difficult to objectify. Hence, their stories demonstrate that not only tangible places, such as the home and Gardner's (2011) third places, are meaningful. Instead, there are also other (sometimes no longer existing) meaningful places in neighbourhoods that cannot be recognised by others because they are intangible. These include places that demonstrate a sense of community that people find unique and want to remember, such as the flat scheduled for demolition or the cemetery with the Polish husband. We call these intangible but meaningful places fourth places, as they play an important role for older people in relation to ageing-in-place. 'The notion of intangible places as fourth places adds value by providing for the addition of new insights to meanings of ageing-in-place. These places share a similarity with Rowles' (1983) 'incident places' as they acquire meaning through experiences, memories and history. Memories are, 
according to Degnen (2015), continually reconstructed in interactions with other users of these places. While 'incident places' that evoke such sentiments, and 'third places', that enable relationships, are both tangible places, the places we describe here are intangible. They are important, although they do not exist (any more). They embody personal, lived experiences that can only be kept alive via stories. Gardner explained that an informal, natural neighbourhood network is embedded in third places, through which older adults' wellbeing is enhanced. Our study demonstrates how intangible places affect people's relationships and interactions with their neighbourhood in a similar way. It is via the stories about intangible places that older adults connect with and attach to their (previous and current) neighbours and community.

One of the main limitations of this study is its small sample. Our aim was that the activities could take place within a few weeks to enable professionals and older adults to share their stories in a dialogue meeting. However, the purposive sampling employed probably attracted participants who are (more) engaged in their community and committed to ageing-in-place. The selection method for this sampling suggests that older people who are less active or feel socially isolated were probably excluded. Furthermore, although we did not prevent people from sharing stories about their own homes, the emphasis on lifecycle-robust neighbourhoods as a means towards achieving ageing-in-place might have led to the fact that most photographs depicted places in the neighbourhood, not in their homes. Because we prioritised older people's voices, we could not fully explore professionals' stories (i.e. no interviews were conducted). Nevertheless, photovoice gave agency to all participants in the sense that they all could participate in setting the meeting's agenda and a broad diversity of experiences could be shared. It would be interesting to include a larger sample, with a wider variety of inhabitants in future studies to explore whether other layers can be added to meanings of ageing-in-place. The differences in the perspectives of older adults and professionals suggest a need for further exploration of their perspectives and of the relation with other perspectives, such as those of policymakers. Using a similar design could offer more opportunities for a dialogue about the meanings of place in relation to ageing.

Our findings demonstrate the importance older people give to being heard and acknowledged through the places they value as important for ageing-in-place. Asking participants to take photographs gave them an opportunity to think about ageing-in-place in a different way. Their stories about fourth places substantiate the individuality of lived experiences and emphasise a need for a more sensitive and customised approach from policymakers. We agree with Heathwole-Shank and Cutchin (2016) that it is impossible to construct one liveable place for ageing-in-place that suits everyone. However, the difference between the expectations of professionals about places for ageing-in-place and the experiences of older adults necessitates a continuation of dialogue between policy and practice. This study demonstrates both how methodology matters to exploring experience and how it could be of interest to policymakers willing to involve older adults in future policy developments. By 
demonstrating how intangible places play an important role for older adults and related ageing-in-place process, this paper emphasises the importance of social-constructivism in studying meanings of ageing-in-place.

\section{Acknowledgements}

The authors thank the older adults and professionals in the two neighbourhoods investigated for their willingness to participate in this photovoice study and for sharing their individual experiences of place. Many thanks also to the professionals and municipalities that were willing to cooperate in the practical facilitation of this study. Furthermore we would like to express our gratitude towards our colleagues, who voluntarily facilitated this study by operating as moderators during the two dialogue meetings. We would also like to thank everybody who shared useful comments on earlier drafts of this paper, in particular the participants of the WTMC (Netherlands Graduate Research School of Science, Technology and Modern Culture) dissertation day in April 2016. 


\section{References}

Andrews, G., Cutchin, M., McCracken, K., Philips, D. and Wiles, J., 2007. Geographical Gerontology: The constitution of a discipline. Social Science \& Medicine, 65, o1, 151-168.

doi:https://doi.org/10.1016/j.socscimed.2007.02.047

Andrews, G., Evans, J. and Wiles, J., 2013. Re-spacing and re-placing gerontology: relationality and affect. Ageing \& Society, 33, o8, 1339-1373. doi:https://doi.org/10.1017/So144686X12000621

Blokland, T., 2009. Celebrating Local Histories and Defining Neighbourhood Communities: Place-making in a Gentrified Neighbourhood. Urban Studies, 46, o8, 1593-1610.

doi:https://doi.org/10.1177/0042098009105499

Buffel, T., Phillipson, C. and Scharf, T., 2013. Experiences of neighbourhood exclusion and inclusion among older people living in deprived inner-city areas in Belgium and England. Ageing \& Society, 33, o1, 89-109. http://dx.doi.org/10.1017/ So144686X12000542

Buffel, T., Donder, L. de, Phillipson, C., Dury, S., Witte, N. de and Verté, D., 2014. Social participation among older adults living in medium-sized cities in Belgium: the role of neighbourhood perceptions. Health Promotion International, 29, 04, 655-668. doi: 10.1093/heapro/datoo9

Carpiano, R., 2009. Come take a walk with me: The "Go-Along" interview as a novel method for studying the implications of place for health and well-being. Health \& Place 15, 01, 263-272. doi:10.1016/j.healthplace.2008.05.003

Catalani, C. and Minkler, M., 2010. Photovoice: A review of the literature in health and public health. Health Education and Behavior 37, 03, 424-451. doi:10.1177/1090198109342084

Cele, S., 2006. Communicating Place: Methods for Understanding Children's Experience of Place. Acta Universitatis Stockholmiensis: Stockholm.

Coleman, T. and Kearns, R., 2015. The role of bluespaces in experiencing place, aging and wellbeing: Insights from Waiheke Island, New Zealand. Health \& Place, 35, 206-217. doi:http://dx.doi.org/10.1016/j.healthplace.2014.09.016

Coleman, T., Kearns, R. and Wiles, J., 2016. Older adults' experiences of home maintenance issues and opportunities to maintain ageing in place. Housing Studies. 31, 08, 964-983. doi:http://dx.doi.org/10.108o/o2673037.2016.1164834

Dahlin-Ivanoff, S., Haak, M., Fänge, A. and Iwarsson, S., 2007. The multiple meaning of home as experienced by very old Swedish people. Scandinavion Journal of Occupational Therapy, 14, 25-32. doi:10.108o/11038120601151714

Degnen, C., 2015. Socialising place attachment: place, social memory and embodied affordances. Ageing \& Society, 36, o8, 1645-1667. doi:https://doi.org/10.1017/So144686X15000653

Eriksson, M. and Emmelin, M., 2013. What constitutes a health-enabling neighborhood? A grounded theory situational analysis addressing the significance of social capital and gender. Social Science \& Medicine, 97, 112-123.

Gardner, P., 2011. Natural neighborhood networks - Important social networks in the lives of older adults aging in place. Journal of aging studies 25, 03, 263-271. doi:10.1016/j.jaging.2011.03.007

Gieryn, T., 20oo. A space for place in sociology. Annual review of sociology 26, ol 463-496. doi:10.1145/annurev.soc.26.1463

Hackett, E., Amsterdamska, O., Lynch, M. and Wajcman, J. (Eds.), 20o8. The Handbook of Science and Technology Studies (Third edition). Massachussetts Institute of Technology, Cambridge, MA.

Heatwole-Shank, K. and Cutchin, M., 2016. Processes of developing 'community livability' in older age. Journal of Aging Studies, 39, 66-72. doi:http://dx.doi.org/10.1016/j.jaging.2016.11.oo1

Hees, S. van, Horstman, K., Jansen, M. and Ruwaard, D. 2017. Meanings of 'lifecycle robust neighbourhoods': constructing versus attaching to places. Ageing \& Society, Published online: 23 January 2017, 1-26. doi:https://doi.org/10.1017/ So144686X16001483.

Henke, C. And Gieryn, T., 2008. Sites of Scientific Practice: The Enduring Importance of Place. In: Hackett, E., Amsterdamska, O., Lynch, M. and Wajcman, J. (Eds.), 20o8. The Handbook of Science and Technology Studies (Third edition). Massachussetts Institute of Technology, Cambridge, MA, 353-376.

Hergenrather, K., Rhodes, S., Cowan, C., Bardhoshi, G. and Pula, S., 2009. Photovoice as community-based participatory research: A qualitative review. American Journal of Health Behaviour, 33, o6, 686-698. doi:http://dx.doi.org/10.5993/ AJHB.33.6.6

Hillcoat-Nallétamby, S. and Ogg, J., 2014. Moving beyond 'ageing in place': older people's dislikes about their home and neighbourhood environments as a motive for wishing to move. Ageing \& Society, 34, 10, 1771-1796. doi:10.1017/ So144686X13000482 
Hoven, B. van and Douma, L., 2012. 'We Make Ourselves at Home Wherever We are'. Older People's Placemaking in Newton Hall. European Spatial Research and Policy, 19, o1, 65-69. doi:https://doi.org/10.2478/v10105-012-00o6-7

Kenkmann, A., Poland, F., Burns, D., Hyde, P. and Killett, A., 2017. Negotiating and valuing spaces: The discourse of space and 'home' in care homes. Health \& Place, 43, 8-16. doi:http://dx.doi.org/10.1016/j.healthplace.2016.11.006

Kohon, J. and Carder, P., 2014. Exploring identity and aging: Auto-photography and narratives of low income older adults. Journal of Aging Studies 30, 47-55. doi:10.1016/j.jaging.2014.02.006

Lawton, M. and Nahemow, L., 1973. Ecology and the aging process. In Eisdorfer, C. And Lawton M. (Eds.), The psychology of Adult Development and Ageing. American Pscyhological Assocation: Washington DC, 619-674.

Lockett, D., Willis, A. and Edwards, N., 2005. Through seniors' eyes: an exploratory qualitative study to identify environmental barriers to and facilitators of walking. CJNR (Canadian Journal of Nursing Research) 37, 03, 48-65.

Menec, V., Hutton, L., Newall, N., Nowicki, S., Spina, J. and Veselyuk, D., 2015. How 'age-friendly' are rural communities and what community characteristics are related to age-friendliness? The case of rural Manitoba, Canada. Ageing \& Society, 35, 01, 203-223. doi:http://dx.doi.org/10.1017/So144686X13000627.

Menec, V., Means, R., Keating, N., Parkhurst, G. and Eales, J., 2011. Conceptualizing age-friendly communities. Canadian Journal on Aging 30, 03, 479. doi:https://doi.org/10.1017/So714980811000237.

Milligan, M., 1998. Interactional Past And Potential: The Social Construction Of Place Attachment. Symbolic Interaction, 21, o1, 1-33. http://www.jstor.org/stable/10.1525/si.1998.21.1.1

Novek, S., and Menec, V. 2014. Older adults' perceptions of age-friendly communities in Canada: a photovoice study. Ageing \& Society, 34, 06, 1052-1072. doi:https://doi.org/10.1017/So144686X1200150X

Novek, S., Morris-Oswald, T. and Menec, V., 2012. Using photovoice with older adults: some methodological strengths and issues. Ageing \& Society 32, 03, 451-470.

doi:http://dx.doi.org/10.1017/So144686X11000377

Ottoni, C., Sims-Gould, J., Winters, M., Heijnen, M. and McKay, H., 2016. “Benches become like porches”: Built and social environment influences on older adults' experiences of mobility and well-being. Social Science \& Medicine, 169, 33-41. doi:http://dx.doi.org/10.1016/j.socscimed.2016.08.044.

Peace, S., Holland, C. and Kellaher, L., 2011. 'Option recognition' in later life: variations in ageing in place. Ageing \& Society, 31, 05, 734-757. doi:https://doi.org/10.1017/So144686X10oo1157.

Pink, S., 2013. Doing visual ethnography. Sage: London.

Plouffe, L. and Kalache, A., 2010. Towards global age-friendly cities: determining urban features that promote active aging. Journal of Urban Health, 87, 05 733-739. doi:10.1007/s11524-010-9466-o.

Rowles, G., 1983. Place and personal identity in old age: observations from Appalachia. Journal of Environmental Psychology, 3, 04, 299-313. doi:http://dx.doi.org/10.1016/So272-4944(83)80033-4.

Rowles, G., 1993. Evolving images of place in aging and 'aging in place'. Generations, 17, 02, 65-70.

Stones, D., and Gullifer, J., 2016. 'At home it's just so much easier to be yourself': older adults' perceptions of ageing in place. Ageing \& Society, 36, 03, 449-481. doi:https://doi.org/10.1017/So144686X14001214

Vogelsang, E., 2016. Older adult social participation and its relationship with health: Rural-urban differences. Health \& Place, 42, 111-119. doi:http://dx.doi.org/10.1016/j.healthplace.2016.09.010

Wang, C. and Burris, M., 1997. Photovoice: Concept, methodology, and use for participatory needs assessment. Health education \& behavior 24, 03, 369-387. doi:10.1177/109019819702400309

Wang, C. and Redwood-Jones, Y., 20o1. Photovoice ethics: Perspectives from Flint photovoice. Health education \& behavior, 28, 05, 560-572. doi:10.1177/109019810102800504

Wiles, J, Leibing, A., Guberman, N., Reeve, J. and Allen, R., 2012. The Meaning of “Ageing in Place" to Older People. The Gerontologist, 52, 357-366. doi:10.1093/geront/gnro98

World Health Organization, 2015. World report on Ageing and Health. World Health Organization, Geneva. Available online at http://apps.who.int/iris/bitstream/10665/186463/1/9789240694811_eng.pdf?ua=1 [Accessed 6 June 2017]. 



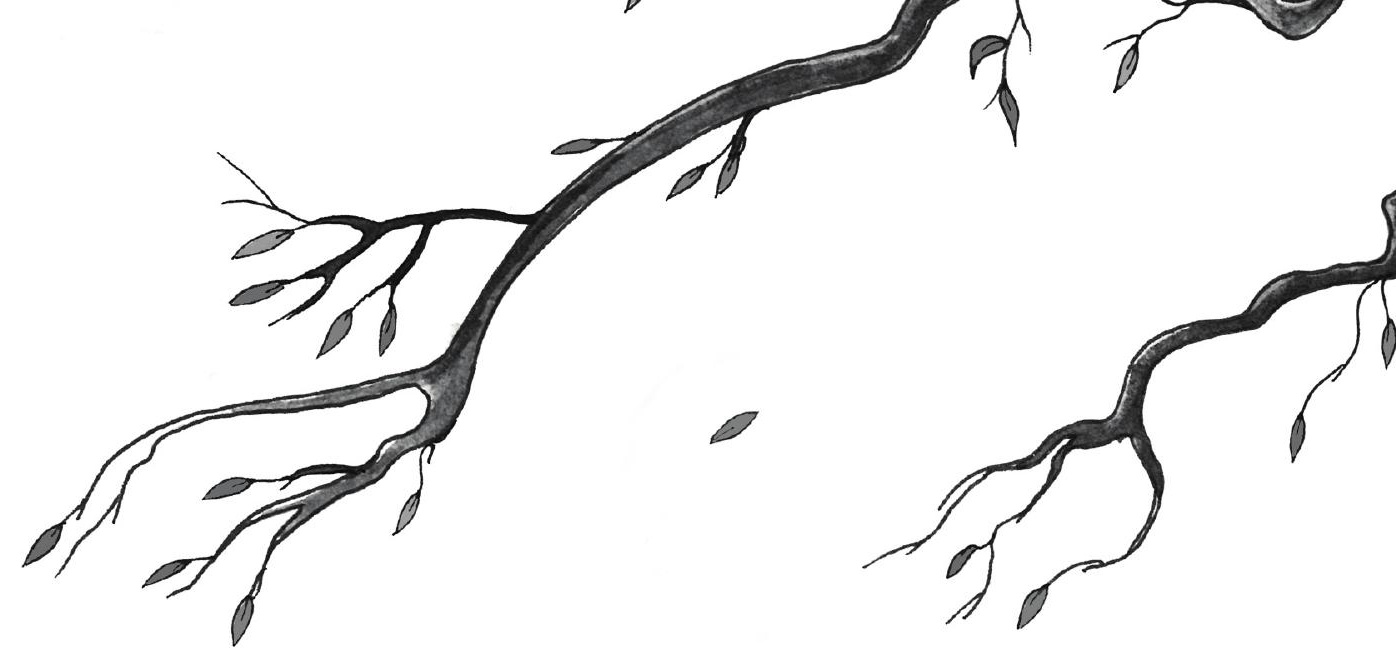

Chapter 6

Discussion 



\subsection{Introduction}

Place plays an important role in relation to ageing, especially since ageing-in-place is regarded to support more independent, healthy and active ageing than ageing in an institutional setting. Ageing-in-place, which is preferred by most older people and in policy, is defined as the ideal that people remain in their own homes and neighbourhoods for as long as possible, with some support if necessary (Wiles et al. 2012). Many policymakers also favour ageing-in-place because of its role in delaying or even avoiding institutional care, which they think is needed to curb increasing healthcare costs caused by ageing populations (Lamb 2014; Lui et al. 2009; Newman and Tonkens 2011; Rudman 2015). To enable ageing-in-place, new ageing policies are developed to increase older people's independence and autonomy by encouraging people's own abilities (empowerment), the use of social support (their informal network) and assistive technologies. Age-friendly communities are promoted as a facility to support ageing-in-place. To improve the understanding of ageing-in-place policies that play a pivotal role in current care reforms, we have conducted a four-year study of the practical results of a local social policy that emphasises the importance of active citizenship and ageing-in-place in constructing so-called lifecycle-robust (neighbourhoods.

Many scholars have extensively investigated notions of ageing-in-place; for instance, by exploring meanings of ageing-in-place for older adults (e.g. Coleman and Kearns 2015; Heathcote 2007; Lager 2015; Wiles et al. 2012). How the social policy of ageing-in-place works out in practice, however, has not yet been studied. We used the approach of Van der Veen (1990) to open the 'black box' of ageing-in-place policies in daily practices. 'Voor Elkaar in Parkstad', the social initiative that we studied, is based on the belief that the neighbourhood can be reconstructed as a mediator of ageingin-place, which is defined as an 'ageing technology' within Science and Technology Studies (STS; cf. Joyce and Mamo (2006) and Neven (2010) on ageing technologies, Brittain, Corner, Robinson and Bond (2010) on place as an ageing technology). To understand the meanings of this policy in practice, we studied different perspectives on the notions of ageing and place through a qualitative research design. This design was based on our main research question: how do ageing-in-place policies work out in practice? From that starting point, we subsequently explored the meanings of citizenship in old age (Chapter 2 ), the translation of policy into professional practice by introducing the kitchen table conversation as a new social technology (Chapter 3) and the meanings of place (Chapter 4 and 5). In this discussion chapter, the main research question of the thesis will be answered by highlighting the results of our study and reflecting on their significance. First, we will present the main insights derived from our study, followed by theoretical and methodological considerations. At the end of this discussion, we will set out the lessons that can be learnt from this study with regard to policy, practice and research. 


\subsection{Constructing lifecycle-robust neighbourhoods: a world of tensions}

Our study demonstrates how ageing-in-place policies may create different practices and various tensions. We distinguished between the development of a policy and its practical capacity to reconstruct neighbourhoods as lifecycle-robust. Although this policy was based on the assumption that lifecycle-robust neighbourhoods should enable ageing-in-place, in practice we distinguished different meanings of ageingin-place. These differences elucidated tensions between policy ideals, professional practices and older adults' experiences, which are induced by new meanings of citizenship in old age, as well as by assumptions made in policy of the malleability of ageing-in-place.

\section{Tensions between policy ideals, professional practices and older adults' experiences}

In this thesis, we elaborated on a variety of tensions in the translation of ageing-inplace from a policy into daily practice. We demonstrated tensions between 1) policy ideals and older adults' experiences, 2) policy ideals and the practices of housing, care and welfare professionals, and 3 ) the ideals and experiences of professionals in translating policy into daily practice on the one hand and older adults as negotiators of their care arrangements on the other hand. These tensions became visible in the different constructions of ageing, place and ageing-in-place.

First, we identified tensions between policy ideals and older adults' experiences. The policy that we studied assumed that reconstructing the neighbourhood as a lifecycle-robust neighbourhood would eventually correspond with the desires and ideals of older people. However, older people were not asked themselves about their actual desires and ideals. Although many distinctions can be made between the different meanings of ageing and place both in policy and in practice, we can state in general that the policy had an ideal of the neighbourhood as an enabler (or regulator) of ageing-in-place. In this context, it should be noted that a clear description of what lifecycle-robustness entails is lacking in policy. During interviews and in meetings, policymakers and directors explained their vision of how the neighbourhood could facilitate older people by adjusting its characteristics. Such characteristics included, among other things, the availability of a social support network, age-friendly homes and access to facilities to increase people's autonomy. The neighbourhood could then be adjusted by adding specific characteristics, thereby empowering citizens to take increased responsibility to take care of each other.

Meanwhile, older people expressed their appreciation of having the aforementioned functional and social facilities and services available in their environment, as well as access to a qualitative social neighbourhood network. Their stories also demonstrate, however, that these characteristics alone do not make their place of 
ageing meaningful. People often choose whether to remain in place or to opt for moving to a more age-friendly place by assessing the value of their current place based on personal memories, history and attachments. Social interactions and the availability of social control are important to many of the older adults interviewed, though these considerations take a different form to what is found in policy. One example of these differences is the proposal of participants involved at a policy level to introduce a 'signalling (warning) function'. They suggested making someone in the neighbourhood responsible for 'signalling' when things go wrong, as such a procedure would both increase the feelings of safety (social control) and facilitate preventive healthcare. Many older people shared how much they cherish their privacy and how they have carefully arranged social control in their environment (or how it has been arranged for them). Although most older adults in our study talked about the importance of social interactions and connections, most of them did not consider a formally organised social control function to be part of their ideal of ageing-in-place - they preferred to have their privacy instead.

Another example of tension between policy and practice is the idea to increase the sense of community by increasing the importance of community centres and by making inhabitants responsible for the organisation of these centres. Although many older people appreciate the availability of community centres, we found that many older people in reality favour more informal meeting places. These can take the form of 'private-public meeting places': open spaces - such as a corner in a corridor of an apartment building - that are accessible to residents or older neighbours but not to others. In these places, older adults can meet and socialise on a daily basis without having to access each other's private domains. In this way, they are better able to have social interactions while maintaining the privacy of their homes; they feel as though they watch out for one another without trespassing on each other's private domains. However, older adults have a huge variety of experiences; some missed real friendships, companionship or particularly the normality of meeting people in the own home instead of at designated places.

In addition to tensions between policy ideals and older people's experiences, we also found tensions between policy and professional practices. As a result of new policy, professionals access the private space of older adults' own homes to negotiate customised care and welfare arrangements. Housing, care and welfare professionals, including neighbourhood nurses, social workers and older adults' advisers, play a crucial role in the translation of this policy of activation and ageing-in-place. In interactions with older people who seek or need support, professionals are expected to activate citizens to remain or become as self-sufficient as possible. Instead of instantly providing care as they had done until recently, professionals now need to explore what people can do themselves. If they conclude that help is indeed needed, they have to find out whether a) people in the individual's informal network (relatives, neighbours or other acquaintances) can support them instead of formal care providers and b) the individual can do anything for the community in return (rec- 
iprocity principle). To facilitate these professionals in translating this policy into practice, the kitchen table conversation was introduced. This concept can be considered to be a social technology in terms of policy. It is introduced as an ideal of a warm, informal, in-depth conversation, preferably held at the private home of the older adult, which should help to translate the ideal of activation and ageing-in-place into practice. The idea is that a kitchen table setting enables professionals to find solutions through informal rather than formal care. As managers and civil servants require professionals to be accountable, as well as to negotiate care instead of only providing it, additional tools including questionnaires (such as a self-sufficiency matrix) and informed consent forms were developed. These tools are intended to provide further guidance for personal conversations, but they should also help to make professionals accountable. While the kitchen table conversation was initially presented as a tool that facilitates and increases the professional space, in practice professionals struggle with the meaning of this tool and of the notion of good care in this new policy. Professionals do not want to be indiscriminate towards older people and their needs, but they do want to fulfil their implicit assignment of curtailing healthcare costs. The kitchen table conversation in practice lacks the clarity required to be used successfully as a social technology. Although it is intended as a mediating tool, in practice it does not provide the desired guidance for professionals. Many factors remain uncontrollable or situationally dependent, whereas a tool needs a measure of predictability in order to work.

In the constructions of ageing-in-place and the role of professional care, we also distinguished tensions between professionals and older adults. Older people have their own expectations of professionals and their role. They often want help instead of an in-depth dialogue about private aspects of their life which they may not consider relevant to their needs and wishes. Furthermore, we found that professionals' constructions of place were for the most part in line with policy. Even for professionals who meet and interact with older adults in their daily practice, their constructions of ageing-in-place differed from those of older people. In their constructions, professionals describe lifecycle-robust neighbourhoods as places that enable ageing-in-place, insofar as they have good housing facilities with services for transport, care, welfare and daily needs in the vicinity. They consider the neighbourhood as a construable place, a place that can be made suitable for ageing-in-place. Although they know that older people are attached to particular places such as old buildings, specific streets or spaces, they still assume that the meaning of the places treasured by citizens may be redefined through a reconstruction of the notion of place. For older adults, these places represent and symbolise different things, but they all entail important attachments to their specific place. They symbolise valuable memories, enable social contacts and offer an individual aspect that makes a place unique to this person. This uniqueness is more individually defined and less malleable than age-friendly houses, facilities, services and meeting opportunities created for older adults. 
Tensions between policy, professionals and citizens are in reality intrinsic to the policy-driven assignment of professionals to negotiate customised care arrangements, preferably through a standardised procedure. On the one hand, the new policy promises increased space to professionals in order to perform their professional tasks. On the other hand, policymakers - as well as housing, care and welfare directors and managers - want to monitor the outcomes of the new policy, partly because they want to know whether budget cuts are being realised. At the same, professionals are asked to involve the neighbourhood in helping individuals recover and regain their self-sufficiency, something that they find extremely difficult. They struggle to satisfy both the citizens and their managers. Although they are willing to help citizens, professionals feel a responsibility to fulfil their new assignment and to translate this new policy into practice. In doing so, they construct the notion of place as an enabler of ageing-in-place, just as it is communicated in policy. However, they simultaneously seek to define good care in this new policy, as they want to do justice to the differences between older people. These older people do not mainly consider their neighbourhood as an enabler or regulator of ageing-in-place, but rather talk about the uniqueness of the living space as a place full of memories and history.

\section{New meanings of citizenship in old age}

The different tensions described above between policy and practice especially concern the meanings that are attributed to citizenship in old age. For decades, citizenship has been associated with legal, political and social entitlements of inhabitants of places. In practice, however, citizenship has become less and less an entitlement, as policy increasingly connects citizenship with an obligation to participate actively and visible in society. Just as many activation policies in present-day Western welfare states, this policy draws on the idea that all older adults who are able to participate in society have to be activated as independent citizens. The assumption is that activation will benefit both society in general and older adults in particular.

Older adults struggle with these presuppositions in policy because they feel that they are being framed as a homogeneous group of passive people (or care consumers), who need to be activated or assisted towards improved independency in the one-size-fits-all solution of ageing-in-place within lifecycle-robust neighbourhoods. While a participatory society with ageing-in-place as a norm is communicated as a policy ideal, in practice older adults wonder what participation really (and what it means if they are no longer able to participate). Most of these citizens experience an intrinsic desire to remain independent, but they want to organise this independency in their own way rather than through the imposition of current policy ideas. The policy assumes that independence can be implemented top-down by educating or empowering people to aim for increased self-sufficiency. However, instead of talking about citizenship, older adults talk about how they give meaning to their daily life. They share how, having retired after more than forty years of hard work, they take 
care of themselves and their homes, remain independent and avoid becoming a burden to others. By doing so, they demonstrate classic elements of citizenship, but they do not always feel acknowledged as citizens. In general, the meanings that they attach to citizenship in old age conflict with the ideas of participation from policymakers, civil servants, directors, managers, professionals and even representatives of older adults, since citizenship and participation are interpreted differently. While older people experience their distinct citizenship status as a publicly acknowledged and self-evidently earned reward for their past contributions to society, this notion seems to be under increasing pressure.

The present thesis demonstrates how policy no longer considers citizenship as a choice and how active participation is promoted as the means to achieve a new citizenship ideal. Although the difference between no longer being active and becoming passive remains opaque/ Let alone what participation actually entails, it is clear that the definition of citizenship in old age by actors involved in developing and implementing this policy is different than the meaning given by older adults. Policy describes citizenship as a crucial element to constructing lifecycle-robust neighbourhoods. When constructing places as enablers of ageing-in-place, citizenship is considered to be one of the main factors. In practice, however, the emphasis in policy on encouraging active and independent citizenship deconstructs and restricts the meaning of citizenship in old age.

\section{Malleability of ageing-in-place}

The aforementioned tensions between policy and practice can be explained by zooming in on the belief in malleability that informs policy. The policy that we studied is based on the idea that the neighbourhood can be turned into lifecycle-robust places, which subsequently enable ageing-in-place and active citizenship. Having a neighbour assume a 'signalling function' to keep an eye on others is just one example of how this policy is translated into practice. In interviews, during meetings and in focus groups, participants involved in the development of this particular initiative shared how they envisioned their practical realisation of the policy ideal. In their view, lifecycle-robust neighbourhoods should not be based solely on the ideal of agefriendly housing facilities with services for transport, care, welfare, and daily needs in the vicinity. More importantly, these neighbourhoods should be embedded in a strong social support network which has to be organised for this purpose. Policy plays an important initiating role in this process, promoting new interpretations of place and meanings in practice. The idea that places enable or regulate ageing-in-place is at odds with daily practice, which reveals different interpretations and experiences of place for different people. Although not meticulously defined in policy, our study demonstrates how the neighbourhood as a technology for ageing-in-place is constructed as an ideal of lifecycle-robustness. This ideal exists of reshaping older adults as independent, active citizens, alongside professionals who empower people 
to pursue ageing-in-place, requiring as little formal help as possible while using the place where they live as a resource. However, this ideal does not clearly incorporate or acknowledge lived experiences and diverging meanings of ageing, place and citizenship from older adults. Nor does it recognise the struggles of professionals to translate ageing-in-place into practice, which is expected to be realised by adding social technologies intended to mediate individual negotiations at the kitchen table.

A strong belief in a malleable care system in general is displayed, or more specifically, a belief in the malleability of neighbourhoods as the new places of care. Although ageing-in-place is described as complicated and open to multiple interpretations, this concept is ruled by the naive assumption that places - like many elements of social life - are inherently malleable. Within these ideals of ageing-inplace, older adults are activated as citizens by discrediting their old age as a distinctive category; professionals empower and mediate older adults in becoming or remaining independent citizens as required; and neighbourhoods enable ageing-in-place by offering the total package of requirements. Policy plans merely make assumptions as to older adults' needs and wishes, based on scientific reports and surveys of local, regional or national organisations such as consultancy agencies or public health services. Although these reports contain important characteristics, they do not fully show how people are actually attached to (or detached from) a place. The stories of older people show how buildings and spaces can make people feel in or out of place. It is interesting how policy almost exclusively focuses on malleable elements in neighbourhoods, instead of on existing elements that make places unique and meaningful for individuals. While there are also older people who make pragmatic, 'optimal' or more suitable choices (moving to an age-friendly apartment or adjusting to a changing neighbourhood), this thesis demonstrates how individuals attach different meanings to places. It also clarifies why some people choose to remain in places based on 'a lifetime of experience', instead of moving to a more suitable place where they can age in relatively good health with close access to care. However, these different experiences often remain unheard in policy.

\subsection{Theoretical considerations}

This thesis demonstrates that ageing-in-place may be desired by many people in policy and in practice, but actual experiences of place and the meaning of ageingin-place differ among policymakers, directors, managers, professionals and older people. The dialogue about lived experiences is complicated by the underlying assumption in policy that neighbourhoods can be made into lifecycle-robust places which enable ageing-in-place. This section contains a reflection on these findings in relation to previous studies of developments in and social policies on activation and ageing-in-place.

How ageing and old age are constructed and how they relate to space and place is 
crucial to understanding the different meanings of ageing-in-place (Andrews, Evans and Wiles 2013). For decades, the meaning of old age has been the object of debate in science and policy (Moreira 2016). Such debates concern the use of chronological age in policy, the distinction between a third (or independent) and fourth (or frail) age, and the meanings of independency (Gilleard and Higgs 2010; Moreira 2016). Although there is no agreement in the literature on the definition of these different ageing frames (Depp and Jeste 2006; Nosraty and Jylhä 2015), a government trend towards more independent, societally active and participative older citizens is obvious in Western welfare states. In other words, there exists a policy ideal of ageing where older adults are activated, to avoid institutionalised care and instead need to age in place and maintain an independent lifestyle (Buffel, Phillipson and Scharf 2013; Coleman and Kearns 2015; Joseph and Chalmers 1995; Wiles et al. 2012). While many ageing-in-place policies and programmes draw on the idea that older people are infirm (Heathcote 2011), the focus of the discourse on healthy, active, successful and positive ageing raises the question of what this entails for the citizenship status of less healthy people. Our study demonstrates an urgency to debate the meanings of citizenship in old age, as government policies have somehow diminished the opportunities for a more passive style of citizenship. Lassen and Moreira (2014) describe that passive and active forms of citizenship are interdependent, advocating an emphasis on the rewards of later life instead of on old age. They consider a place for passivity to be crucial as active ageing is becoming 'a way of life'. However, the present thesis reveals a lack of understanding in policy of current viewpoints in practice, particularly of the entitlements and obligations that come with old age and their importance in constructing citizenship. In effect, ageing-in-place seems to become an implicit precondition for continuing to be counted as a citizen.

This policy shift in the Netherlands is not unique, as similar attempts are made by many other Western governments to encourage and enable ageing-in-place through developing various ageing technologies and policies (see for instance Lassen, Bønnelycke and Otto 2015; López Gómez 2015; Roberts and Mort 2009). The tensions in practice - described above in our findings - stress the importance of study a policy by investigating its meanings in daily practice at the street level. The struggles of professionals to translate the policy into practice while maintaining their ideal of good care, as well as the differing lived experiences of older people, demonstrate that policy only acquires meaning in practice. Policies on active ageing and ageingin-place can be understood as activation policies that are often greatly informed by assumptions about ageing and older peoples as well as by ideals of malleability. The perspective on place as an enabler of autonomy is often being pushed (López Gómez describes this as a 'push for autonomy' in his work on ageing technologies (2015)). Our study confirms Van der Veen's (1990) and Lipsky's argumentation that only a street-level analysis can demonstrate how an activation policy plays out in practice, as the specific settings and contexts affect the various and diverse meanings that people give to policy - and more specifically to ageing and place. Since there is a multitude 
of different interpretations, and since policy only gets its meaning in practice, Van der Veen (1990) argued how important it is to realise that there is more than one kind of agreement to be made. Instead of looking for one solution, one blueprint, and one ideal type of place where an idealised older adult can remain independent for longer, it is important to be aware of the tensions that surround a belief in the malleability of place and of ageing-in-place. Instead, we should endeavour to unravel the underlying differences between situations and find out how the meaning of places differs per individual.

This thesis emphasises the huge variety in meanings of ageing, place and ageingin-place, as has been shown before in other studies (Andrews et al. 2007; Peace, Holland and Kellaher. 2011; Wiles et al. 2012). These other studies demonstrated how policies vary in their emphasis on ageing, distinguishing among others healthy, active, successful and positive ageing. In all these discourses, a shared ideal of ageingin-place is embedded (Sixsmith 2014) - an ideal that has nonetheless been criticised in gerontology for a long time. In 1993, for instance, Rowles stated that the concept of ageing-in-place romanticises the idea that people attach to a place based on social and emotional connections. In reality, however, they make far more rational and pragmatic choices, whereas their attachment to a place is often also based on more pragmatic notion. Peace et al. (2011) argued in favour of a more nuanced ideal, stating that ageing-out-of-place can in individual cases be a better or more realistic choice in pursuing autonomy in old age. Moreover, some older people simply lack financial or other opportunities to choose where they want to age, which forces them to ageing-in-place, even when they prefer otherwise (Phillipson 2007). Although we found that some older people indeed make predominantly rational and pragmatic choices by moving to an age-friendly apartment, our findings also demonstrate a more nuanced and complicated practice. While we can confirm that good housing facilities with services for transport, care, welfare, and daily needs in the vicinity are considered important for ageing-in-place by older people, we demonstrated that it is also worthwhile to unravel the less pragmatic or rational arguments for ageing-inplace. Why and how people attach to a particular place depends on other factors as well. Our study adds to these so-called lived experiences, by underlining the value of a social constructivist approach to unravel the meanings of place and understand what happens there. For this reason, we focused on stories and individual experiences instead of quantifiable characteristics such as demographics. Our results consequently confirm the importance attached by Wiles et al. (2012) to maintaining an identity in old age (p. 364):

"Ageing in place" was seen as an advantage in terms of a sense of attachment or connection, practical benefits of security and familiarity, and as being related to people's sense of identity through independence and autonomy. 
The role of the community in attaching meaning to ageing-in-place is also articulated in the work of Gardner (2011) on 'third places', places that enhance people's wellbeing because they enable informal and non-obligatory relationships. Our study confirms that it is important for people to construct their own role in the community, but we also found that this desire concerns not only on tangible but also on rather intangible places. Older people attach meaning to places based on the history, individual memories, past and present relationships, and interactions at these spaces. In addition to the existing literature on place attachment and ageing-in-place, we underlined the importance of these intangible places by distinguishing them as 'fourth places'. This argument also confirms Gieryn's (2000) findings that places become meaningful through the social relations that they mediate. He argues that a space does not become a place until attachments and relationships are created there. By contrast, we saw how policymakers merely draw on assumptions of older adults' needs and wishes, based on scientific reports and surveys of local, regional or national organisations. Although these reports contain important characteristics, they do not fully grasp how people are actually attached to (or detached from) a place. Buildings and spaces can make people feel in or out of place. Places can include or exclude people, as they constitute social relations (Lamont and Molnár 2012). The heterogeneity in older adults' experiences explains this dichotomy. It also clarifies why some people - as already established by Joseph and Chalmers in 1995 - choose a lifetime of experience over the most suitable place to age in relatively good health, while others prefer an age-friendly apartment specifically constructed for older adults, for instance. Knowledge of these experiences is required for a better interpretation of the quantitative data.

To explore a variety of perspectives on an ageing-in-place policy and its practices, we used insights from Science and Technology Studies (STS). STS is a discipline that studies how science, technology and society interact (Hackett, Amsterdamska, Lynch and Wajcman 2008; Oudshoorn and Pinch 2003). Scholars within STS who are interested in ageing have studied sociomaterial technologies that are developed to enable ageing-in-place and assistive technologies such as telecare and patient alarms. In addition, they have analysed more mundane arrangements that are embedded in everyday lives and that help older people to maintain their independency and autonomy (López Gómez 2015; Milligan, Roberts and Mort 2011; Mol, Moser and Pols 2010; Roberts and Mort 2009). In this thesis, we used a slightly different approach. Instead of looking at how a specific technology within the neighbourhood enables or regulates ageing-in-place, we considered the neighbourhood as a technology in itself. This approach enabled us to have a broader view on how older people give meaning to ageing-in-place and how their neighbourhoods can be considered as enablers or regulators. We started by describing how the neighbourhood is assumed in policy to be malleable and capable of being reconstructed as a place that enables ageing-inplace. This assumption caused tensions as to how participants and older people give meaning to this policy in practice. Presuppositions about ageing, about older adults 
as passive recipients of care and about technology as a 'fixer' for a lack of autonomy and independency have been criticized before within STS and feminist work (Joyce and Loe 2010; López Gómez 2015; Neven 2010; Peine and Neven 2011; Roberts and Mort 2009). Following their insights and the findings of this thesis, it can be argued that the ideal of 'normalising' older adults as independent citizens as a starting point for policymaking should be reassessed. For this purpose, the following question should be asked: who are these older people, and how do they give meaning to the different elements of ageing-in-place? Ageing-in-place is not simply accomplished by developing a policy of lifecycle-robust neighbourhoods. Interactions and sensitivities in practice play a crucial role and need to be unravelled. In order to strengthen the idea of participation and the ability to age-in-place, it might be interesting to start from the perspectives of older people in developing a policy on ageing.

\subsection{Methodological considerations}

In this thesis, we aimed to unravel the meanings of an ageing-in-place policy. We monitored this policy in practice for more than four years using ethnographic methods. Having the opportunity to study a policy in practice for such a long period is exceptional. Our ability to select and monitor activities in actual practice enabled us to come to terms with the dynamics of ageing-in-place. We were not primarily concerned with whether this practice was a success, nor did we explore its effects or results. Instead, we investigated the meanings of this policy in practice to open the 'black box' of tensions between policy and practice of this activation technology. Unravelling these meanings helped us to understand the process that takes place and the tensions between the perspectives of different stakeholders in this practice. The various perspectives show that the act of translating policy into practice also constitutes a reconstruction in and of this process. It is important to understand these dynamics when evaluating the success or quality of policy, as they can be helpful in redesigning similar policies.

In following this process, we became aware of the fact that translating a policy in practice is much more complicated than policy documents and concepts suggest. These documents view older adults as a group which only needs to be enabled to continue living in their own place. Monitoring this policy in practice revealed many complications and tensions, as the dynamism of practice cannot be made to wait for policy to be developed further. In effect the professional at the kitchen table decides on the interpretation of policy, while the civil servant decides in local interactions what age-friendly means. While it seems at first sight that stakeholders generally agree on the necessity of this policy, their underlying motives and perspectives differ. We combined different ethnographic methods in this study, such as analysis of documents, interviews, observations, focus groups and photovoice. This design enhances the credibility of our findings, as different methods confirmed and strengthened 
each other. Focus groups were not only used to collect information but also provided extra opportunities for member checks. We created further opportunities for member checks by giving presentations of our interim results on a regular basis, in different meetings and for different participants involved in this study. There was always space for people to provide us with feedback, while all participants of focus groups and dialogue meetings (photovoice project) received short written reports with an additional opportunity to provide us with feedback. Some of these participants responded only to confirm our findings, others added experiences or shared other ideas which led to adjustments.

As we monitored this policy in practice during the research period, its content was shaped and new matters were highlighted based on previous events. This research design enabled us to encompass unforeseen circumstances, such as the decision of one municipality to transform this practice from a project into an ongoing process. Furthermore, working as a multidisciplinary team not only helped to confirm our findings, it also sharpened our analysis through a reflection on our data from different angles. Initially, we focused on the collaboration process between the multitude of different actors involved in this practice. In discussing the outcomes of the data collection, other main themes were singled out for use throughout this thesis.

In reflecting on the methodological approach to this study, its limitations need to be mentioned. While the unique characteristics of the case study, as described in the introductory chapter, underlined its urgency and relevance, it also complicated the generalisation of its findings. In our case, we did not measure the outcomes or the success of a policy, but we were interested in its translation into practice. We noted that many governments of Western welfare states are in similar positions and that ageing-in-place is globally considered as a preferred strategy to maintain or achieve a sustainable care and welfare system. Nevertheless, the findings in our study are bound to the particularities of the case. An ageing and shrinking population in a largely urban region with its own particular cultural history gives rise to its own unique circumstances. The meanings that participants in the study attach to this policy in practice are affected by many particular characteristics. As a consequence, similar practices in other regions might work out differently and probably entail different meanings.

We did not investigate the meaning of this policy in practice, nor did we study how ageing-in-place is constructed. However, by comparing our findings to other studies in different settings, it is possible to identify relevant interfaces. Despite local differences, the discussions arising from our study are confirmed by other studies. The notion of citizenship is obviously changing, as ideas of individualisation, responsibilisation and participation recur in a variety of studies (e.g. Lamb 2014; Newman and Tonkens 2011; Rudman 2015). Ongoing debates on the role of discretionary space and other new technologies in the development of professional work only reinforce the importance of studying this field (Broadhurst et al. 2010; Evans 2011; Høybye-Mortensen 2015; Kruiter, Bredewold and Ham 2016). This importance 
is also evident from the differences in policy perspectives on, and experiences of, place attachment (see among others Lager 2015; Milligan 2012). Monitoring an ageing-in-place policy in practice made clear how complicated it is to unravel 'genuine' experiences or voices in these practices, even from people who participate in interviews, observations and focus groups.

Several scholars had previously aimed to unravel the diverse and genuine stories of older people who live independently and give meaning to ageing-in-place (Lager 2015; Kohon and Carder 2014; Menec et al. 2015; Novek, Morris-Oswald and Menec 2012). They used innovative and social methodologies, such as walking interviews during which the interviewer took photographs of places that were considered to be important (Lager, Van Hoven and Huigen 2013) and storytelling studies based on auto-photography by older adults (Kohon and Carder 2014, Novek, Morris-Oswald and Menec 2012). Despite the many challenges in conducting such research (Novek, Morris-Oswald and Menec 2012), social methodologies offer the opportunity to unravel different stories than the more traditional methodologies have done so far. Although traditional methodologies helped us to find tensions between policy, practice and the experiences of older adults, these tensions remained implicit. There seemed to be no genuine dialogue between policymakers (as developers of ageingin-place), housing, care and welfare professionals (as implementers in practice) and older adults (as users). Through our study, we aimed to facilitate such a dialogue by organising a photovoice project.

That we eventually chose to add a photovoice project once more highlights our increasing awareness of the meanings that older adults attached to these practices. Photovoice facilitates a conversation about the different meanings of places in relation to ageing-in-place. This conversation reveals the heterogeneity of practices, the complexity or impossibility of creating an age-friendly place and the desirability of hearing people's voices and using them to construct participatory communities. While the value of traditional representation techniques and the efforts of participants from formal representative organisations should not be underestimated, our study demonstrated that an exclusive reliance on representatives rather than on actual users can create new tensions in practice when they tell different stories and add different experiences. However, it is inevitable that some voices among all the different perspectives in this study still remain unheard.

\subsection{The future of ageing-in-place}

Based on our findings and reflections presented above, this section provides a number of recommendations for policy, practice and future research.

The primary concern addressed by this thesis is that the ideal of malleability in policy causes a variety of tensions in practice. Current ageing-in-place policies are basically 
constructed top-down, informed by quantifiable characteristics that increase the urgency to reform. This thesis emphasises the need for policymakers - as well as directors, managers and civil servants in housing, care and welfare organisations - to become more sensitive to and aware of the tensions that policies create in practice. It is crucial that policymakers start using the experiences of the people who are the focus of their policy. It would be highly recommendable that they engage in a real and ongoing dialogue with people in the neighbourhoods that they intend to affect with their policy.

How older people give meaning to policy and ageing-in-place should be viewed as a structural component of developing new policies, rather than as an opposing view that needs to be reframed. The development of a new definition of citizenship in old age further increases the need for a more interactive way of policymaking. The experiences and perspectives of professionals and older people can be of great value to policymaking, as they reveal a much more nuanced perspective on the use of place than policy assumes. The acknowledgement of the history of a place and the lived experiences that it contains can be used to enhance the construction of lifecycle-robust neighbourhoods. In line with previous studies (Coleman and Kearns 2015; Joseph and Chalmers 1995; Wiles et al. 2012), this thesis confirms that many older people prefer a lifetime of experiences over a merely functional place. It is therefore advisable to think of ways to improve people's opportunities to remain in place by using their attachment to such places. Their views can help to inform future policies that are better tailored to citizens needs and professionals' abilities. By using people's experiences, the much-debated and ongoing gap between policy and practice can be bridged.

To facilitate a more realistic policy development, professionals also need to share the experiences and tensions in their daily practices. At the same time, policymakers have to attune to these practices by embracing applicable social technologies. Professionals struggle to fulfil policy assignments in practice and simultaneously do justice to the differences between older people. For quite some time now, the need for a new type of professional is being debated (Duyvendak, Knijn and Kremer 2006). Changes in education are necessary to enable this new professionalism, but it is perhaps even more important to realign the expectations of professionals with actual experiences in practice. Policies are often based on ideals and presuppositions, while failing to acknowledge that practices are situated in place and sometimes lack the malleability ascribed to them in theory. When enthusiastic pioneering professionals experience tensions in trying to translate a new policy ideal into practice, they should concede that suggested improvements cannot sufficiently address these difficulties in reality. We already argued how the kitchen table conversation, which was introduced as a mediating social technology, lacks predictability in practice. Because it falls short of a real social technology, the kitchen table conversation fails as a mediator of ageing-in-place. The expectations of professional capacities are also based on idealised situations. If professionals need discretionary space to fulfil their assignment of acti- 
vating citizens rather than taking care of them, this cannot be accomplished merely by allowing professionals more time to negotiate a care and welfare arrangement. Instead, professionals also need to know how to use their space and feel competent to use this space.

To do justice to older people's ideals, as well as to the perspectives of professionals working with older people on a daily basis, new and interactive methods can be helpful. In practice, rather traditional participation strategies are often used: surveys are conducted, participation evenings are organised to discuss active citizenship opportunities within a community (Kampen, Verhoeven and Verplanke 2013), focus groups are used to elicit opinions on ageing-in-place (Lindenberg and Westendorp 2014) and representatives are allowed to participate as members of formal boards and panels (Tonkens 2016). Our thesis confirms Tonkens' argument that the influence of these participation forms is often limited. Tight schedules exist to discuss policies that for the most part are already set in stone and do not allow much space for more personal experiences. Moreover, these rather traditional representation methods lack the genuine voices of many older adults, as participation in policy meetings is often limited to active citizens who know how to activate their entitlements (Bang and Sørensen 1999; Bang 2004). Giving a voice to older adults' experiences and starting a dialogue requires the opening of the 'black box' between policy and practice. By doing so, a more genuine and representative voice can be heard, which moves beyond the fulfilment of a political obligation to participation through formal representative instruments. Policymakers need to be aware that a one-size-fits-all approach does not exist (cf. Buffel et al. 2014; Winterton and Warburton 2011).

To be able to draw out these different voices, older people play a significant role in getting themselves, their experiences and needs heard. Existing representative organisations already play a role in policymaking processes. However, in line with Bang's (2004) argumentation, these organisations are often limited to actively participating people and fail to include citizens who are less vocal. Many representatives build on their professional experience and are selected for their knowledge of policy and policy development processes. To get a more representative perspective, older people from different societal backgrounds and neighbourhoods and with different needs must be involved. Instead of remaining unheard, these people should activate themselves and be activated to get themselves heard. One way for them to reaching this goal is to take advantage of existing opportunities, such as calls for participation by policymakers and scholars. Policymakers, representative organisations and older people are jointly responsible for achieving this aim. For instance, instead of selecting participants on the basis of policy experience, people without such knowledge and experience - and the concomitant biases - should also be considered.

We, as scholars, can facilitate the dialogue between older people, professionals and policymakers or developers about differences in policy and practice. The use of more interactive and innovative methodologies, such as photovoice can be very fruitful in this respect. Moreover, as scholars, we are also responsible for the framing 
of older people in research. The findings described in this study illustrate the need to remain sensitive to different perspectives in policy and practice. As STS scholars, we need to prevent assumptions start to define ageing-in-place, both in science and in policy. We studied an innovative public care initiative, designed as a collaboration process between many different organisations and local governments, and funded by public means. Although the public aspect was not accentuated in this thesis, this theme can be elaborated in future research. The role of science within this process affected participants' expectations, which may also be explored further by drawing on studies of the relationship between science and society in STS.

This study confirms the statement made more than a decade ago by Poland, Lehoux, Holmes and Andrews (2005), which held that the diversity of settings where health and social care take place will only increase further as a result of policy strategies and older people's desires to age in place. This development means that there are fewer standardised situations in which care is used and provided. This thesis corroborates their call for further research on user experiences of the settings of ageing-in-place. These experiences will help to unravel the uniqueness and place sensitivity of spaces, as well as the dual function of places as living spaces for people and actual ageing technologies. To clarify the different characteristics of places, future research needs to reconstruct narratives of experiences in policy and practice (including those of older people as users, professionals as mediators, and policymakers and directors as developers). As a consequence, social constructivism and street-level analysis - which are indispensable to find the particularities of policies in practice -may become even more important within our increasingly diverse society. 


\section{References}

Andrews, G., Evans, J. and Wiles, J., 2013. Re-spacing and re-placing gerontology: relationality and affect. Ageing \& Society, 33, 08, 1339-1373. doi:https://doi.org/10.1017/So144686X12000621

Bang, H., 2004. Everyday makers and expert citizens. Building political not social capital. Working paper. Australian National University: Canberra.

Bang, H. and Sørensen, E., 1999. The everyday maker: A new challenge to democratic governance. Administrative Theory \& Praxis, 21, 03, 325-341. doi:http://dx.doi.org/10.108o/10841806.1999.11643381

Brittain, K., Corner, L., Robinson, L. and Bond, J., 2010. Ageing in place and technologies of place: the lived experience of people with dementia in changing social, physical and technological environments. Sociology of Health \& Illness, 32, 02, 272-287. doi:10.1111/j.1467-9566.2009.01203.x

Broadhurst, K., Wastell, D., White, S., Hall, C., Peckover, S., Thompson, K., Pithouse, A. and Davey, D., 2010. 'Performing 'Initial Assessment': Identifying the Latent Conditions for Error at the Front-Door of Local Authority Children's Services', British Journal of Social Work, 40, 02, 352-37o. doi: https://doi.org/10.1093/bjsw/bcn162

Buffel, T., Donder, L. de, Phillipson, C., Dury, S., Witte, N. de and Verté, D., 2014. Social participation among older adults living in medium-sized cities in Belgium: the role of neighbourhood perceptions. Health Promotion International, 29, 04, 655-68. doi: 10.1093/heapro/datoo9

Buffel, T., Phillipson, C. and Scharf, T., 2013. Experiences of neighbourhood exclusion and inclusion among older people living in deprived inner-city areas in Belgium and England. Ageing \& Society, 33, o1, 89-109. http://dx.doi.org/10.1017/ Sol44686X12000542

Coleman, T. and Kearns, R. 2015. The role of bluespaces in experiencing place, aging and wellbeing: Insights from Waiheke Island, New Zealand. Health \& Place, 35, 206-217.

doi:http://dx.doi.org/10.1016/j.healthplace.2014.09.016

Depp, C. and Jeste, D., 2006. Definitions and predictors of successful aging: a comprehensive review of larger quantitative studies. The American Journal of Geriatric Psychiatry, 14, o1, 6-20.

https://doi.org/10.1097/o1.JGP.oooo192501.03069.bc.

Duyvendak, J. W., Knijn, T. and Kremer, M., 2005. Policy, People, and the New Professional. AmsterdamUniversity Press: Amsterdam.

Evans, T., 2011. 'Professionals, Managers and Discretion: Critiquing Street-Level Bureaucracy', British Journal of Social Work, 41, 368-386. doi:https://doi.org/10.1093/bjsw/bcq074

Gieryn, T., 2000. A space for place in sociology. Annual Review of Sociology, 26, o1, 463-96. doi:10.1145/annurev.soc.26.1463

Gilleard, C., and Higgs, P., 2010. Aging without agency: Theorizing the fourth age. Aging \& Mental Health, 14, 02, 121-128. http://dx.doi.org/10.1080/13607860903228762

Hackett, E., Amsterdamska, O., Lynch, M. and Wajcman, J. (Eds.), 20o8. The Handbook of Science and Technology Studies (Third edition). Massachussetts Institute of Technology: Cambridge, MA.

Heathcote, E., 2007. Old age and the city. BMJ, 343, 1-3. doi:10.1136/bmj.d4418

Høybye-Mortensen, M., 2015. 'Decision-Making Tools and Their Influence on Caseworkers' Room for Discretion', British Journal of Social Work, 45, 6oo-615. doi:https://doi.org/10.1093/bjsw/bct144

Joseph, A. and Chalmers, A., 1995. Growing old in place: a view from rural New Zealand. Health \& Place, 1, 02, 79-9o. doi:https://doi.org/10.1016/1353-8292(95)ooo11-A

Joyce, K. and Loe, M., 2010. A sociological approach to ageing, technology and health. Sociology of Health \& Illness, 32, 02, doi:171-18o. 10.1111/j.1467-9566.2009.01219.x

Joyce, K. and Mamo, L., 2006. Graying the cyborg. Age Matters: Realigning Feminist Thinking. Routledge: New York.

Kampen, T., Verhoeven, I. and Verplanke, L. (Eds.), 2013. De affectieve burger. Hoe de overheid verleidt en verplicht tot zorgzaamheid [The affective citizen]. Van Gennep:Amsterdam.

Kohon, J. and Carder, P., 2014. Exploring identity and aging: Auto-photography and narratives of low income older adults. Journal of Aging Studies, 30, 47-55.

doi:https://doi.org/10.1016/j.jaging.2014.02.006

Kruiter, A., Bredewold, F. and Ham, M., 2016. Dichter bij de burgers, was de belofte. Maar niemand lijkt te weten hoe. NRC, 20 May 2016. https://www.nrc.nl/nieuws/2016/05/20/dichter-bij-de-burger-was-de-belofte-maar-nieman1619783-a1340699

Lager, D., Hoven, B. van and Huigen, P., 2013. Dealing with change in old age: Negotiating working-class belonging 
in a neighbourhood in the process of urban renewal in the Netherlands. Geoforum 50, 54-61. doi:http://dx.doi. org/10.1016/j.geoforum.2013.07.012

Lager, D., 2015. Perspectives on ageing in place. Older adults' experiences of everyday life in urban neighbourhoods. University of Groningen: Groningen.

Lamb, S., 2014. Permanent personhood or meaningful decline? Toward a critical anthropology of successful aging. Journal of Aging Studies, 29, 41-52.

doi:http://dx.doi.org/10.1016/j.jaging.2013.12.006

Lamont, M. and Molnár, V., 2002. The study of boundaries in the social sciences. Annual Review of Sociology, 28, 167-195. doi: https://doi.org/10.1146/annurev.soc.28.110601.141107

Lassen, A. and Moreira, T., 2014. Unmaking old age: Political and cognitive formats of active ageing. Journal of Aging Studies, 30, 33-46. doi: https://doi.org/10.1016/j.jaging.2014.03.004

Lassen, A., Bønnelycke, J. and Otto, L., 2015. Innovating for 'active ageing' in a public-private innovation partnership: creating doable problems and alignment. Technological Forecasting and Social Change, 93, 10-18. doi: https://doi. org/10.1016/j.techfore.2014.01.006

Lindenberg, J. and Westendorp, R., 2015. Overcoming Old in Age-Friendliness. Journal of social work practice, 29, ol, 85-98. doi:http://dx.doi.org/10.1080/02650533.2014.993949

López Gómez, D., 2015. Little arrangements that matter. Rethinking autonomy-enabling innovations for later life. Technological Forecasting and Social Change, 93, 91-101.

doi:https://doi.org/10.1016/j.techfore.2014.02.015

Lui, C., Everingham, J., Warburton, J., Cuthill, M. and Bartlett, H., 2009. What makes a community age-friendly: A review of international literature. Australasian Journal on Ageing, 28, 03, 116-121. doi:10.1111/j.1741-6612.2009.00355.x

Menec, V., Hutton, L., Newall, N., Nowicki, S., Spina, J., and Veselyuk, D., 2015. How 'age-friendly' are rural communities and what community characteristics are related to age-friendliness? The case of rural Manitoba, Canada. Ageing \& Society, 35, 01, 203-223. doi:https://doi.org/10.1017/So144686X13000627

Milligan, C., Roberts, C. and Mort, M., 2011. Telecare and older people: who cares where? Social Science \& Medicine, 72, 03, 347-354. doi:https://doi.org/10.1016/j.socscimed.2010.08.014

Milligan, C., 2012. There's No Place Like Home: Place and Care in an Ageing Society. Ashgate Publishing, Ltd.: Farnham.

Mol, A., Moser, I. and Pols, A. (Eds.), 2010. Care in practice: On tinkering in clinics, homes and farms. Transcript Verlag: Bielefeld.

Moreira, T., 2016. De-standardising ageing? Shifting regimes of age measurement. Ageing \& Society, 36, o7, 1407-1430. doi:https://doi.org/10.1017/So144686X15000458

Neven, L., 2010. 'But obviously not for me': robots, laboratories and the defiant identity of elder test users. Sociology of Health \& Illness, 32, 02, 335-347. doi:10.1111/j.1467-9566.2009.01218.x

Newman, J. and Tonkens, E., 2011. Participation, responsibility and choice: Summoning the active citizen in western European welfare states. Amsterdam University Press: Amsterdam.

Nosraty, L., Jylhä, M., Raittila, T. and Lumme-Sandt, K., 2015. Perceptions by the oldest old of successful aging, Vitality 90+ Study. Journal of Aging Studies, 32, 50-58

doi:https://doi.org/10.1016/j.jaging.2015.01.002

Novek, S., Morris-Oswald, T. and Menec, V., 2012. Using photovoice with older adults: some methodological strengths and issues. Ageing \& Society, 32, 03, 451-470. http://dx.doi.org/10.1017/So144686X11000377

Oudshoorn, N. and Pinch, T., 2003. How Users Matter: The Co-construction of Users and Technology (Inside Technology). The MIT Press: Cambridge, Massachusetts.

Peace, S., Holland, C. and Kellaher, L., 2011. 'Option recognition' in later life: variations in ageing in place. Ageing \& Society, 31, 05, 734-57. doi:https://doi.org/10.1017/So144686X10001157

Peine, A. and Neven, L., 2011. Social-structural lag revisited. Gerontechnology, 10, 3, 129-139. doi:http://dx.doi.org/10.4017/gt.2011.10.3.002.00

Phillipson, C., 2007. The 'elected' and the 'excluded': sociological perspectives on the experience of place and community in old age. Ageing \& Society, 27, 03, 321-42. doi:https://doi.org/10.1017/So144686Xo6005629

Poland, B., Lehoux, P., Holmes, D. and Andrews, G., 2005. How place matters: unpacking technology and power in health and social care. Health \& Social Care in the Community, 13, 02, 170-180. doi: 10.1111/j.1365-2524.2005.00545.x

Roberts, C. and Mort, M., 2009. Reshaping what counts as care: Older people, work and new technologies. ALTER-European Journal of Disability Research/Revue Européenne de Recherche sur le Handicap, 3, 02, 138-158. doi:https:// 
doi.org/10.1016/j.alter.2009.01.004

Rowles, G. 1993. Evolving images of place in aging and 'aging in place'. Generations, 17, 02, 65-70.

Rudman, D., 2015. Embodying positive aging and neoliberal rationality: Talking about the aging body within narratives of retirement. Journal of Aging Studies, 34, 10-20.

doi:https://doi.org/10.1016/j.jaging.2015.03.005

Sixsmith, J., Sixsmith, A., Malmgren Fänged, A., Naumanne, D., Kucseraf, C., Tomsone, S., Haak, M., Dahlin-Ivanoff, S. and Woolrych, R., 2014. Healthy ageing and home: The perspectives of very old people in five European countries. Social Science \& Medicine, 106, 1-9.

doi:https://doi.org/10.1016/j.socscimed.2014.01.006

Tonkens, E., 2016. Professions, service users and citizenship. Deliberation, choice and Responsibilitiy. In: Dent, M., Bourgeaults, I., Denis, J. and Kuhlmann, E. (2016). The Routledge Companion to the Professions and Professionalism. Routledge: New York.

Veen, van der, R., 1990. De sociale grenzen van beleid. Een onderzoek naar de uitvoering en effecten van het stelsel van sociale zekerheid. Stenfert Kroese: Leiden / Antwerpen.

Wiles, J., Leibing, A., Guberman, N., Reeve, J. and Allen, R., 2012. The meaning of "ageing in place" to older people. The gerontologist, 52, 03, 357-366. doi:https://doi.org/10.1093/geront/gnro98

Winterton, R. and Warburton, J., 2011. Models of care for socially isolated older rural carers: barriers and implications. Rural and Remote Health, 11, 03, 1678. 


The Dutch government, like other Western welfare governments, struggles with the challenges of an ageing population combined with growing healthcare expenditures. For this reason, ongoing efforts are made to reform the system and create a sustainable care regime based on the ideals of a participatory society. Instead of automatically providing care for those in need, governments emphasise the importance of individuals' own responsibilities and opportunities. Such deinstitutionalisation is promoted by reconstructing the neighbourhood as a place that encourages and enables older people to remain in place for longer. This thesis describes how a particular ageingin-place policy works out in practice.

For over four years, we studied the practices of 'Voor Elkaar in Parkstad' (meaning 'getting things done in Parkstad), a Dutch innovative local care initiative that was introduced in 2012 to change communities into so-called 'lifecycle-robust neighbourhoods'. Municipalities, organisations for housing, care and welfare (including a healthcare insurance organisation) and organisations that represent older adults decided that local challenges could only be faced conjointly. A collaboration effort was initiated, with the underlying policy goal 'to develop neighbourhoods for ageing-in-place'. The initiative draws on national and international debates about participation, active citizenship, empowerment, the role of professional work (social work) and ageing-in-place.

Instead of a traditional evaluation of this policy, which would focus on effects and outcomes, we emphasised its process by examining perspectives on this policy and its implementation in practice. Inspired by Van der Veen's (1990) social constructivist approach of studying social policy in practice, we understand social reality as being constructed by and depending on the meanings that people attach to it. We investigated these meanings both in policy and in practice, aiming to open Van der Veen's 'black box of daily practice' (1990, p. 233). In addition to this approach, Science and Technology Studies (STS) served as a framework for our analysis (Hackett et al. 2008). Within STS the relationship between science, technology and society is studied. We explored the neighbourhood as an ageing-in-place technology, based on its construction as a lifecycle-robust neighbourhood. This approach enabled us to explore underlying tensions, as the formerly static notion of place now has its own agency.

To investigate this policy in practice, our main research question was as follows: how do ageing-in-place policies work out in practice? We explored the meanings of citizenship in old age (Chapter 2 ), professional practices to translate ageing-in-place into care and welfare practices (Chapter 3 ) and the meanings of place (Chapter 4 and 5 ). To this purpose, we used a qualitative research design with the help of ethnographic methods. The different methods used - document study, interviews, observations, focus groups and photovoice - helped to explore a policy (process) in actual practice and consider the development of ageing-in-place. By analysing the ideas and experiences of policymakers; civil servants; housing, care and welfare directors, managers 
and professionals; representatives of older adults and older adults themselves, we gained insight into the meanings and dynamics of this policy in practice.

Chapter 2 explores constructions of citizenship in old age. In redesigning the Dutch care system, the national government wants to change its welfare state into a participatory society. Neighbourhoods, the places where citizens live, act and age, are expected to play a pivotal role within this activation policy. Neighbourhoods have to become 'lifecycle-robust', meaning that older people can live there independently for longer. To achieve this lifecycle-robustness, participation is considered elementary. While citizenship in general - and social citizenship in particular - has always been related to certain entitlements, its definition is currently shifting to encompass increasing obligations. In the Netherlands, all citizens have been asked to participate as much and as actively as possible, older adults included. Notions of old age and older adults have evolved over the years. Older adults used to be classified as a group of people who, after retirement, received the 'social recognition of a hard-earned life', including a great deal of autonomy in choosing how to grow old. New ideals of citizenship affect these notions of old age, thereby disenfranchising older adults as a specific category of citizens. A full citizenship status only appears to be achievable for people who remain independent and active in society. Citizenship is presented as a state of being that all people can achieve when participating actively in society. It could be claimed that according to these new ideals, passivity is no longer a choice when striving for citizenship.

Constructions of what citizenship and participation mean in practice differ. Although policymakers and civil servants, directors and managers, professionals and representatives of older adults - all involved in the development and execution of the new policy - share a belief that an activation policy is needed, their interpretations vary. Policymakers and civil servants emphasise the sociopolitical context of giving meaning to citizenship in old age. While they feel pressurised by the assignment to decrease local healthcare expenditures and activate older adults to be participative and self-sufficient, they also believe in the necessity of this assignment. Activation of people in their own places is considered to be achievable. According to policymakers and civil servants, citizens need to be activated and enabled to remain or become independent. Older people are expected to rid themselves of what are considered negative developments from the past, including an emphasis on being a care and welfare-consumer. Directors and managers construct older adults' citizenship by talking about the organisation of care. They aspire to a system that focuses on actual needs, where customised care can be negotiated. According to them, ageing-in-place is genuinely in line with older adults' wishes, although they need to be stimulated to take or retake their responsibilities.

During kitchen table conversations, care and welfare professionals convene with older adults in their own homes, where they are expected to mediate the activation policy. In reflecting on these meetings, professionals express pride in pioneering a new care system, mainly when they experience opportunities to empower older 
adults. However, professionals also highlight some of the downsides of the new policy, as it may be too optimistic or foster 'too high' expectations of the capabilities of professionals and overlook the needs of the frail older adults. At the same time, older adults try to live their lives as independently as possible. While representatives of older adults discuss the need for activation and empowerment in similar terms as the 'designers' of the project, most older adults themselves tell different stories. They share how they are proud still to be independent and how they already feel activated. They contemplate their daily life and aim to ensure that they remain independent for longer. Instead of presenting themselves as demanding or dependent, they stress their reluctance to ask for help unless they really cannot do without. However, while they feel an urge to remain independent, they also express an entitlement to carefree retirement days.

The new activation policy expects care and welfare professionals to play an important role as mediators of active citizenship and ageing-in-place. In Chapter 3, their new role is explored by investigating so-called kitchen table conversations. Kitchen table conversations are introduced as a social technology to facilitate and manage professionals in constructing their new role. In this role, professionals are expected to activate and empower citizens to remain as independent as possible, while repressing the urge to assume that responsibility themselves. The kitchen table conversation is based on the idea that kitchen tables symbolise opportunities for warm, open, informal and in-depth dialogues. By assigning professionals to visit older people at their homes, policymakers expect that professionals can talk with them more easily and encourage ageing-in-place while simultaneously cutting back on healthcare costs (promoting informal over formal care solutions). At the kitchen table, professionals and older citizens discuss individual care and welfare needs, as well as older people's opportunities to arrange their own care in their informal networks. By observing professionals while they conducted such conversations, we aimed to unravel how kitchen table conversations work out in practice as a social technology and how they help professionals and older citizens to attune to each other when negotiating care. Our observations showed an ambiguity in the new professionalism, as the kitchen table conversation lacks the necessary characteristics of a tool such as standardisation and predictability. We observed how the conversations raised questions of agency, for instance, when professionals - as representatives of the government - entered the private space of older adults to negotiate people's independence. Instead of warm dialogues based on equal power positions, the professional/citizen relationship is based on an unequal power distribution. This inequality causes some citizens to follow the lead of the professional, while others refrain from cooperating without knowing what they stand to gain or lose by doing so.

Chapter 4 and Chapter 5 both address the meanings of lifecycle-robust neighbourhoods. Lifecycle-robust neighbourhoods are introduced as an elementary tool to achieve ageing-in-place. In Chapter 4 , this concept is unravelled through traditional qualitative methods. Document analysis, interviews, observations and focus 
groups demonstrated how, on the one hand, the developers of this initiative - policymakers; housing, care and welfare directors; and representatives of older adults - gave meaning to lifecycle-robust neighbourhoods as age-friendly places. On the other hand, stories that older adults shared as the inhabitants of these neighbourhoods and the 'users' of these places clarified how they experience the notion of place in relation to ageing. Instead of being malleable policy objects, older adults are mainly emotionally attached to their particular place through their relations with its inhabitants. Although policy criteria such as the availability of facilities or services and age-friendly homes are also considered important by older adults, they attach meaning to places because of personal, emotional bonds. Existing private-public meeting places play an important role for them, whereas developers believe that age-friendliness can be constructed by adding services or facilities and by assigning new 'signalling functions' to people in these neighbourhoods. However, even with all these elements that formally make a place 'age-friendly', some older adults still prefer aging-in-place to the comfort of living close to care and other facilities.

Although Chapter 4 explored constructions of place by older adults, it also demonstrated the difficulty for individuals actually to explain what makes a place important. Moreover, it demonstrated how the voice of older adults in developing these new lifecycle-robust neighbourhoods often appears to remain unheard. To facilitate a dialogue about the meaning of lifecycle-robustness and to explore the concept further, we initiated a photovoice project as described in Chapter 5 . In this project, housing, care and welfare professionals and older inhabitants participated. They took photographs of places in the neighbourhoods in which they lived or worked and which they considered important for ageing-in-place. We expected professionals to attach different meanings to ageing-in-place than the 'developers' of policy (described in Chapter 4), since they are actively operating in the neighbourhoods on an almost daily basis. However, their images and stories turned out to be in line with those of the 'developers'. Both groups mostly depicted construable, age-friendly places, accentuating the proximity of facilities or services and the existence of age-friendly apartments, thereby framing the neighbourhood as a technology for ageing. While older adults also photographed such places, they have a more personal meaning. For instance, a bus stop is not photographed because bus services are important, but because this particular bus service helps this individual to get to the hospital. In addition, older adults also photographed other places which they considered as even more important for ageing-in-place. Photographs of open spaces, forests, street corners, cemeteries, and so on were taken because of the stories, memories and histories that they hold. These special and unique places that constitute people's lived experiences embody their attachment to the neighbourhood and to their neighbours, as well as their preference for ageing-in-place. However, they are often overlooked because they are intangible and only exist in the perceptions of individuals. We argue to distinguish these important but intangible places as fourth places, in addition to what in literature are called first (the home), second (the workplace) and third 
(public places that enable social interactions) places.

In Chapter 6, we formulated an answer to the main research question: how do policies to make ageing-in-place work out in practice? The main findings of this thesis were presented, elaborating on how the translation of this policy into practice induced 1) tensions between policy ideals, professional practices and older adults' experiences. In turn, these tensions led to 2) new meanings of citizenship in old age. The tensions described are caused by strong belief by policymakers in the 3 ) malleability of ageing-in-place through a reconstruction of the neighbourhood. Furthermore, the theoretical considerations of this thesis are discussed, explaining how it relates to a variety of discourses. First, it is explained how this thesis relates to the study of social and ageing policies, as well as to the enduring importance of street-level analysis. Subsequently, the relationship of this study to other gerontological studies of ageing and place is explained, including the significance of this study for notions of ageing, place and ageing-in-place in gerontology. Furthermore, it is highlighted how current ageing policies relate to the meanings of citizenship and participation. Finally, the importance of STS to study these kind of policies is emphasised, explaining how the construction of neighbourhoods as technologies for ageing helps to discover other meanings of ageing-in-place policy in practice.

To understand the value of this thesis, a reflection on its ethnographic methods is included, as well as a discussion of its limitations and future implications for policy, practice and science. Our study provides insight into new ways of identifying different voices in practice, through the use of methods from social studies (photovoice in particular). Moreover, it demonstrates how policy creates ambiguities in practice for professionals and older people. These ambiguities underscore the importance of maintaining a dialogue between policy and practice, as all participants have the ability to affect how a policy works out in practice. Scholars can facilitate this dialogue by providing new insights and combining different perspectives on the subject of ageing-in-place. 



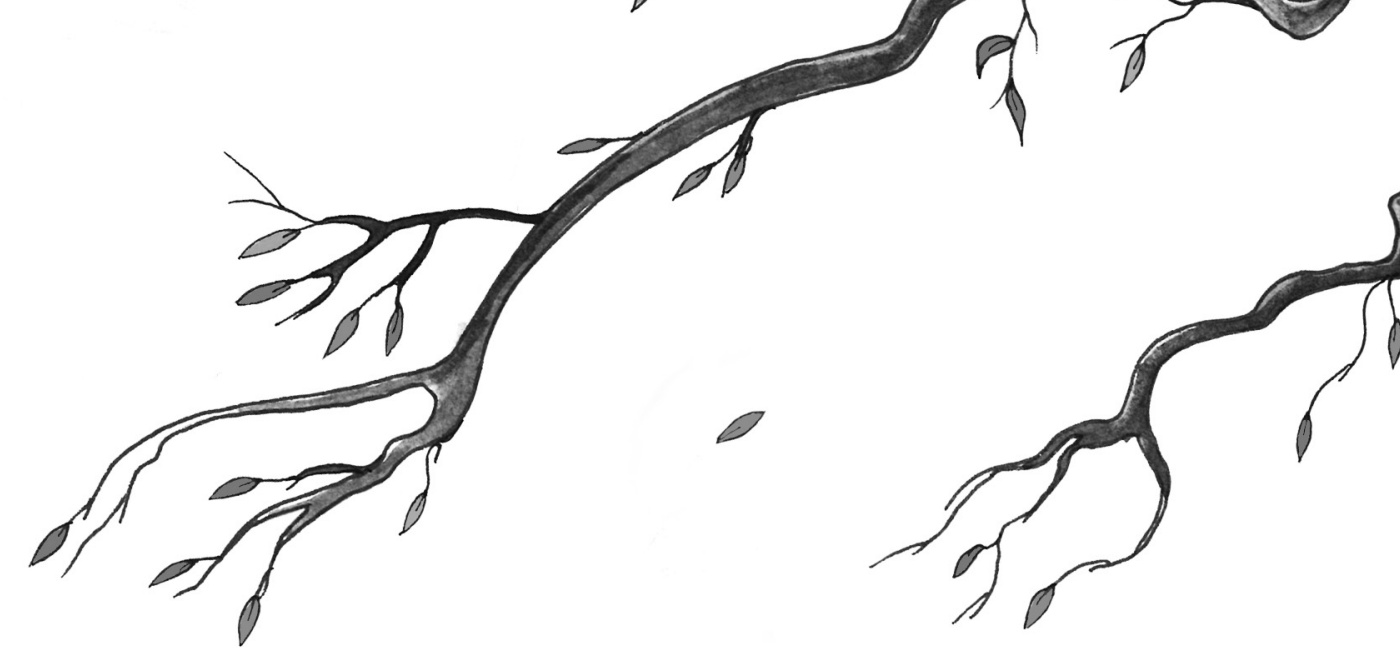

Samenvatting 

De Nederlandse regering worstelt, net als andere regeringen van Westerse welvaartsstaten, met de uitdagingen van een vergrijzende bevolking in combinatie met toenemende gezondheidszorguitgaven. Er worden daarom voortdurend pogingen gedaan om het systeem te hervormen en tot een duurzaam zorgstelsel te komen, gebaseerd op de idealen van een participatiesamenleving. In plaats van automatisch zorg te verstrekken voor hen die er om vragen, benadrukken overheden het belang van eigen verantwoordelijkheden en mogelijkheden van individuen. Deze de-institutionalisering wordt gepromoot door de buurt te reconstrueren als een plaats die ouderen aanmoedigt en in staat stelt om langer in hun plaats te blijven wonen. Deze thesis beschrijft hoe een specifiek ageing-in-place beleid in praktijk uitwerkt. Ageing-in-place is een Engelstalige term die in de wetenschap wordt gebruikt om het proces te beschrijven waarbij een persoon zolang als mogelijk op een plek van eigen keuze te kunnen blijven wonen, ook, of vooral als hij of zij ouder wordt. Omwille van de leesbaarheid en duidelijkheid is ervoor gekozen deze Engelse term in deze Nederlandstalige samenvatting verder niet te vertalen.

Gedurende ruim vier jaar, bestudeerden we praktijken van 'Voor Elkaar in Parkstad', een Nederlandse innovatief lokaal zorginitiatief dat in 2012 werd geïntroduceerd om buurten te veranderen in zogenaamde 'levensloopbestendige buurten'. Gemeenten, woon-, zorg- en welzijnsorganisaties (inclusief een zorgverzekeraar) en ouderenvertegenwoordigers besloten dat zij de lokale uitdagingen alleen gezamenlijk aan konden pakken. Een samenwerkingstraject werd geïnitieerd, met als onderliggend beleidsdoel 'het ontwikkelen van levensloopbestendige buurten' (gericht op het bevorderen van ageing-in-place). Het initiatief ligt in lijn met discussies op nationaal en internationaal niveau over participatie, actief burgerschap, empowerment (d.w.z.: het activeren van mensen en hen stimuleren gebruik te maken van hun 'eigen kracht'), de rol van de professional en zijn of haar (sociaal) werk en ageing-in-place.

In plaats van een traditionele beleidsevaluatie, die gericht zou zijn op effecten en uitkomsten, focusten wij op het proces. Dit deden we door de verschillende perspectieven op dit beleid en de implementatie daarvan in praktijk te onderzoeken. We zijn hierbij geïnspireerd door Van der Veen's (1990) sociaal-constructivistische benadering voor het bestuderen van sociaal beleid in praktijk. We begrijpen de sociale werkelijkheid daarom als geconstrueerd door en afhankelijk van de betekenissen die mensen er aan geven. We bestudeerden deze betekenissen zowel in beleid als in praktijk, om op deze manier de door Van der Veen's genoemde 'black box van de dagelijkse praktijk' te kunnen openen (1990, p.233). In aanvulling hierop, maakten we gebruik van Science and Technology Studies (Wetenschaps- en Techniekstudies, STS) als een kader voor onze analyse (Hackett et al. 2008). Binnen STS wordt de relatie tussen wetenschap, technologie en de maatschappij bestudeerd. We onderzochten de buurt als een ageing-in-place technologie, gebaseerd op haar constructie als een levensloopbestendige buurt. Deze benadering stelde ons in staat om onderliggende spanningen te onderzoeken, zoals de anders statische notie van plaats, die binnen deze benadering een eigen betekenis (of agency) heeft. 
Om dit beleid in praktijk te onderzoeken, gebruikten we de volgende centrale onderzoeksvraag: hoe ziet ageing-in-place beleid eruit in praktijk. We onderzochten betekenissen van burgerschap van ouderen (Hoofdstuk 2), professionele praktijken om ageing-in-place te vertalen in zorg en welzijnspraktijken (Hoofdstuk 3 ) en betekenissen van plaats (Hoofdstukken 4 en 5 ). Om dit te kunnen doen, gebruikten we een kwalitatief onderzoeksdesign waarbij we gebruikmaakten van etnografische methoden. De verschillende methoden die we gebruikten - documentstudie, interviews, observaties, focusgroepen en photovoice (letterlijk te vertalen als fotostem) - hielpen om een beleid(sproces) te onderzoeken in een echte praktijk en de ontwikkeling van ageing-in-place te beschouwen. Door ideeën en ervaringen van beleidsmakers (bestuurders); beleidsmedewerkers; woon-, zorg- en welzijnsdirecteuren, managers en professionals; vertegenwoordigers van ouderen en ouderen zelf te analyseren, verwierven we inzicht in de betekenissen en dynamiek van dit beleid in praktijk.

Hoofdstuk 2 gaat in op de verschillende betekenissen van burgerschap die uit ons onderzoek naar voren kwamen. In het hervormen van het Nederlandse zorgsysteem, wil de nationale regering de welvaartsstaat veranderen in een participatiesamenleving. Er wordt verwacht dat buurten, als de plaatsen waar burgers leven, acteren en ouder worden, een centrale rol spelen in dit activeringsbeleid. Buurten moeten 'levensloopbestendig' worden, wat inhoudt dat ouderen er langer zelfstandig moeten kunnen blijven wonen. Om deze levensloopbestendigheid te bereiken, wordt participatie als elementair beschouwd. Terwijl burgerschap in het algemeen - en sociaal burgerschap in het bijzonder - altijd gerelateerd is geweest aan bepaalde rechten, verschuift haar definitie momenteel naar een die steeds meer verplichtingen met zich meeneemt. In Nederland wordt van alle burgers, en dus ook van ouderen, gevraagd om zoveel en actief als mogelijk te participeren. Betekenissen van 'oud' en ouderen zijn door de jaren heen geëvolueerd. Ouderen werden geclassificeerd als een groep mensen die, na hun pensioen, 'sociale erkenning kregen door een welverdiend pensioen', inclusief een grote mate van autonomie in het kiezen hoe ze oud wilden worden. Nieuwe idealen van burgerschap beïnvloeden deze betekenissen van 'ouderdom', waarbij de rechten die ouderen ontlenen als zijnde een specifieke categorie burgers afnemen. Een volledige burgerschapsstatus blijkt enkel nog haalbaar voor mensen die onafhankelijk en actief blijven binnen de maatschappij. Burgerschap wordt gepresenteerd als een staat van zijn die mensen kunnen bereiken door actief te participeren in de maatschappij. Er kan worden gesteld dat op basis van deze nieuwe idealen, passiviteit niet langer een keuze is wanneer je burgerschap nastreeft.

Constructies van wat burgerschap en participatie betekenen verschillen in praktijk. Hoewel beleidsmakers en ambtenaren, directeuren en managers, professionals en vertegenwoordigers van ouderen - allemaal betrokken in de ontwikkeling en uitvoering van het nieuwe beleid - een overtuiging delen dat een activeringsbeleid nodig is, verschillen hun interpretaties. Beleidsmakers en ambtenaren benadrukken de sociaalpolitieke context om betekenis te geven aan burgerschap van ouderen. Hoewel ze zich onder druk gezet voelen door de opdracht om de lokale gezondheids- 
zorgkosten te verlagen en ouderen te activeren tot participatie en zelfstandigheid, geloven zij ook in de noodzaak van deze opdracht. Het activeren van mensen in hun eigen plaats wordt als haalbaar beschouwd. Volgens beleidsmakers en ambtenaren, moeten burgers geactiveerd en in staat gesteld worden om onafhankelijk te kunnen blijven of worden. Van ouderen wordt verwacht dat zij afstand nemen van wat als negatief beschouwde ontwikkelingen uit het verleden, waaronder een focus op het (vooral) zijn van zorg- en welzijnsconsumenten. Directeuren en managers geven betekenis aan het burgerschap van ouderen door te spreken over de organisatie van zorg. Zij streven een systeem na dat focust op werkelijke behoeften, waarin kan worden onderhandeld over zorg op maat. Volgens hen is ageing-in-place in feite in overeenstemming met de wensen van ouderen, maar moeten deze ouderen worden gestimuleerd om (opnieuw) hun verantwoordelijkheden te nemen.

Tijdens keukentafelgesprekken komen zorg- en welzijnsprofessionals samen met ouderen in de woningen van ouderen. Waar van de professionals wordt verwacht dat zij het activeringsbeleid mediëren, spreken professionals hun trots uit om te mogen pionieren in een nieuw zorgsysteem, vooral wanneer zij ervaren dat er mogelijkheden zijn om ouderen te empoweren. Maar, deze professionals belichten ook de keerzijdes van het nieuwe beleid, omdat het misschien wel te optimistisch is of omdat 'te hoge' verwachtingen worden gekoesterd ten aanzien van de mogelijkheden van professionals, terwijl de behoeften van kwetsbare ouderen over het hoofd worden gezien. Tegelijkertijd proberen ouderen zelf hun leven zo onafhankelijk te leven als mogelijk. Terwijl ouderenvertegenwoordigers de noodzaak tot activering en empowerment bediscussiëren door soortgelijke termen te gebruiken als de 'ontwerpers' van het initiatief', vertellen de meeste ouderen zelf andere verhalen. Zij delen hoe ze nog altijd trots zijn om nog zelfstandig te zijn en hoe ze zich reeds geactiveerd voelen. Ze reflecteren op hun dagelijks leven en proberen te verzekeren dat ze zo lang mogelijk zelfstandig kunnen blijven. In plaats van zichzelf te presenteren als behoeftig of afhankelijk, benadrukken zij hun afkeer om hulp te moeten vragen, tenzij ze echt niet meer zonder kunnen. Maar, ook al voelen ze een grote behoefte om onafhankelijk te blijven, ze geven ook aan dat ze recht hebben op een zorgeloze oude dag (pensioen).

Het nieuwe activeringsbeleid verwacht van zorg- en welzijnsprofessionals dat zij een belangrijke rol spelen als bemiddelaars van actief burgerschap en 'ageing-in-place'. In Hoofdstuk 3 is hun nieuwe rol onderzocht door zogenaamde keukentafelgesprekken te bestuderen. Keukentafelgesprekken zijn geïntroduceerd als een sociale technologie die professionals moet faciliteren en sturen om betekenis te kunnen geven aan hun nieuwe rol. In deze nieuwe rol wordt van professionals verwacht dat zij burgers activeren en empoweren om zolang en zoveel als mogelijk zelfstandig te blijven, terwijl ze tegelijkertijd een drang moeten onderdrukken om deze verantwoordelijkheden over te nemen. Het keukentafelgesprek is gebaseerd op het idee dat keukentafels mogelijkheden symboliseren voor warme, open, informele en diepgaande dialogen. Door professionals de opdracht te geven om ouderen in hun eigen huis te bezoeken, 
verwachten beleidsmakers dat professionals gemakkelijker met ouderen kunnen spreken en ageing-in-place kunnen bevorderen, terwijl ze tegelijkertijd kunnen bezuinigen op gezondheidszorgkosten (door het promoten van informele in plaats van formele zorgoplossingen). Aan de keukentafel, bediscussiëren professionals en oudere burgers individuele zorg- en welzijnsbehoeften, alsook de mogelijkheden van ouderen om hun eigen zorg te regelen binnen hun informele netwerken. Door het observeren van professionals terwijl zij dit soort gesprekken voerden, wilden we onderzoeken hoe dergelijke keukentafelgesprekken in praktijk als een sociale technologie werken en zien op welke manier zij professionals en oudere burgers helpen om bij het onderhandelen over zorg beter op elkaar af te kunnen stemmen. Onze observaties lieten een ambiguïteit in dit nieuwe professionalisme zien, omdat het keukentafelgesprek niet de benodigde karakteristieken van zo'n sociale technologie heeft, zoals standaardisatie en voorspelbaarheid. We observeerden hoe de gesprekken vragen met betrekking tot agency opriepen, bijvoorbeeld op het moment dat professionals - als vertegenwoordigers van de overheid - het privédomein van ouderen binnenkomen om over de zelfstandigheid van deze mensen te onderhandelen. In plaats van een warme dialoog gebaseerd op gelijke machtsposities, is er in de professional/burger relatie sprake van een ongelijke machtsverdeling. Deze ongelijkheid zorgt ervoor dat sommige burgers de aanwijzingen van de professional volgen en daarop meebewegen, terwijl anderen weigeren om mee te werken zonder eerst te weten wat zij daarbij kunnen winnen of verliezen.

Hoofdstuk 4 en Hoofdstuk 5 gaan allebei over de betekenissen van levensloopbestendige buurten. Levensloopbestendige buurten zijn geïntroduceerd als een elementair middel om ageing-in-place te kunnen bewerkstelligen. In Hoofdstuk 4, is dit concept onderzocht met behulp van traditionele kwalitatieve methoden. Documentanalyse, interviews, observaties en focusgroepen laten zien hoe, aan de ene kant de ontwikkelaars van dit initiatief - beleidsmakers; woon-, zorg- en welzijnsdirecteuren; en ouderenvertegenwoordigers - betekenis geven aan levensloopbestendige buurten als leeftijdsvriendelijke plaatsen. Aan de andere kant, hielpen verhalen die ouderen deelden als inwoners en 'gebruikers' van deze buurten bij het inzicht krijgen in hun ervaringen met de betekenissen van plaats gerelateerd aan ouder worden. In plaats van buurten te zien als maakbare beleidsobjecten, voelen ouderen zich vooral emotioneel verbonden aan specifieke plekken door relaties met buurtgenoten. Hoewel beleidscriteria, zoals toegang en beschikbaarheid van faciliteiten, diensten en leeftijdsvriendelijke woningen ook door ouderen als belangrijk worden beschouwd, hechten zij vooral aan hun plaats vanwege persoonlijke, emotionele banden. Bestaande zogenaamde private-publieke ontmoetingsplaatsen spelen een belangrijke rol voor hen, terwijl de (beleids)ontwikkelaars geloven dat leeftijdsvriendelijkheid kan worden geconstrueerd door diensten of faciliteiten toe te voegen aan een plaats en door een nieuwe 'signaalfunctie' toe te wijzen aan mensen in deze buurten. Ondanks al deze elementen die plaatsen formeel gezien 'leeftijdsvriende- 
lijk' maken, blijven sommige ouderen de voorkeur geven aan ageing-in-place boven het comfort om dichtbij dergelijke zorg- en andere faciliteiten te wonen.

Hoewel in Hoofdstuk 4 betekenissen van plaats voor ouderen al werden onderzocht, liet het ook zien hoe moeilijk het is voor personen om daadwerkelijk uit te leggen wat een plaats nu eigenlijk belangrijk voor hen maakt. Meer nog, het werd duidelijk dat de stem van ouderen in het ontwikkelen van deze nieuwe levensloopbestendige buurten vaak ongehoord blijft. Om een dialoog te faciliteren over de betekenis van levensloopbestendigheid en het concept ageing-in-place verder te kunnen onderzoeken, zetten we een photovoice-project op zoals is beschreven in Hoofdstuk 5. In dit fotoproject participeerden, woon-, zorg- en welzijnsprofessionals en ouderen. Zij fotografeerden platsen in de buurten waarin zij woonden of werkten die zij als belangrijk beschouwden in relatie tot ageing-in-place. We verwachtten daarbij dat professionals andere betekenissen aan ageing-in-place zouden geven dan de 'beleidsontwikkelaars' (beschreven in Hoofdstuk 4), omdat zij vrijwel dagelijks actief aan het werk zijn in de buurten (en met de ouderen die daar wonen). Hun beelden en verhalen bleken echter veelal op een lijn te liggen met die van de 'ontwikkelaars'. Beide groepen deelden vooral perspectieven van maakbare, ouderenof leeftijdsvriendelijke plaatsen, waarbij zij het accent legden op de nabijheid van faciliteiten en diensten en de aanwezigheid van leeftijdsvriendelijke appartementen. De buurt werd beschouwd als een technologie die ondersteunend is voor het fijn ouder worden. Hoewel ouderen ook soortgelijke plaatsen fotografeerden, hebben deze plaatsen voor hen een andere, meer persoonlijke betekenis. Een bushalte is bijvoorbeeld niet gefotografeerd omdat busvervoer in het algemeen belangrijk is, maar omdat deze specifieke buslijn deze persoon helpt om tot in het ziekenhuis te komen. In aanvulling daarop fotografeerden ouderen plaatsen die zij ook als belangrijk beschouwden voor ageing-in-place. Foto's van open ruimtes (braakliggend terrein bijvoorbeeld), bossen, straathoeken, begraafplaatsen enzovoort werden gemaakt omdat ze verhalen, herinneringen en geschiedenissen in zich dragen. Deze speciale en unieke plaatsen construeren de belevenissen van mensen. In deze plaatsen zitten de manieren verweven waarop zij aan hun buurt en aan hun buren hechten. Ze laten ook hun voorkeur voor ageing-in-place zien. Dit zijn plaatsen die vaak over het hoofd worden gezien omdat ze niet-tastbaar zijn en alleen bestaan in de percepties van individuen. We pleiten er daarom voor om deze belangrijke maar niet-tastbare plaatsen te onderscheiden als 'vierde plaatsen' (fourth places), in aanvulling op wat in de literatuur als eerste (thuis), tweede (de werkplek) en derde (publieke plaatsen die sociale interacties mogelijk maken) plaatsen worden onderscheiden.

In Hoofdstuk 6 formuleerden we een antwoord op onze centrale onderzoeksvraag: hoe werkt een ageing-in-place beleid uit in praktijk? De belangrijkste bevindingen van deze thesis zijn daarin gepresenteerd, door in te gaan op hoe de vertaling van dit beleid in praktijk zorgde voor 1) spanningen tussen beleidsidealen, professionele praktijken en de ervaringen van ouderen. Deze spanningen leidden onder andere tot 2) nieuwe betekenissen van burgerschap van ouderen. De spanningen 
zoals beschreven zijn veroorzaakt door een sterk geloof van beleidsmakers in de 3) maakbaarheid van ageing-in-place, een maakbaarheid door het reconstrueren van de buurt (als levensloopbestendig). Verder zijn de theoretische overwegingen van deze thesis bediscussieerd, door uit te leggen hoe zij zich verhouden ten aanzien van verschillende discoursen. Ten eerste is uitgelegd hoe deze thesis zich verhoudt tot het bestuderen van sociaal en verouderingsbeleid, maar ook hoe het een blijvend belang van het doen van street-level analysis laat zien. Vervolgens is de relatie van deze studie ten aanzien van andere gerontologische studies op het gebeid van ouder worden en plaats uitgelegd, inclusief het belang van deze studie voor betekenissen van ouder worden, plaats en ageing-in-place binnen de gerontologie. Verder is belicht hoe het 'verouderingsbeleid' in verschillende plaatsen zich verhoudt tot betekenissen van burgerschap en participatie. Tot slot is het belang van STS in het bestuderen van dit soort beleid benadrukt, waarbij is uitgelegd hoe het begrijpen van buurten als technologieën ter ondersteuning aan het ouder kunnen worden in de eigen buurt, helpt om andere betekenissen van een ageing-in-place-beleid in praktijk te ontdekken.

Om de waarde van deze thesis te kunnen begrijpen, is (ook) een reflectie op de etnografische methoden toegevoegd, met daarnaast een discussie van de beperkingen van de studie en implicaties voor de toekomst van beleid, praktijk en wetenschap. Onze studie geeft inzicht in nieuwe manieren om verschillende stemmen in de praktijk te kunnen identificeren, door gebruik te maken van methoden uit de sociale studies (photovoice in het bijzonder). De photovoice methode laat opnieuw zien hoe beleid ambiguïteit creëert in de praktijk voor professionals en ouderen. Deze ambiguïteit benadrukt het belang van het onderhouden van een dialoog tussen beleid en praktijk, omdat alle participanten de mogelijkheid hebben om te beïnvloeden hoe beleid in praktijk uitpakt. Onderzoekers kunnen deze dialoog faciliteren door te voorzien in nieuwe inzichten en door verschillende perspectieven op het onderwerp ageing-in-place te combineren. 




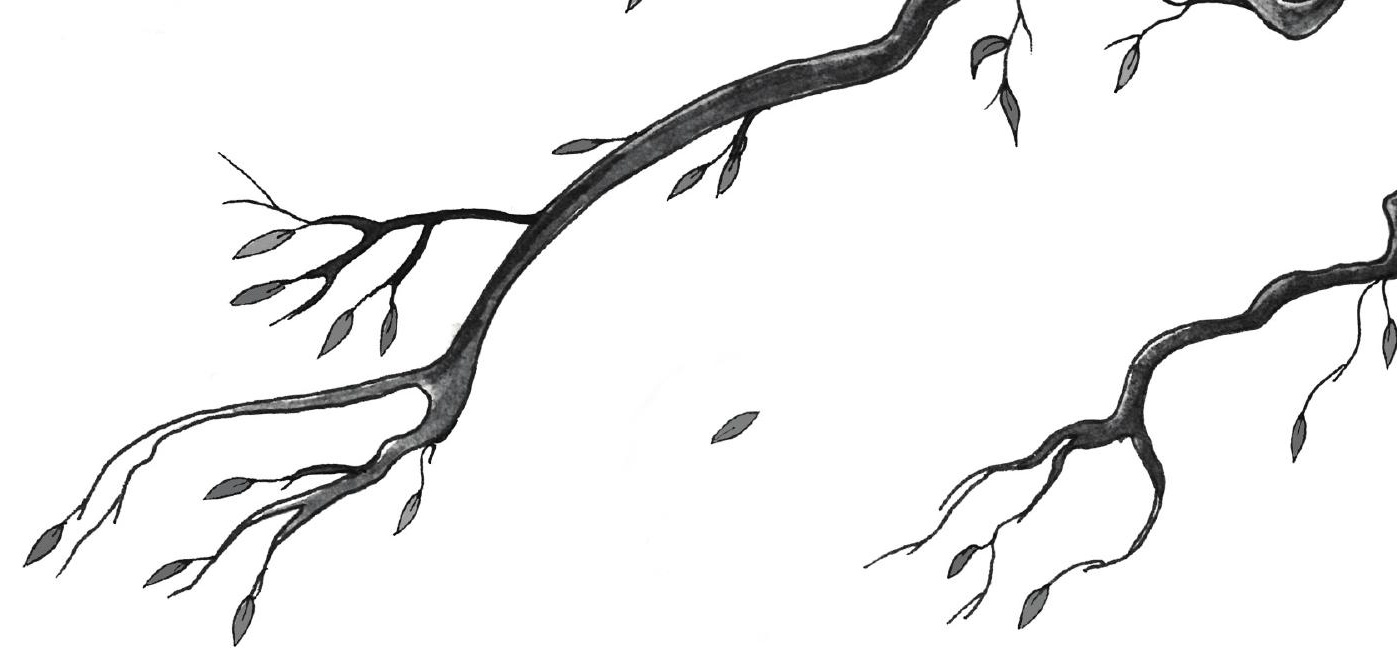

Valorisation 

'Research process and public policymaking are often distinct and asynchronous processes', Lavis (2006) argues in his work on knowledge translation processes. We experienced this while doing our fieldwork. Rather than using a predetermined research protocol our research approach was based on an open design; our findings determined what was needed next. During recurring presentations of our research plans and preliminary findings, policymakers, directors, professionals and other participants in the audience almost always commented: 'That's all well, but, what do we gain from this? How will this benefit our daily practice?'

This valorisation chapter aims to add to the findings presented and discussed throughout this thesis. On the following pages an elaboration follows on three different elements that relate to the valorisation of this study: firstly, an overview is given of the different activities that took place during the study to disseminate our findings and to valorise our knowledge. Secondly, future directions for further valorisation are described. Finally, a reflection is added on the meaning of our valorisation efforts and on the meaning of doing an ethnographic inspired research 'in the wild', aiming to answer the questions introduced above.

\section{Valorising while doing}

As the introductory sentences of this chapter already illustrated, the valorisation of this study was organised largely parallel to the research activities on which this thesis draws. Given that we followed a social policy in practice, investigating different perspectives on this policy while it was being developed and implemented, it was crucial for us to be able to study those elements that were raised as meaningful by our participants. By following a policy in practice, the study itself was inscribed with a certain societal relevance that needed to be unravelled.

Firstly, we organised feedback rounds on a regular basis during our fieldwork period. The study presented in this thesis was conducted using a social-constructivist approach, in which perspectives were explored on how a social policy towards ageing-in-place worked out in practice. Different meanings of some major elements (such as citizenship and a new professionalism) within this policy were demonstrated. Most presentations were organised as feedback activities for participants within the social policy we studied. Preliminary findings were presented to participants, often concluding with one or more statements to ignite further discussion, always with an opportunity for feedback and questions. Occasions during which these presentations were organised include: meetings of steering committees, workings groups, project groups and case management meetings. The idea behind sharing our findings with the participants in the policy process we studied, was that they would be able to benefit while the study was ongoing from what we found. Thereby we explained that by demonstrating our findings we aimed to offer participants a mirror, based on which they could choose to adjust or change directions. We explicitly did not aim to come up 
with specific directions about what they should be doing, nor did we confirm or deny that what they were doing was the best way to do things. We aimed to valorise our findings not only by continually feeding back our findings, but also by asking for feedback on our findings and suggestions for our research process. As the main researcher, I wrote several blogs for a webpage used exclusively by participants in this policy. I shared some of the insights and activities during this trajectory, asked for feedback and introduced future plans. Furthermore, a group of representatives of older adults followed me during the first phase of this study, to get insights in the developments of the policy in practice while simultaneously offering me advice, feedback and suggestions. Thereby we aimed to increase the relevance for older adults of the study in progress.

A second approach for valorisation was thus by configuring our research design during the process. We chose our definite research activities and topics based on what we found during our study. For instance, we found that many policymakers, directors, civil servants and managers expressed how they expected that professionals would make a difference in translating the policy to practice, by contributing to a participatory society and the ageing-in-place ideal. Subsequently, we organised focus groups and observations to explore the meaning of this 'new professionalism' for these professionals. Throughout the study, several focus groups with different themes were organised following this idea. We also held a workshop about participation during a meeting for professionals, civil servants, managers, directors, policymakers and older people (and their representatives) and arranged a photovoice project. Of all these activities (short) reports were sent to participants for further feedback and confirmation. The photovoice project - on which we reported elaborately in Chapter 5 of this thesis - was specifically set up with the aim to facilitate a dialogue between those involved in the policy process, and older adults who were affected by the policy. During our study, we found tensions between the ageing-in-place policy and the experiences of older adults in practice. But we also found how older adults experienced difficulties or constraints to share their experiences while being interviewed or during focus groups. Therefore, we looked for another method that could be helpful for people to share their perspectives and their experiences of place. Photovoice proofed to be a valuable method for this effort. In addition to older adults to participate in a photovoice project, we also invited professionals working in the neighbourhoods were these adults live. Doing so, we aimed to spark a conversation between policy and practice, including a dialogue on older adults lived experiences. Although we might not have bridged this policy-practice gap, photovoice helped to illuminate differences between policy and experiences in practices and enabled a dialogue between professionals and older adults.

Findings of this study were further disseminated for a broader professional and scientific audience. Presentations and discussions of the different parts of this study took place during several national and international conferences, seminars and workshops. Insights were used as input for educational and training activities. Lastly, dissemination took place by sharing our findings in national and international papers, as well as within this thesis. 
Photographs of a selection of the valorisation activities during this study
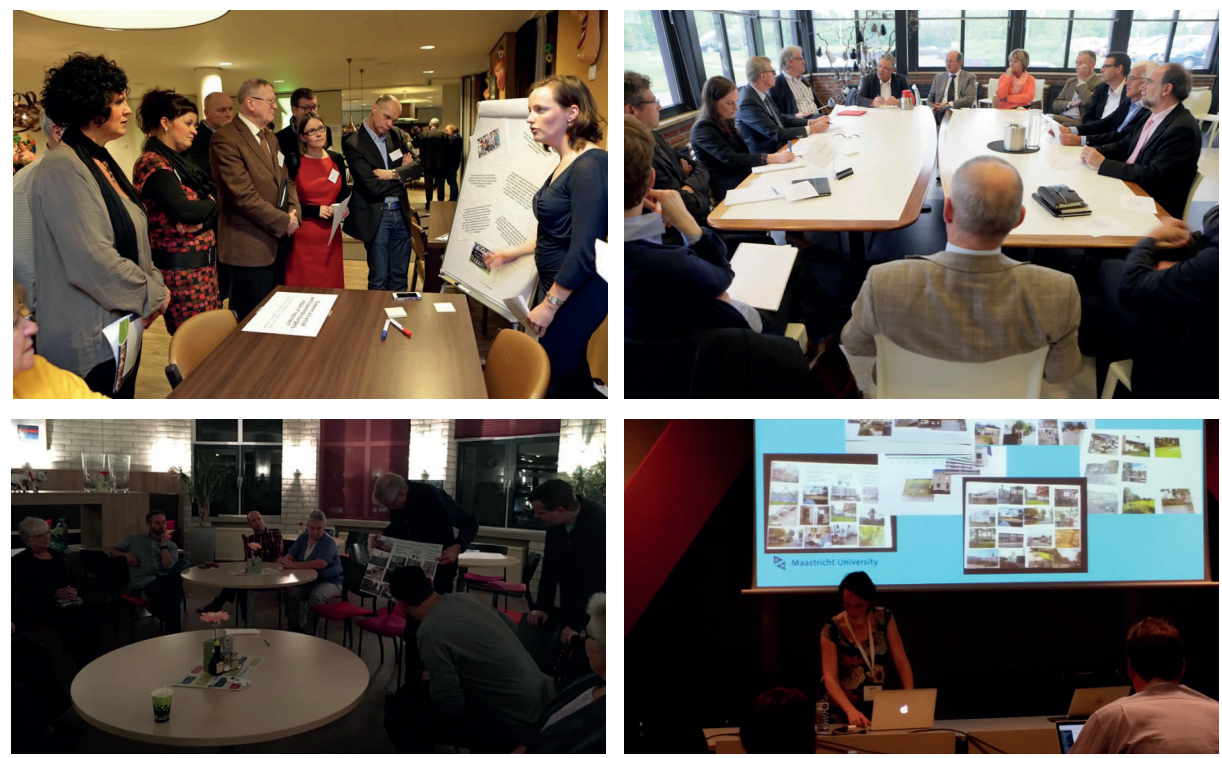

\section{Continuing the valorisation process}

Despite our efforts to share and draw on our findings during our trajectory, some work can be done to increase the relevance of this thesis. Firstly, further investigation and development of methodologies to give voice to older people is needed. In this thesis, several methods (interviews, observations, focus groups, photovoice) were used to explore the perspectives of older people and the meanings of ageing-in-place for them. We demonstrated how each method helps to unravel new meanings. Confirming the value accredited to these methods by policymakers and other scholars may require testing in a more diverse sample size in order to consider different perspectives. Advancement of the method used, an exploration of the usability of other methods and a comparison that clearly demonstrates the differences between the separate methods will help to advance our efforts to give voice to how older people give meaning (to ageing-in-place in this dissertation).

In my assignment as a postdoctoral researcher at the department Tranzo, at Tilburg University, I explore new ways to investigate how to give voice to older people in a meaningful way. My assignment aims to realise a structure that enables older people (including older people receiving intramural care) to participate fully as well as meaningful in the Academic Collaborative Centre of Older Adults. The Centre is a network of scholars and healthcare organisations devoted to conducting applied studies related to care and welfare. In this assignment, the first author draws on ideas of this thesis, but also extends the meaning of this thesis by including older people in 
residential care settings. Secondly, the development of a training to use such methods for policymakers, professionals and older adults can help to enable more dialogue between policy and practice. In this way, tensions created by different meanings of policy in practice can be explored collaboratively. A manual to use photovoice, and in addition the support of an independent scholar, offering reflections while participating, can be helpful in practice for municipalities who aim to explore policy-practice differences and tensions. Thirdly, to advance the scientific meaning of this study and more broadly, of our knowledge of ageing-in-place and of ageing-in-place technologies, an exchange with other scholars is indispensable. A concrete way of sharing and advancing this knowledge takes places within the Socio-Gerontechnology Network. Lastly, further translations of our findings for popular professional Dutch journals could be made to increase knowledge about this study.

A continuation of the valorisation process is important, as this study demonstrated how policy largely draws on assumptions of old age based on the idea that old age is only a phase with an increasing need for care and other help to remain independent and participative. The experiences of older people shared in this thesis show that there are many older people who live independently and have different needs and expectations than inscribed in current activation and ageing-in-place policies. To increase our insights in the perspectives of a broader group of older adults, and create awareness in policy about the different experiences of different people, further research is necessary. Joyce, Peine, Neven and Kohlbacher (2016) call these assumptions a negative rhetoric, based on which 'policymakers, companies, researchers, and lobby groups around the world commonly suggest that aging will lead to a global crisis for health-care systems, for pension schemes, for the innovative capacity of economies, and for the social relations between age groups' (p. 915). Encouraging policymakers (as well as companies, researchers and lobby groups) to include the experiences of all older adults in designing new age-friendly futures, requires us to continue unravelling how assumptions on ageing affect policies and their practices. Older people in particular should be given the means to learn about and articulate their ideals on policy.

\section{Reflecting on meanings of valorisation}

Downey and Zuiderent Jerak state in their chapter on Making and Doing in the recently updated Handbook of Science and Technology Studies: 'In order for STS (Science and Technology Studies) claims to become relevant for others beyond the field, STS scholars must build the elements necessary for those claims to travel into new settings and gain position and status within them. Such elements pertain to what STS scholars judge to be the key analytical issues at stake, as well as to the concrete activities they undertake to address those issues within the settings' (2016: p. 226). This statement could also apply for this thesis more broadly. Not only the question what STS is for is relevant and needs to be taken in mind when conducting 
an STS-inspired research. The widely-held debate about the meaning of science that has been held during the past few years in the Netherlands demonstrates the importance of thinking about how our work is meaningful, as well as about the ways we can pursue to demonstrate the meaningfulness and relevance of our work for society.

In a position paper entitled 'Why Science Does Not Work as It Should And What To Do about It' by Dijstelbloem, Huisman, Miedema and Mijnhardt (2013) and several discussion papers, such as a paper about The Academic Manifesto by Halffman and Radder (2015), the meanings of science in and for society have been discussed. These papers question a culture of accountability within academia through 'measurement, increased competition, efficiency, 'excellence', and misconceived economic salvation' (Halffman and Radder 2015). The fact that a valorisation addendum is obligatory since 2014 at Maastricht University, and the upcoming debate on the recent appointment of a new president of the VSNU (Association of universities in the Netherlands), demonstrates a need to further define what Dutch science is for. It demonstrates how (Dutch) scholars are afraid science will be redesigned as a business, solely based on economic and short-term societal relevance. But also, that a need for further clarification of the role of science in society is experienced, as (social) scientists do affect and interact with both policy and practice. Bos (2016), for instance, in her dissertation showed how science policies affect the societal goals scientists embed in their research. She argues that scientists use big words like healthcare or sustainability to emphasise the societal relevance of their work.

The reason these events and movements are mentioned here, is that especially in applied social science, expectations are often that society will benefit from it on a relatively short term. Policymakers, organisations' directors and lobbyists are involved in applications for research funds, expecting it to be relevant eventually. An interaction and involvement between science and society which is necessary to enable research to take place in practice, but that also comes with responsibilities to maintain scientific impact as well.

As, social scientists, we should be aware of our scientific value and impact, and of the different meanings participants in our research give to our work. The aim of the study underlying this thesis was to investigate a policy in practice to be able to learn from this process. By sharing findings and planning research activities we wanted to be of benefit for current practices. However, it was never the aim to steer or strictly guide practice, or to draw conclusions on whether specific current practices were right or wrong. By sharing our reflections, we wanted to inspire participants to reflect on their practice. Simultaneously, as we asked participants in this process to invest some time in our research activities, it was helpful in conducting research activities when participant considered our study relevant.

It was never the intention of our study to delay any of the processes we were exploring. However, as the main investigator, I did found how some participants had quite high expectations of our study. At the start of this trajectory, some participants shared how they expected the university to guide them through this policy process 
in some way. They hoped for innovative insights on which they could draw, or a confirmation that they were right on track, that what they were doing was right. This demonstrates how scholars are accredited with agency (in a variety of ways) in the policies and practices they study. As scholars, we need to be aware since this affects the practices we study as well as how we can perform our jobs. It raises questions about to what extent we are accountable for our research activities on the one hand, and eventually for the interpretation of our findings on the other. Although we did always emphasise that it was not our intention nor position to explain how things should be done better, we aimed to facilitate the process by sharing our findings and reflections, inviting participants to reflect on these as well. We explained how it was the responsibility of the audience to decide on whether and how to use and translate these insights for their own benefit.

By reiterating the nuance of our activities and outcomes, and that we did not aim to 'steer' in practice, we intended to explicate our position as researchers. However, in practice we experienced different ideas about the role of research in this process. During an introductory presentation in the steering committee, the research approach and some preliminary findings were presented. While discussing the preliminary findings one of the directors commented: 'Listen, we can presume everything has been calculated very carefully, that they have scored these assumptions, they have added and subtracted, and that what is presented renders those things that have been said. So, we need to do something with this.' During another meeting, when we discussed how our study could be of benefit to improve current practices, a director elaborated on how he 'did not really had something' with research, meaning that he had limited interest in research. In other interviews participants shared how they were frustrated or annoyed by their friendly competing colleagues who wanted to wait for research findings before acting, who wanted to follow research. However, these participants explained that it would not benefit practice if they kept waiting and waiting for research outcomes. Some participants emphasised how they deemed it to be of high value that a professor (supervising the study on which this thesis draws) attended the steering committee meetings. These expectations demonstrate how the presence of scholars in practice, affects the practice they study. While some thought research findings and recommendations should be followed, others argued research should follow practice and might not even be of actual relevance for them. Either way, this leaves a question of how to deal with such assumptions about research, and more specifically, to what extent scholars are accountable for translating their knowledge.

This thesis emphasises the importance of experiential, place-bound, situated knowledge. The expertise of older adults living in their neighbourhoods and professionals who experience how policy affects their daily practices should be used more often and regularly to improve social policies. It is up to us as scholars to help unravel how policy works out in practice, to offer reflections on policy in practice (solicited and unsolicited) and to facilitate dialogues where needed. How social policies work 
out in practice is situated, each place and its context is different, inhabitants have individual and situated perspectives that affect the translation of policy. Therefore, we should not aim for a singular recipe for ageing-in-place or a blueprint for lifecycle-robust neighbourhoods. While insights and experiences at other places can be helpful to inspire new policies, policymakers also should be aware they act in unique environments.

The best way to find out how a new policy can be developed and adjusted to the needs and characteristics of their neighbourhood, is by initiating open and sincere dialogues with inhabitants. Not (or not only) by organising a consultation or participation evening, but by experimenting with ways to truly involve all kinds of inhabitants and by searching for people's perspectives by giving them voice, by finding ways that capture the voices of a more diverse group of older adults. Not only people who are already actively involved as representatives or politicians, but also people who remain yet unheard. As social scientists, we should pursue to explore their unheard stories and facilitate dialogues in our research. Simultaneously, to increase our impact and the value of our work, we should also remain sharing how we 'make and do' to enable further developments of knowledge on ageing-in-place and a mutual knowledge-translation between science, policy and practice. 


\section{References}

Bos, C., 2016. Articulation: how societal goals matter in nanotechnology. Doctoral dissertation, Utrecht University: Utrecht.

Dijstelbloem, H., Huisman, F., Miedema, F. And Mijnhardt, W., 2014. Why science does not work as it should. And what to do about it. Retrieved from: http://www.scienceintransition.nl/wp-content/uploads/2013/10/Science-in-Transition-Position-Paper-final.pdf [accessed on September 10, 2017)

Downey, G. and Zuiderent-Jerak, T., 2016. Making and Doing: Engagement and Reflexive Learning in STS. In: Felt, U., Fouché, R., Miller, C. and Smith-Doerr, L. (Eds.)., 2016. The Handbook of Science and Technology Studies. MIT Press: Cambridge, MA.

Halffman, W. and Radder, H., 2015. The academic manifesto: From an occupied to a public university. Minerva, 53, 02 , $165-187$.

Joyce, K., Peine, A., Neven, L. and Kohlbacher, F., 2016. Aging: The Sociomaterial Constitution of later life. In: Felt, U., Fouché, R., Miller, C. and Smith-Doerr, L. (Eds.). (2016). The Handbook of Science and Technology Studies. MIT Press: Cambridge, MA.

Lavis, J., 2006. Research, public policymaking, and knowledge-translation processes: Canadian efforts to build bridges. Journal of Continuing Education in the Health Professions, 26, o1, 37-45. 



Hèhè, het is zover, waar vier jaar eens heel lang leken vlogen ze opeens voorbij. Tijd om stil te staan bij al die mensen die me hebben geholpen dit proefschrift te voltooien.

Allereerst, alle ouderen (of burgers, bewoners, cliënten...) die hun verhalen en ideeën met mij deelden. Dank jullie wel! Ik blijf het bijzonder vinden dat onbekenden met mij zulke persoonlijke details en verhalen willen delen en bereid zijn met een fototoestel op pad te gaan. Terwijl ik niet veel meer te bieden heb dan een luisterend oor en later een computer waarmee ik poog inzicht te bieden in de betekenissen van ouder worden in de eigen buurt. Hopelijk draag ik een beetje bij om toekomstige ontwikkelingen in beleid en wetenschap 'oudervriendelijker' te maken. Bedankt voor jullie tijd, jullie geduld en jullie openheid. Hoe belangrijk jullie bijdrage is geweest, blijkt hopelijk uit dit proefschrift! Kijk alleen al naar de kaft. Met veel dank aan Evelien Jagtman voor het ontwerp. Ook zonder de participatie van ouderenvertegenwoordigers, professionals, beleidsmedewerkers, managers, directeuren en bestuurders van tig organisaties op het gebied van wonen, welzijn en zorg had dit proefschrift er heel anders uitgezien. Mijn oprechte dank dat jullie tijd maakten voor al mijn vragen en jullie bereidheid om mij mee te laten kijken. Verder wil ik alle leden van het interne TP4-overleg bedanken, vooral Bert, Evelyne, Marlou, Rick, Nathalie en Ingrid. Dank voor jullie nooit afnemende interesse voor en betrokkenheid bij mijn onderzoek, jullie enthousiasme en het altijd mee willen denken over de vragen die ik stelde. Sharon, voordat ik begon, startte jij dit onderzoek. Je verzamelde literatuur, interviewde participanten en nam deel aan bijeenkomsten. Informatie waar ik dankbaar gebruik van heb gemaakt.

Mijn promotiebegeleidingsteam: Dirk, Maria en Klasien. Bedankt voor jullie vertrouwen om samen met mij dit traject aan te gaan. Hoewel we elkaar niet dagelijks zagen, heb ik wel altijd het gevoel gehad dat ik een stevige basis had om op terug te vallen als het nodig was. Dat jullie mij steeds vrij hebben gelaten om mijn eigen keuzes te maken, mijn eigen traject uit te stippelen en mezelf als onderzoeker te ontdekken en ontwikkelen vind ik een enorm voorrecht. Dat jullie me daarbij aanmoedigden privé ook te (blijven) genieten was geweldig. Ik vind het bijzonder om van en met jullie te mogen leren.

Dirk, ik weet zeker dat iedereen die met jou heeft samengewerkt het zal herkennen als ik het heb over jouw oprechte betrokkenheid bij je promovendi. Ik denk niet dat er een bijeenkomst is geweest die je niet bent gestart met de vraag 'Hoe gaat het met jou?' en als ik even niks liet horen kwam daar altijd wel een mailtje. Je hebt me steeds alle ruimte gegeven die ik nodig had en was er als ik daar om vroeg. Of dat nu was om knopen door te hakken of voor een allerlaatste detaillistische controle, op het moment dat ik het vroeg stond jij voor me klaar! Wat ik heel bijzonder vind en waar ik je voor altijd dankbaar voor zal zijn is dat je me de ruimte hebt gegeven om niet alleen tijdens maar ook na mijn verlof optimaal te kunnen genieten van mijn dochter. 
Maria, zonder jou was dit onderzoek er niet geweest. Jij schreef het subsidievoorstel en was de link met de GGD. Zo zorgde je er in het begin voor dat ik makkelijk toegang had tot de betrokkenen bij 'Voor Elkaar in Parkstad' en je faciliteerde me waar je maar kon op veel verschillende manieren, ondanks je altijd drukke agenda. Tijdens mijn promotietraject werd je bijzonder hoogleraar. Ik vind het een hele eer dat ik een rol heb mogen spelen op die voor jou zo bijzondere dag. Dankjewel ook voor het meeleven met mijn persoonlijke wel en wee en je hulp bij het vinden van een nieuwe baan.

Klasien, als ik vastliep had jij het vaak al eerder door dan ikzelf. Je maakte tijd voor me vrij om mee te denken ('niet schrikken van het rood') of op het allerlaatste moment mijn abstracts nog wat bij te schaven en naar een hoger niveau te tillen. Je hielp me door met nieuw concepten of suggesties te komen. Door jouw kritische blik voelde het soms alsof mijn papers nooit af zouden komen, maar altijd hielp je me ook om de benodigde diepgang te vinden. Je stimuleerde me deel te nemen aan het WTMC-programma, wees me op relevante congressen en was er om tijdens mijn presentatie op de EASST Conference in Barcelona support te verlenen, waar ik hoogzwanger zo graag nog naartoe wilde. Dankjewel!

De leden van de beoordelingscommissie, Prof. dr. Ruud Kempen, Dr. Louis Neven, Prof. dr. Griet Roets, Dr. Mare Knibbe en Prof. dr. Tsjalling Swierstra, bedankt voor jullie bereidheid om mijn manuscript te lezen en te beoordelen.

Iets langer dan vier jaar was HSR een, zij het wat ver van huis, fijne thuisbasis. Voor ontspanning tussen het onderzoeken en schrijven door was er altijd een luisterend oor te vinden bij het koffieapparaat, tijdens de lunch, op de lange treinreis naar of van huis en tijdens borrels. Vooral met mijn collega-promovendi was het altijd gezellig! Inmiddels zijn de meesten van 'ons' gepromoveerd en zijn jullie je volgende stappen aan het zetten. Het was fijn om jullie als lotgenoten te hebben en ik hoop dat onze paden zich blijven kruisen. Ook waren jullie altijd bereid mee te denken en te helpen. Thérèsa, Bram, Laura, Maike en Bart, jullie hielpen als tafelbegeleiders in mijn fotoproject. Superfijn en leuk om dit met jullie te kunnen delen! Inge, jij was al iets langer bezig met 'iets soortgelijks' bij Klasien en bij jou kon ik met heel veel vragen terecht. Dankjewel! Bijzondere dank ook aan het secretariaat voor alle ondersteuning. Vooral Brigitte, voor het supersnel plannen van overleggen en regelen van werkelijk van alles, Joanna voor het ondersteunen daarbij en Suus, voor je hulp, onder andere tijdens focusgroepen en bij het maken van fotoverslagen.

Dan WTMC, dank aan Sally Wyatt, Willem Halffman, Teun Zuiderent-Jerak, Geert Somsen, Bernike Pasveer en Govert Valkenburg voor het mogelijk maken van al die inspirerende workshops en summer schools in Ravenstein en later de dissertation days. Ik heb veel van jullie en van de altijd interessante activiteiten geleerd. Een welkome en uitdagende afwisseling die me altijd weer hielp te realiseren dat ik niet de enige ben die dit soort onderzoek doet. Thanks to Steve Epstein and Gary Downey for two very inspiring summer schools. I'll never forget the wonderful making and doing 
assignment! A big thank you as well to my fellow PhD students, WOW, you're all so smart and eloquent. I've learned a great deal from you all and I hope we'll meet again!

To all the experts in the Socio-Gerontechnology network. I think it's great we've met and even greater that we're working together to advance our knowledge. Our meetings inspired me to continue as a scholar. I hope my work at Tilburg University will further add to our common efforts. Thank you all! Katrien en Leonieke, bedankt voor het bieden van een mooie kans om te onderzoeken hoe we ouderen structureel en vooral betekenisvol een stem kunnen geven in de academische werkplaats Ouderen van Tranzo.

Sanne, Bart, Laura en Maike. Wat een feest om vier jaar lang leuke en gezellige dingen te kunnen delen met jullie. Jullie boden niet alleen een luisterend oor als ik het nodig had, maar zorgden zeker ook voor de nodige ontspanning. Ik koester onze gezellige activiteiten. Sanne jouw enthousiasme en Bart, jouw humor, maakten dat het altijd leuk was op Dub én in Beuningen. Dat wordt hopelijk vervolgd! Laura en Maike, hoe fijn om me zo op mijn plek te kunnen voelen, het was altijd feest op onze kamer en tijdens onze uitjes. Laura, jouw positiviteit, luisterend oor en relativeringsvermogen waardeer ik, je quotes die de deur haalden waren geweldig ;-) Je doet mooi werk zoals je hebt laten zien tijdens jouw verdediging in juni en hebt een prachtige thuisbasis samen met Gaston. Bedankt voor de vele malen dat ik bij jullie mocht logeren! Maike, ik zie je als een enorm ambitieus persoon en toen je vertelde over je wens om Harkness Fellow te worden wist ik dat het zou lukken. En dan ben je ook nog eens de allerleukste Duitser die ik ken! Dat je zonder aarzelen afreisde naar Wenen om op Daphne (die ik geen nacht wilde missen) te passen zodat ik een expertbijeenkomst kon bijwonen vond ik geweldig. Ik heb genoten van onze bijzondere roadtrip! Samen met Mark zorgde je voor nog zo'n fijn Maastrichts logeeradres en Mark bood zelfs nog technische hulp op het allerlaatste moment! Dank jullie wel. Superjammer dat je er niet bij kunt zijn om dit proefschrift live mee te vieren in december Maike, dan vieren we jouw grote dag in november wel dubbel zo goed!

Mogelijkheden voor ontspanning waren er ook buiten het werk genoeg de afgelopen jaren. Al mijn oud-collega's, Bredagenoten, kennissen, vrienden en familieleden die ik hier niet bij naam ga noemen: bedankt dat jullie er waren en zijn.

Familie Groen! Goos, Marie-Louise, Maarten, Geert, Lisa en Joost, het werkstuk is af! ;-) Dank voor jullie interesse, betrokkenheid, maar meer nog dat jullie altijd een welkome en veilige haven bieden voor ons.

Thomas en Vincent. Weet dat ik ongelooflijk dankbaar en trots ben dat ik jullie zus mag zijn. Vincent, als een echte grote broer deed jij me voor hoe dat moet, dat promoveren. Hoezeer we ook kunnen verschillen in onze interesses, ergens liggen die ook dicht bij elkaar en voor advies over promoveren kon ik altijd bij je terecht. María Clara, thank you for being a part of the family and for making my big brother happy! Thomas, mijn kleine grote broer. Je blijft altijd de jongste maar bent wat mij betreft ook zeker de stoerste. Wat jij allemaal alleen durft te ondernemen en wat je 
allemaal voor elkaar krijgt vind ik fantastisch. Het is fijn dat jij altijd betrokken bent bij mij en bij ons kleine meisje en dat je me helpt als ik het nodig heb.

Lieve pap en mam, hoe fijn dat jullie hier vandaag bij mij zijn. Ik vind het enorm bijzonder om deze mijlpaal met jullie te mogen delen. Jullie hebben mij altijd gestimuleerd om mijn eigen weg te gaan en mijn eigen keuzes te maken. Ook als de weg die ik wilde kiezen niet de gebaande was of een andere dan jullie hadden kunnen bedenken. Vooral dat doen waar ik me zelf goed bij voel is jullie devies. Me zeker ook niet te veel aantrekken van bepaalde normen als dat belemmert. Als het nodig is, dan vormen jullie een vangnet, een warme basis om op terug te vallen als ik dat wil. Ik zeg het niet altijd met zoveel woorden maar ik meen het wel oprecht: bedankt voor alle steun, interesse en het meedenken in alles. Dat jullie (samen met google translate) mijn artikelen proberen te begrijpen vind ik geweldig! Dat jullie samen fijn oud mogen worden op de plek waar jullie zo graag wonen.

Lieve Frank, jij had de dj's voor mijn promotiefeest al geregeld nog voordat mijn eerste artikel was gepubliceerd. Volgens mij zegt dat genoeg :-). Ik hou onwijs veel van jou, ben supertrots op alles wat jij doet, hoe je jouw dromen najaagt met green-vinyl.com, dat je mijn allerbeste en liefste maatje bent, maar vooral ook op wie jij bent en op dat wij samen het mooiste delen dat er is. Ons lieve kleine meisje! Lieve Daphne, jij vergezelde mij tijdens het afronden van dit proefschrift. De lange dagen waarop ik thuis, onderweg in de trein, of op kantoor in Maastricht werkte was ik nooit helemaal alleen. Wat een feest om deze laatste fase samen met jou te mogen doorbrengen en inmiddels alweer bijna een jaar van jou te mogen genieten. Ik hoop dat je altijd zo vrolijk kunt blijven als je nu bent en heel gelukkig oud mag worden. Heb je je vriendjes al ontdekt op het omslag? Omdat ageing-in-place al begint als we nog helemaal niet met ouder worden bezig zijn. Ik ben trotser dan trots en geniet elke moment van en met jullie samen! Everything Now! ;-)

Susan

September 2017 




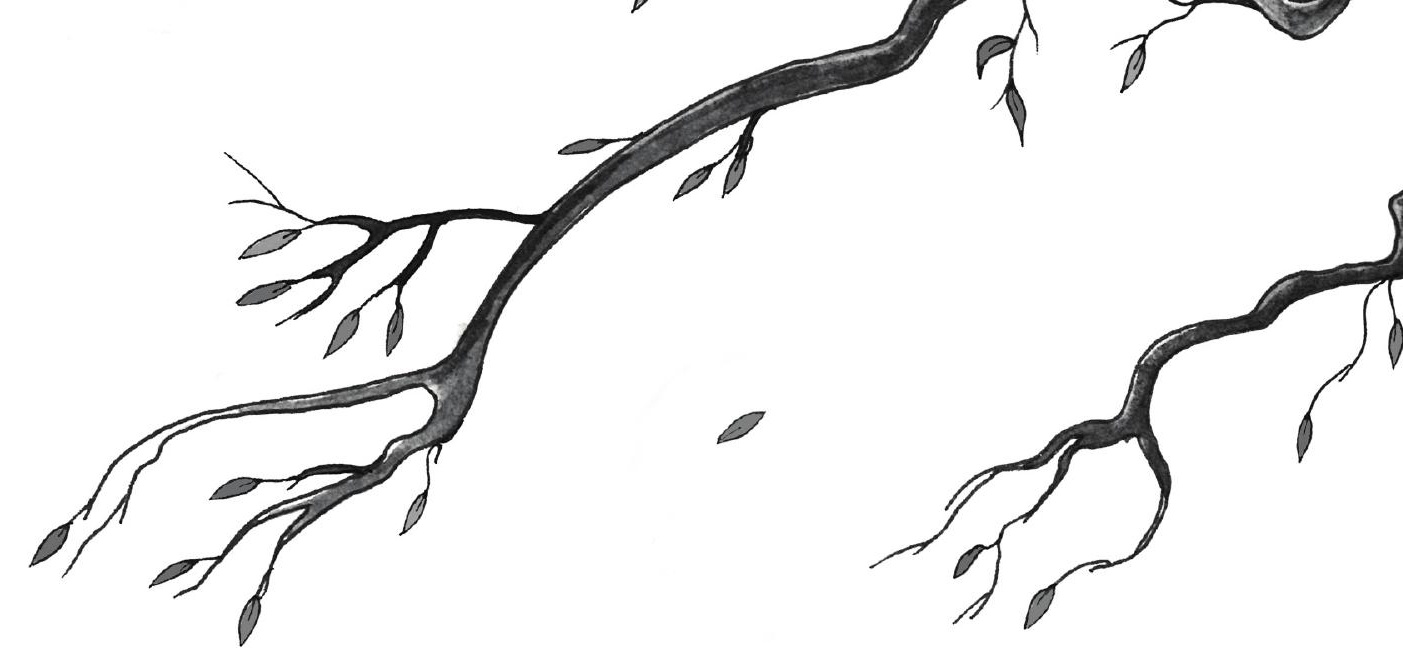

About the author 



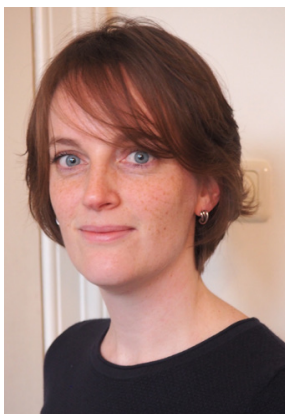

Susan van Hees was born on January $31^{\text {st }}, 1985$ in Heerlen, the Netherlands. In 2003 she received her gymnasium diploma from B.C. Schöndeln in Roermond. After graduating from secondary school, she started a study in historical sciences at Leiden University. She changed universities and enrolled at Tilburg University a year later, in 2004. She finished both her Bachelor (in 2007) and her Master (in 2008) in Public Administration at the Faculty of Law at Tilburg University. Immediately after receiving her Master's degree Susan started working as a junior consultant for the BMC Groep, a Dutch interim and consultancy agency, with an expertise in the public and not-for-profit sector. Until May 2012 she completed several (interim-)assignments, including working as a project-assistant at GGZ Nederland. In this position, she co-edited a book for and by mental health professionals and scholars, which included experiences and good practices related to Routine Outcome Monitoring in mental health.

In June 2012, she started as a PhD student at the department of Health Services Research. This department is part of the Care and Public Health Research Institute (CAPHRI) of Maastricht University. The PhD-project was related to the Academic Collaborative Centre for Public Health Limburg. While working on her thesis, Susan participated in the graduate program of the Netherlands Graduate Research School for Science, Technology and Modern Culture (WTMC). During her PhD trajectory Susan was involved in teaching activities in the Bachelor program of Health Sciences and the Master program of Healthcare Policy, Innovation and Management. She was involved as a tutor, trainer, lecturer and planning group member. In 2013 Susan was a representative of fellow PhD students at the department of Health Services Research. Furthermore, Susan participated and presented during several national and international seminars and conferences. She is a member of the Socio-Gerontechnology network, a network of experts in the field of social studies of gerontechnology.

Since August 2017 Susan holds a position as a postdoctoral researcher at the department Tranzo, Scientific Centre for Health and Welfare of Tilburg University. She focuses on giving (and embedding) a voice to older adults within the Academic Collaborative Centre for Older Adults.

Susan is in a relationship with Frank Groen and together they are the proud parents of a daughter named Daphne who was born in September 2016. 




\section{International Publications}

Susan van Hees, Klasien Horstman, Maria Jansen and Dirk Ruwaard, 2015. Conflicting notions of citizenship in old age: An analysis of an activation practice. Journal of Aging Studies, 35, 178-189. doi: http://dx.doi.org/10.1016/j.jaging.2015.09.0o1

Susan van Hees, Klasien Horstman, Maria Jansen and Dirk Ruwaard, 2017. Meanings of 'lifecycle-robust neighbourhoods': constructing versus attaching to places. Ageing \& Society, Published online: 23 January 2017, 1-26.

doi: https://doi.org/10.1017/So144686X160o1483

Susan van Hees, Klasien Horstman, Maria Jansen and Dirk Ruwaard, 2017. Photovoicing the neighbourhood: understanding the situated meaning of intangible places for ageing-in-place. Health \& Place, 48C, 11-19.

doi: https://doi.org/10.1016/j.healthplace.2017.08.007

Susan van Hees, Klasien Horstman, Maria Jansen and Dirk Ruwaard. How Does an Ageing Policy Translate into Professional Practices? An Analysis of Kitchen Table Conversations in the Netherlands. Under review.

\section{National Publications}

Susan van Hees, Klasien Horstman, Maria Jansen and Dirk Ruwaard, 2015. Betekenissen van burgerschap van ouderen in de participatiesamenleving. Een analyse van 'Voor Elkaar in Parkstad'. Tijdschrift voor Gezondheidswetenschappen, 93, 05, 191-196. doi:10.1007/s12508-015-0076-9.

\section{Conference contributions}

Susan van Hees, Dirk Ruwaard, Maria Jansen and Klasien Horstman, August 31 September 3, 2016. Life cycle robust neighbourhoods as ageing-in-place technologies. EASST Conference, Science and Technology by Other Means. Barcelona, Spain.

Susan van Hees, Klasien Horstman, Maria Jansen and Dirk Ruwaard, September 17 - September 20, 2014. Soft technologies of the participatory society. EASST Conference, Situating Solidarities: social challenges for science and technology studies. Toruń, Poland.

Susan van Hees, Klasien Horstman, Maria Jansen and Dirk Ruwaard. April 10 - 11 2014. Ouderen en burgerschap [older adults and citizenship]. NCVGZ, Perspectieven op de Volksgezondheid. Rotterdam, The Netherlands. 